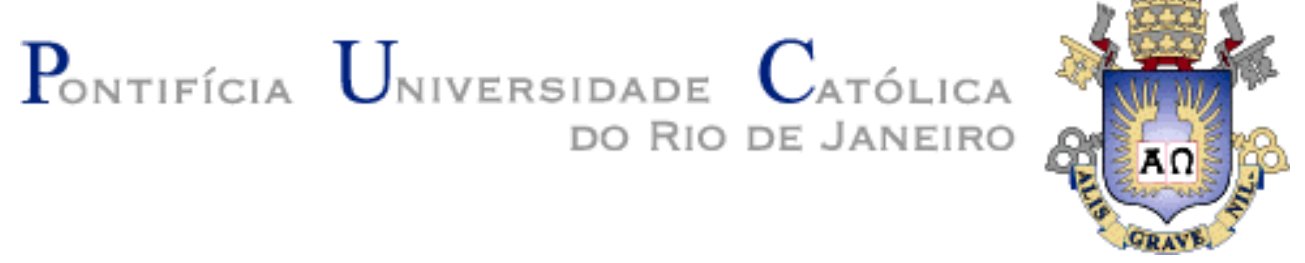

Giovana Brandão Ribeiro Linhares

Construção Colaborativa de Requisitos de Qualidade

Tese de Doutorado

Tese apresentada como requisito parcial para obtenção do grau de Doutor pelo Programa de Pósgraduação em Informática do Departamento de Informática da PUC-Rio.

Orientador: Prof. Julio Cesar Sampaio do Prado Leite

Rio de Janeiro

Setembro de 2020 


\section{Giovana Brandão Ribeiro Linhares}

\section{Construção Colaborativa de Requisitos de Qualidade}

Tese apresentada como requisito parcial para obtenção do grau de Doutor pelo Programa de Pós-graduação em Informática do Departamento de Informática da PUC-Rio. Aprovada pela Comissão Examinadora abaixo.

Prof. Julio Cesar Sampaio do Prado Leite

Orientador

Departamento de Informática - PUC-Rio

Prof. Alberto Barbosa Raposo

Departamento de Informática - PUC-Rio

Prof. Marcos Kalinoswski

Departamento de Informática - PUC-Rio

Prof. Marcos Roberto Da Silva Borges

Departamento de Informática - TECNUN

Prof. Pedro Alexandre de Mourão Antunes

Departamento de Informática - ULisboa

Rio de Janeiro, 30 de setembro de 2020 
Todos os direitos reservados. É proibida a reprodução total ou parcial do trabalho sem autorização da universidade, do autor e do orientador.

\section{Giovana Brandão Ribeiro Linhares}

Atua no mercado de Tecnologia da Informação desde 1993. Mestre em Informática - PPGI/UFRJ em 2009.

Ficha Catalográfica

Ribeiro Linhares, Giovana Brandão

Construção Colaborativa de Requisitos de Qualidade / Giovana Brandão Ribeiro Linhares; orientador: Julio Cesar Sampaio do Prado Leite - Rio de Janeiro: PUC, Departamento de Informática, 2020.

v., $141 \mathrm{f}$, ; il. ; 29,7 cm.

1. Tese (doutorado) - Pontifícia Universidade Católica do Rio de Janeiro, Departamento de Informática.

Inclui referências bibliográficas.

1. Informática - Teses. 2. Engenharia de Requisitos 3. Requisitos Não funcionais 4. Colaboração I. Julio Cesar Sampaio do Prado Leite. II. Pontifícia Universidade Católica do Rio de Janeiro. Departamento de Informática. III. Título. 


\section{Dedicatória}

Para meu pai Sergio (In Memoriam), Ele me ensinou o principal, através de seu exemplo.

Para meu filho Guilherme, Ele passou boa parte da infância admirando eu fazer esse trabalho, e o seu olhar me deu força para ir até o final. 


\section{Agradecimentos}

À minha mãe Marisa, pelo crucial apoio financeiro para que eu me dedicasse exclusivamente a pesquisa. Ela investiu não só recursos monetários mas também esperança.

Ao meu orientador, por ter acreditado em mim. Minha eterna gratidão.

Aos professores da banca, que desde a proposta, me ajudaram a enriquecer o trabalho.

À professora Simone Barbosa que no momento em que tudo poderia ter dado errado, me aconselhou e me ajudou a continuar. Também sem ela, esse trabalho não existiria.

Aos funcionários do DI. Em especial a Regina e ao Cosme, sempre prestativos a esclarecer, ajudar de todas as formas, a entender e atender aos protocolos burocráticos.

O presente trabalho foi realizado com apoio da Coordenação de Aperfeiçoamento de Pessoal de Nível Superior - Brasil (CAPES) - Código de Financiamento 001. 


\section{Resumo}

Giovana Brandão Ribeiro Linhares; Sampaio do Prado Leite, Julio Cesar. Construção Colaborativa de Requisitos de Qualidade. Rio de Janeiro, 2020. 107p. Tese de Doutorado - Departamento de Informática, Pontifícia Universidade Católica do Rio de Janeiro.

Em geral, os Requisitos Não-funcionais (RNFs) só são tratados nas atividades relacionadas à arquitetura do software, e, muitas vezes, apenas durante a implementação. Essa situação resulta em custos mais altos e menor qualidade do software. Este trabalho estuda mecanismos para ressaltar os RNFs durante as atividades de construção de requisitos.

A escolha dos requisitos pelos diversos interessados, dentro do processo de elicitação de requisitos do software através do consenso, é um problema complexo. Representar e estruturar dinâmicas de grupos, que são compostas por ações humanas, é um desafio. Durante o processo de decisão em grupo ocorre o debate de um conjunto de idéias, nem sempre expostas de maneira clara e nem sempre entendidas por todos da mesma forma. O debate envolve vários "perfis" de participantes, com pontos de vista distintos, e por vezes conflitantes. Sendo tais diferenças, em contra partida, fundamentais para a qualidade da decisão em grupo, pois as ideias são analisadas sob vários "ângulos".

Um processo colaborativo de construção de RNFs e seu suporte computacional são propostos. A abordagem de Negociação - Colaboração é reutilizada para trabalhar especificamente RNFs. Leva em consideração não apenas a construção dos RNFs em si, mas também a construção de suas interdependências. Tais interdependências entre os requisitos impactam a própria decisão sobre os RNFs a serem construídos.

A avaliação do processo foi apoiada por um software desenvolvido para suporte, ao mesmo tempo, de mecanismos de Negociação-Colaboração e de atividades de especificação de RNFs. O software é assíncrono e distribuído geograficamente, facilitando a comunicação em grupo, mesmo que com membros distantes fisicamente.

Foram realizadas três atividades avaliativas e os resultados produzidos demonstraram indícios positivos ao uso do processo na construção de RNFs. Para cada um dos projetos usados nas avaliações, foi produzida uma lista de RNFs cujo a consistência foi julgada pelos participantes envolvidos como suficientemente satisfatória. O número de RNFs foi dobrado nas três atividades de construção, revelando uma maior cobertura relativa aos atributos de qualidade inicialmente elencados para os softwares.

\section{Palavras-chave}

Engenharia de Requisitos; Requisitos Não Funcionais; Colaboração; Negociação. 


\section{Abstract}

Giovana Brandão Ribeiro Linhares; Sampaio do Prado Leite, Julio Cesar. Collaborative Construction of Quality Requirements. Rio de Janeiro, 2020. 107p. Tese de Doutorado - Departamento de Informática, Pontifícia Universidade Católica do Rio de Janeiro.

Non-Functional Requirements (NFRs) are often managed late, either during design or, more often, just at implementation. This trend results in higher costs and low-quality software. Our work studies mechanisms to support RNFs, based on the collaborative dynamics of a negotiation process, during the requirements' construction activities As such, we created a collaborative strategy for the construction of NFRs. An evaluation was conducted using a tailored tool built to implement the proposed Negotiation-Collaboration mechanisms.

The choice of requirements by various stakeholders, within the process of eliciting software requirements through consensus, is a complex problem. Representing and structuring group dynamics, which are composed of human actions, is a challenge. During the group decision-making process, a set of ideas is debated, not always clearly expressed and not always understood by everyone in the same way. The debate involves several "profiles" of participants, with different and sometimes conflicting points of view. Such differences, however, are fundamental to the quality of the group decision, as the ideas are analyzed from various perspectives.

A collaborative strategy for building RNFs and their computational support is proposed. The Negotiation-Collaboration approach is reused to work specifically with RNFs. It takes into account not only the construction of the RNFs themselves, but also the construction of their interdependencies. Such interdependencies between the requirements impact the decision on the RNFs to be built.

The strategy evaluation was supported by software developed to support, at the same time, Negotiation-Collaboration mechanisms and RNFs specification activities. The software is asynchronous and geographically distributed, facilitating group communication, even with physically distant members.

Three evaluative activities were carried out, and the results showed positive indications for the use of the strategy in the construction of RNFs. For each of the projects used in the evaluations, a list of RNFs was produced, whose consistency was judged by the participants involved to be sufficiently satisfactory. The number of RNFs was duplicated in the three construction activities, revealing greater coverage regarding the quality attributes initially listed for the software.

\section{Keywords}

Requirements Engineering; Non-Functional Requirements; Collaboration; Negotiation. 


\section{Sumário}

1 Introdução 13

1.1. Motivação 13

$\begin{array}{ll}\text { 1.2. Problema } & 13\end{array}$

$\begin{array}{ll}\text { 1.3. } & \text { Objetivos da Pesquisa } \\ \end{array}$

$\begin{array}{ll}\text { 1.4. } & \text { Contribuições Esperadas } \\ & 16\end{array}$

$\begin{array}{ll}\text { 1.5. } & \text { Organização do Documento } \\ \end{array}$

2 Fundamentos 18

2.1. Requisitos Não Funcionais (RNFs) 18

2.2. Negociação - Colaboração 20

$\begin{array}{ll}\text { 2.3. } & \text { Questões da Pesquisa } \\ \end{array}$

2.4. Desenho da Pesquisa 25

3 Trabalhos Relacionados 33

3.1. Construção Colaborativa de Requisitos 34

3.2. Apoio à Elicitação de RNFs 36

3.3. Reutilização de Conhecimento em RNFs $\quad 37$

4 A Construção de RNFs 39

4.1. Modelo de Discussão de RNFs 39

4.2. Processo para Construção de RNFs 41

4.3. Integração de Catálogos de RNFs 53

4.4. Representação dos Impactos entre Requisitos 55

4.5. O Exemplo "Atualização Cadastral" 57

4.6. Suporte Computacional 61

$\begin{array}{lll}\text { 4.6.1 RNF Colab } & 61\end{array}$

4.6.2 Requisitos do Software 62

4.6.2.1 Lista de Requisitos $\quad 62$ 
4.6.2.2 Regras de Uso $\quad 64$

$\begin{array}{lll}\text { 4.6.2.3 Informações Geradas } & 68\end{array}$

4.6.2.4 Rastreabilidade entre N-C e o RNF Colab 71

$\begin{array}{lll}\text { 4.6.3 } & \text { Arquitetura } & 73\end{array}$

5 Estudos de Casos $\quad 79$

5.1 Descrição dos Casos e Participantes 80

$\begin{array}{lll}\text { 5.2 Procedimentos de Coleta de Dados } & 87\end{array}$

5.3 Procedimentos de Análise de Dados 89

$\begin{array}{lll}5.4 & \text { Resultados } & 91\end{array}$

$\begin{array}{lll}\text { 5.4.1 O Uso do Processo } & 91\end{array}$

$\begin{array}{ll}\text { 5.4.2 As Respostas ao Questionário } & 107\end{array}$

$\begin{array}{lll}5.5 \text { Ameaças } & 120\end{array}$

6 Conclusão 123

6.1. Contribuições 123

6.2. Comparação com Trabalhos Relacionados 126

6.3. Limitações 128

$\begin{array}{ll}\text { 6.4. Trabalhos Futuros } & 130\end{array}$

Referências Bibliográficas 132

Anexo I - Termo de Consentimento Livre e Esclarecido 138

Anexo II - Questionário Qualitativo 141 


\section{Lista de Figuras}

Figura 1. Atividades de Engenharia de Requisitos (Silva, 2006).............................18

Figura 2. Qualidades dos Requisitos de Qualidade............................................. 19

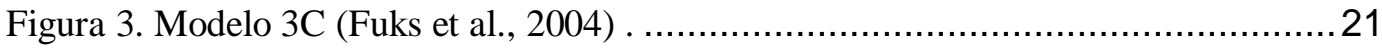

Figura 4. Tipos de Atitudes Durante a Negociação (Ramires, 2004)..........................22

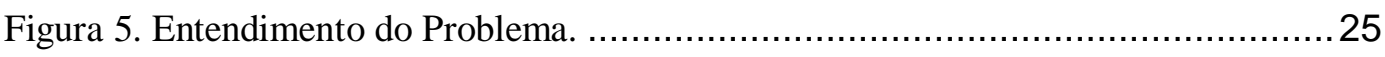

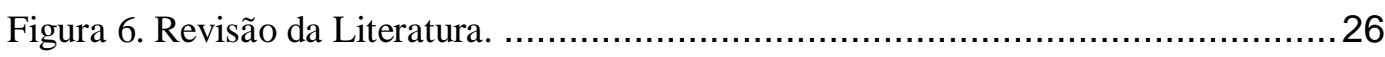

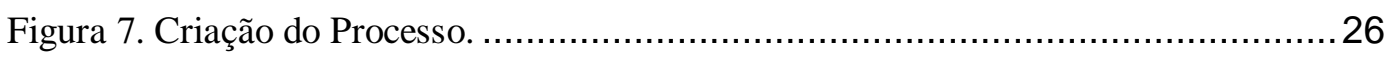

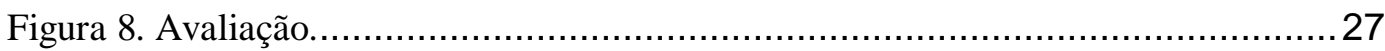

Figura 9. Metodologia Empírica para Validação de Processos (Shull, 2001) ................30

Figura 10. Modelo IBIS (Touchstone, 2000; Wikipedia, 2020)................................ 40

Figura 11. Modelo IBIS adaptado (Linhares e Leite, 2020). ................................... 40

Figura 12. Atores e suas Ações (Linhares de Leite, 2019)........................................ 45

Figura 13. Os estados do RNF (Linhares e Leite, 2019) ...................................... 46

Figura 14. Dinâmica de Negociação-Colaboração (Linhares e Leite, 2019)..................47

Figura 15. Macro Processo de Construção de RNFs. ............................................. 49

Figura 16. Exemplo Integração Transparência e Confiança: Informativo. .....................54

Figura 17 a, b. V-GRAF Original (a) e Adaptado (b) (Silva, 2006). ...........................56

Figura 18. Simplificação do V-GRAF (Linhares e Leite, 2020) ................................57

Figura 19. SIG da Atualização Cadastral ......................................................... 60

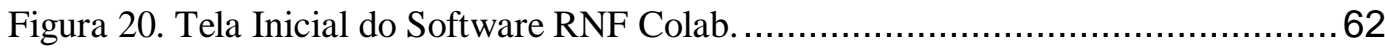

Figura 21. Arquitetura do RNF Colab. ........................................................... 73

Figura 22. Esquema Lógico do Banco de Dados do RNF Colab. ............................ 78

Figura 23. SIG Inicial Cesta de Medicamentos ................................................. 93

Figura 24. Resultado da Pontuação Participantes RNF Colab ................................ 100

Figura 25. Resultado da Pontuação Participantes TUP Virtual................................ 105

Figura 26. Conjunto de problemas x Conjunto de soluções ................................... 126 


\section{Lista de Tabelas}

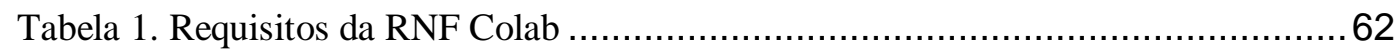

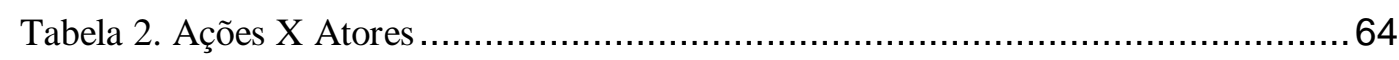

Tabela 3. Parâmetros para Pontuação dos Participantes ...............................................69

Tabela 4. Avisos X Momento Disparo ............................................................ 71

Tabela 5. Princípios da Negociação-Colaboração X RNF Colab ............................... 71

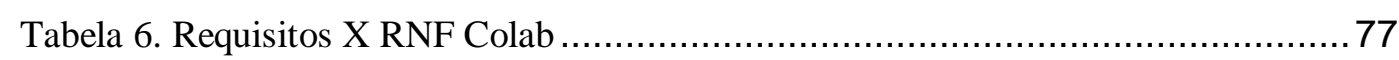

Tabela 7. Perfil dos Participantes: Cesta de Medicamentos .....................................81

Tabela 8. Atividades e Durações: Cesta de Medicamentos ...................................... 82

Tabela 9. Perfil dos Participantes: RNF Colab.................................................. 84

Tabela 10. Atividades e Durações: RNF Colab.................................................. 84

Tabela 11. Atividades e Durações: TUP Virtual ................................................. 86

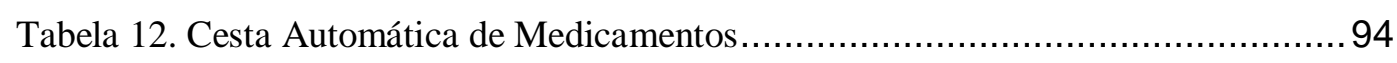

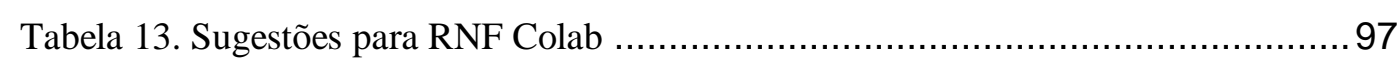

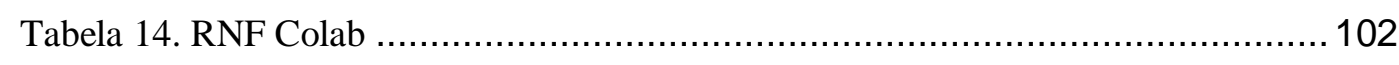

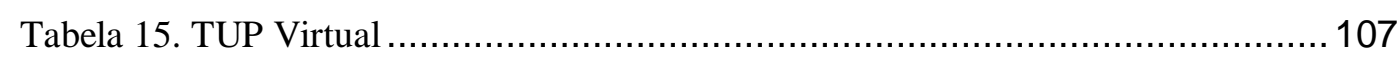

Tabela 16. Sobre o Uso do Processo ........................................................... 108

Tabela 17. Sobre o Processo Proposto ....................................................... 110

Tabela 18. Opinião dos Participantes acerca dos mecanismos de apoio .................... 112

Tabela 19. Sobre a adoção do Processo (com o RNF Colab) ...................................114

Tabela 20. Questões de Pesquisa x Percepção dos Participantes ............................... 119

Tabela 21. Comparação com os Trabalhos Relacionados I ...................................127

Tabela 22. Comparação com os Trabalhos Relacionados II.................................. 128 


\section{Lista de Abreviaturas e Siglas}

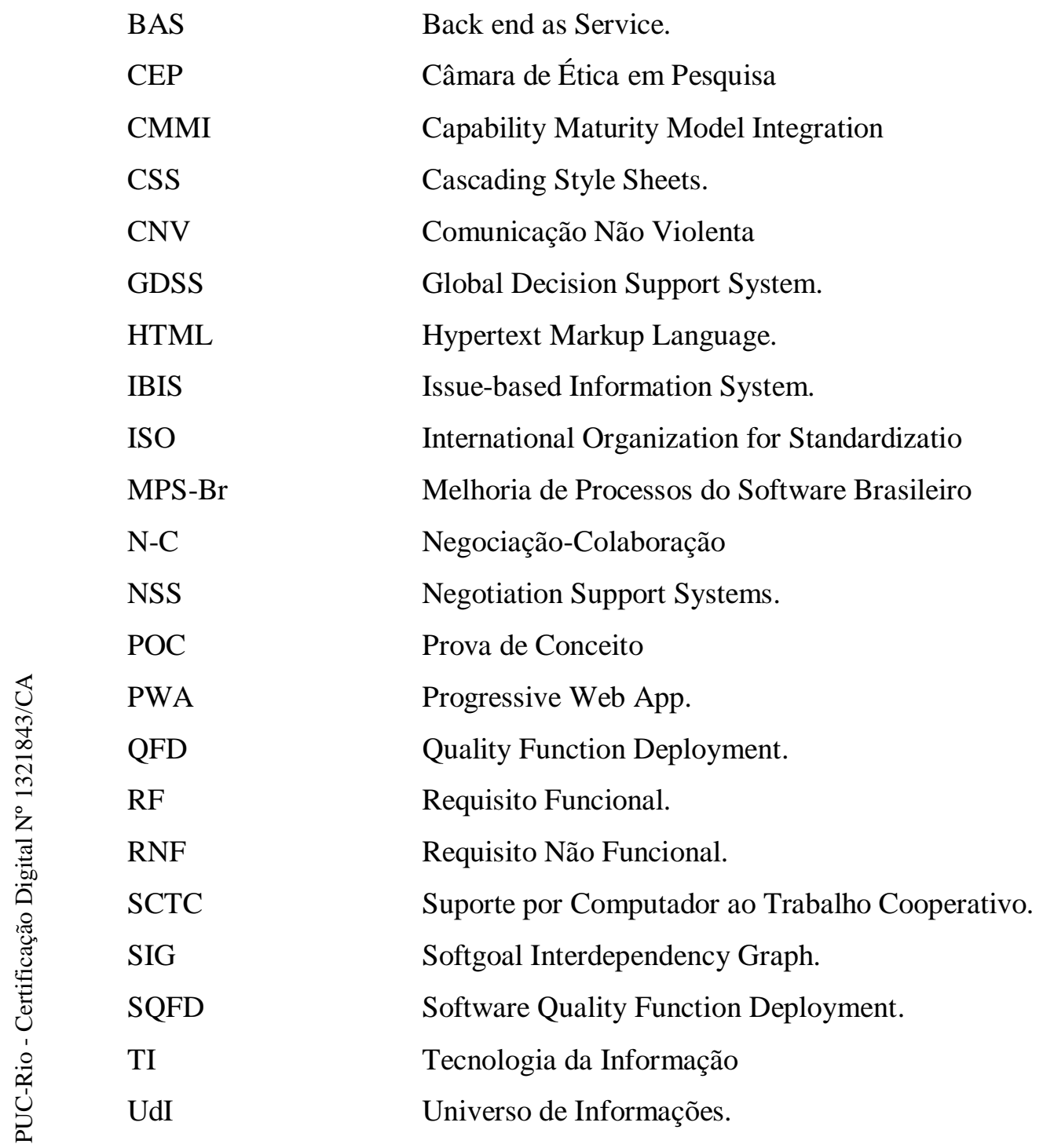




\section{Introdução}

Neste Capítulo, apresentamos de forma sucinta, a motivação, o problema, os objetivos, e as contribuições relacionadas a presente tese. Também descrevemos a organização dos capítulos do texto.

\subsection{Motivação}

É cada vez mais intenso o dinamismo dos processos do mundo real, sendo as informações e variáveis que os permeiam e os influenciam, cada vez maiores, em número e diversidade. Por outro lado, os softwares que apoiam tais processos precisam apresentar soluções com qualidade. Esse contexto caracteriza novos desafios para a Engenharia de Requisitos (Jarke et al., 2011).

Fortalecer a qualidade do software é a motivação principal da pesquisa. O fortalecimento da qualidade do software passa obrigatoriamente pelo âmbito de Requisitos Não Funcionais (RNFs) bem definidos e satisfatoriamente implementados (Chung e Leite, 2009). Segundo Boehm (Boehm , 1996), sem um conjunto bem definido de RNFs e seu cumprimento adequado, os projetos de software são vulneráveis a falhas. Por este motivo a presente pesquisa delimita-se aos RNFs.

Os RNFs são requisitos de qualidade, subjetivos, e sua definição é ainda mais complicada que a de Requisitos Funcionais (RF), por dependerem da percepção individual acerca de um determinado ponto, existindo diferentes pontos de vista e, perfis técnicos (Martín et al.., 2011). Os critérios de aceitação de RNFs não estão claramente definidos a priori. Herbert (Cunha, 2014) utiliza a expressão "satisfeito a contento" (satisfeito a um nível consideravelmente aceitável), para tradução do termo em inglês "satisfice", introduzindo por Simon (Simon, 1959) na década de 50 .

\subsection{Problema}

O problema abordado nesta tese é a baixa qualidade da especificação de RNFs e por consequência, dos próprios RNFs. Em geral, os RNFs são tratados durante as 
atividades relacionadas à arquitetura do software, e, muitas vezes, até na implementação, acarretando maiores custos e menor qualidade dos softwares (Martín et al., 2011; Silva et al., 2016). Além disso, faltam métodos robustos para se lidar com RNFs ao desenvolver e implementar softwares, principalmente no tratamento de interdependências entre RNFs (Svensson et al., 2012). Faltam soluções que considerem a relações entre RNFs, que caso sejam conflitantes, ajudam na priorização dos mesmos (Shah et al., 2019). Também é difícil processar e reutilizar sistematicamente o conhecimento atual sobre os RNFs (Sadi, 2020).

O problema, muitas vezes, é agravado em empresas que terceirizam o desenvolvimento de software. Nestes contextos, existe a empresa cliente, que contrata o desenvolvimento de software, e a empresa fornecedora, que fornece serviço de desenvolvimento de software. Ocorre que não há compartilhamento de responsabilidades relacionadas a requisitos, há apenas interações através da transferência de tarefas, dificultando a coesão em torno do objetivo comum (Freitas, et al., 2007). Situação similar ocorre quando existe uma divisão entre departamentos de uma grande empresa, cujos departamentos que precisam do software solicitam o desenvolvimento do mesmo, ao departamento de Tecnologia da Informação (TI). Acrescenta-se ainda, o fato de que a produção de software é cada vez mais distribuída (on-site, distribuído / offshore, multi-site), exigindo que as organizações busquem modelos de colaboração aderentes a esse contexto (Rocha et al., 2010).

Para complementar o entendimento do problema, aliando aos achados na literatura sobre o assunto, a pesquisadora contatou profissionais de TI da indústria. No contato informal com esses profissionais questionamos se os RNFs eram negligenciados, e em caso afirmativo, porque isso ocorria. Aqueles que acreditavam no problema verbalizaram diferentes motivos, que classificamos em 8 tipos, listados abaixo:

1. Urgência em ver o projeto começar a ser implementado, e para atender a rapidez desejada, algumas atividades, dentre elas a elaboração dos RNFs, são postergadas ou até não são realizadas. 
2. Falta de modularidade, organização e boa comunicação entre as frentes de trabalho.

3. Falta de envolvimento das áreas técnicas na concepção dos requisitos do software, sendo envolvidas as áreas de negócio majoritariamente.

4. Os usuários solicitantes focam no funcional e não se atentam em listar as qualidades desejadas, que ficam subentendidas.

5. Visão antiga dos conceitos de "mini mundo" perfeito, caminhos felizes, recursos ilimitados que a teoria em análise de sistemas de alguns anos atrás difundiu e como foi muito utilizada, deixa vícios até hoje.

6. São requisitos "áridos", menos conhecidos pelos usuários, mais técnicos e não tangíveis, isso é, são difíceis de se especificar.

7. Não são preocupações do "início", porque no "início" preocupa-se com a função. Se ainda nem tem a funcionalidade clara, fica difícil levantar o que é necessário em termos de qualidade a ser empregada.

8. Muitas vezes os usuários negligenciam os RNFs achando que esse aspecto do software deve ser pensado apenas por TI. Não conhecem e não sabem solicitar características de qualidade. Existe um "jogo de empurra" entre as áreas usuárias e TI. E acaba que os RNFs não são bem trabalhados. É um problema de processo, papeis e responsabilidades.

Os motivos explicitados ilustram uma visão similar à encontrada na literatura e complementam o entendimento do problema.

\subsection{Objetivos da Pesquisa}

O objetivo principal da presente pesquisa é "atacar" o problema de baixa qualidade de RNFs, melhorando o processo de construção dos mesmos. Em outras palavras, nosso objetivo, é criar um processo de construção de RNFs de maior qualidade e que fortaleça por consequência, a qualidade dos RNFs produzidos. Para a construção de RNFs obter sucesso é fundamental fomentar o debate sobre as 
interdependências entre os requisitos durante o processo de construção, tanto entre os RNFs e RFs, quanto entre os RNFs em si.

É importante esclarecer que existe uma separação entre a qualidade do produto e qualidade do processo. Nosso objetivo é melhorar a qualidade do produto RNFs. Para atingir tal objetivo, focamos em estruturar, de forma mais eficiente e eficaz, o processo de construção de RNFs. Investimos na qualidade do processo visando a melhora da qualidade do produto. Avaliações feitas seguindo os princípios da ISO (Koscianski, 2007), ou CMMI (CMMI, 2011), ou MPS.Br (Softex,2020), por exemplo, medem o processo para aferir a qualidade do produto.

Baseando-se no conceito de que o Requisito do Software é uma composição de conhecimentos do Domínio, do Contexto, e de necessidades específicas de um grupo social (R=D.C.r) (Leite, 2017), e nas características de qualidade de um requisito apresentadas por Mylopoulos (Mylopoulos, 2018), as seguintes perguntas caracterizam os objetivos específicos da pesquisa (Linhares e Leite, 2019; Linhares e Leite, 2020):

- Como aumentar a atenção aos RNFs?

- Como aumentar a qualidade dos RNFs?

- Como apoiar a construção colaborativa de RNFs?

\subsection{Contribuições Esperadas}

Primeiramente, a contribuição se dá no âmbito do debate sobre qualidade de software, já que a pesquisa atenta para os RNFs, fundamentais para a busca de qualidade. Parte-se da premissa de que sendo implementados corretamente, os RNFs vão acarretar um impacto positivo na qualidade do software.

A contribuição central da pesquisa é a criação do processo colaborativo de construção de RNFs. O processo fomenta e organiza o debate sobre as interdependências entre requisitos, e estrutura a sua rastreabilidade para cada uma das discussões relacionadas aos requisitos.

O processo utiliza o conhecimento existente sobre RNFs contido nos Catálogos de RNFs, e para ser possível este reuso criamos uma maneira de integrar 
os Catálogos de RNFs e alimentar uma base de conhecimento para as futuras consultas.

Também como contribuição importante temos a criação de uma nova linguagem para estruturar o debate sobre as interdependências entre os requisitos e para representação dos RNFs e respectivas interdependências em Diagramas Orientados a Objetivos.

A avaliação do processo foi apoiada por um software desenvolvido para suporte, ao mesmo tempo, de mecanismos de Negociação-Colaboração e de atividades de especificação de RNFs.

\subsection{Organização do Documento}

A presente tese conta com cinco Capítulos, além desta introdução. O Capítulo 2 contém a fundamentação teórica com os conceitos utilizados de RNFs e Negociação-Colaboração e o método utilizado para a elaboração da tese. O Capítulo 3 contém a revisão da literatura com o resumo dos trabalhos relacionados. O Capítulo 4 descreve o processo proposto para a solução do problema, e apresenta a implementação do mesmo. O Capítulo 5 traz a avaliação preliminar do processo proposto. Por último, é descrita a conclusão, incluindo as contribuições, limitações e trabalhos futuros.

No link: https://github.com/gbribeirol/RNFColab.git.estão disponíveis o código do software desenvolvido RNF Colab, e o respectivo manual do usuário. Também estão disponíveis os questionários respondidos pelos participantes da avaliação, e os dados produzidos durante o estudo de caso 2 - RNF Colab (lista de requisitos e interdependências, histórico organizado das discussões e pontuação dos participantes). 


\section{Fundamentos}

Neste Capítulo, abordamos os conceitos utilizados na tese envolvendo os RNFs, e a definição do binômio Negociação-Colaboração. Apresentamos também o método usado para a pesquisa da tese.

\subsection{Requisitos Não Funcionais (RNFs)}

As atividades de Engenharia de Requisitos, eliciar, modelar e analisar, ocorrem simultaneamente e de forma incremental, ao longo de todo o desenvolvimento do software (Silva, 2006). Os sucessivos refinamentos na construção de requisitos, para a compreensão e aceitação dos envolvidos, não é trivial.

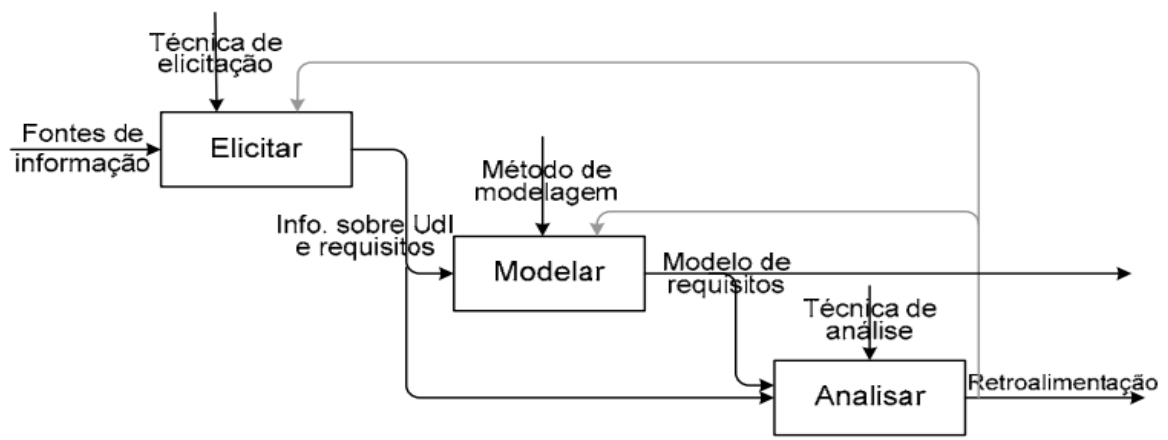

Figura 1. Atividades de Engenharia de Requisitos (Silva, 2006).

Por sua vez, os RNFs são ainda mais complicados de serem construídos, por conta de suas características de qualidade, isso é, características subjetivas. Os RNFs são (Cysneiros, 2001):

Qualificadores: são atributos de qualidade, que restringem as funcionalidades diretas do software. Por exemplo: performance, confiabilidade, acessibilidade, portabilidade, manutenibilidade, entre outros.

Transversais: a inclusão de um RNF em uma especificação de requisitos, impacta RF, bem como outros RNFs já elicitados (interdependências entre RNFs). O impacto pode ser positivo, contribuindo assim para sua satisfação a contento, ou negativo, influenciando para não satisfação. 
Subjetivos: um RNF raramente pode ser considerado totalmente satisfeito. Porque são geralmente subjetivos, tratam de aspectos de qualidade, assim sendo podem ser vistos, interpretados e conceituados de forma diferente por diferentes pessoas. O termo "satisfice" ou seja, satisfeito a contento, é usado por esse motivo.

Leite (Leite, 2001) aborda os RNFs como aspectos de qualidade na definição do próprio software, isso é, defende que aspectos de qualidade devem ser tratados no próprio processo de definição do software, como as características de qualidade do produto. Isso acaba por acarretar que gerenciar requisitos significa não só gerenciar aspectos de funcionalidade, mas também gerenciar aspectos de qualidade.

Freitas et al. (Feitas et al., 2007) define que maior qualidade de requisitos significa: redução de ambiguidades, aumento do entendimento e completeza, diminuição de indefinições e retrabalho, apontamento de prazos e custos mais próximos da realidade. Além disso, defende que a apresentação dos requisitos possua nível de detalhamento que garanta o entendimento dos que irão utilizá-los.

Em (Mylopoulos, 2018), são abordadas as qualidades dos requisitos. Simples e direto, o autor listou características para um requisito de qualidade satisfatório: não deve ser ambíguo ou conflitante, deve ser justificável, completo, tangível, correto e preciso. Embora, como já mencionado, um RNF nunca possa ser considerado totalmente satisfeito.

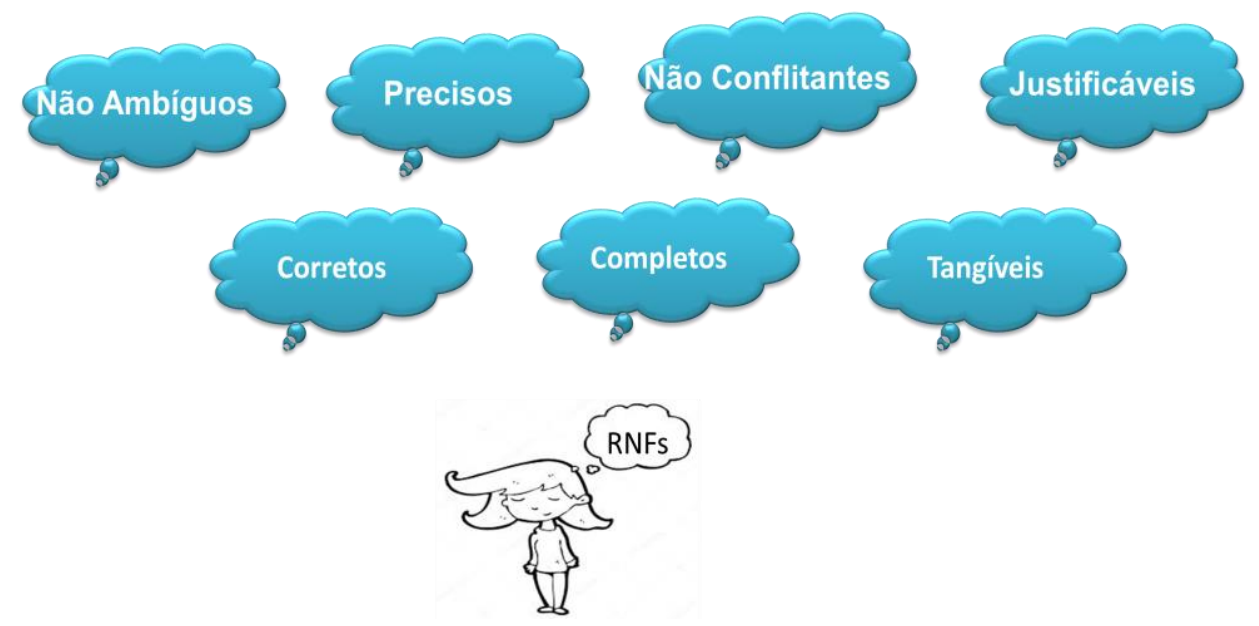

Figura 2. Qualidades dos Requisitos de Qualidade. 
A qualidade pode ser abordada de diferentes formas. Como já mencionamos, é algo subjetivo. Ocorre na Engenharia de Software uma dificuldade de se medir a qualidade. Como alternativa busca-se melhorar o processo de produção para se adquirir maior confiança na qualidade do produto final. Embora seja importante a avaliação da qualidade de software nas duas visões, processo e produto (Tsukumo et al., 1997). A presente pesquisa propõe um novo modo de construção de RNFs (processo) com objetivo de gerar um conjunto de RNFs (produto) de melhor qualidade.

O modelo proposto pela ISO/IEC 9126(NBR13596) tem como objetivo servir de referência básica na avaliação de produto de software. O modelo define seis categorias de características de qualidade de software e suas respectivas sub características (Koscianski et al., 1999). As características e sub características, listadas pela ISO para avaliação da qualidade do software, são RNFs. Parte-se da premissa de que sendo implementados corretamente, os RNFs acarretam um impacto positivo na Qualidade do Software.

\subsection{Negociação - Colaboração}

A Negociação-Colaboração surge no trabalho de um grupo de pessoas ao longo de processos que exigem a tomada de decisões. A Engenharia de Requisitos envolve intensa interação entre interessados na construção dos requisitos e os engenheiros de requisitos. Por isso o olhar para o binômio negociação-colaboração é tão importante. O processo de Negociação-Colaboração pretende estruturar o trabalho de um grupo de pessoas que possuem diferentes pontos de vista, embora compartilhem de um objetivo em comum.

Em (Marczak et al., 2009) a colaboração é examinada tanto na dimensão técnica como no âmbito das relações sociais e se enfatiza que alcançar uma colaboração eficaz é um desafio contínuo no desenvolvimento de software, e a engenharia de requisitos herdou esse desafio.

Fuks et al. (Fuks et al., 2004), apresentam uma abordagem de implementação de softwares colaborativos, baseada no Modelo 3C (Comunicação, Coordenação e Cooperação). O Modelo 3C estrutura o trabalho em grupo, enfatizando aspectos de colaboração. Para trabalhar em grupo os indivíduos 
precisam se comunicar, se coordenar e cooperar em conjunto num espaço compartilhado.

As trocas ocorridas durante o trabalho em grupo geram compromissos que são gerenciados pela coordenação, que por sua vez organiza e dispõe as tarefas que são executadas na cooperação. Ao cooperar, os indivíduos têm necessidade de se comunicar para negociar e tomar decisões sobre situações previstas e não previstas inicialmente.

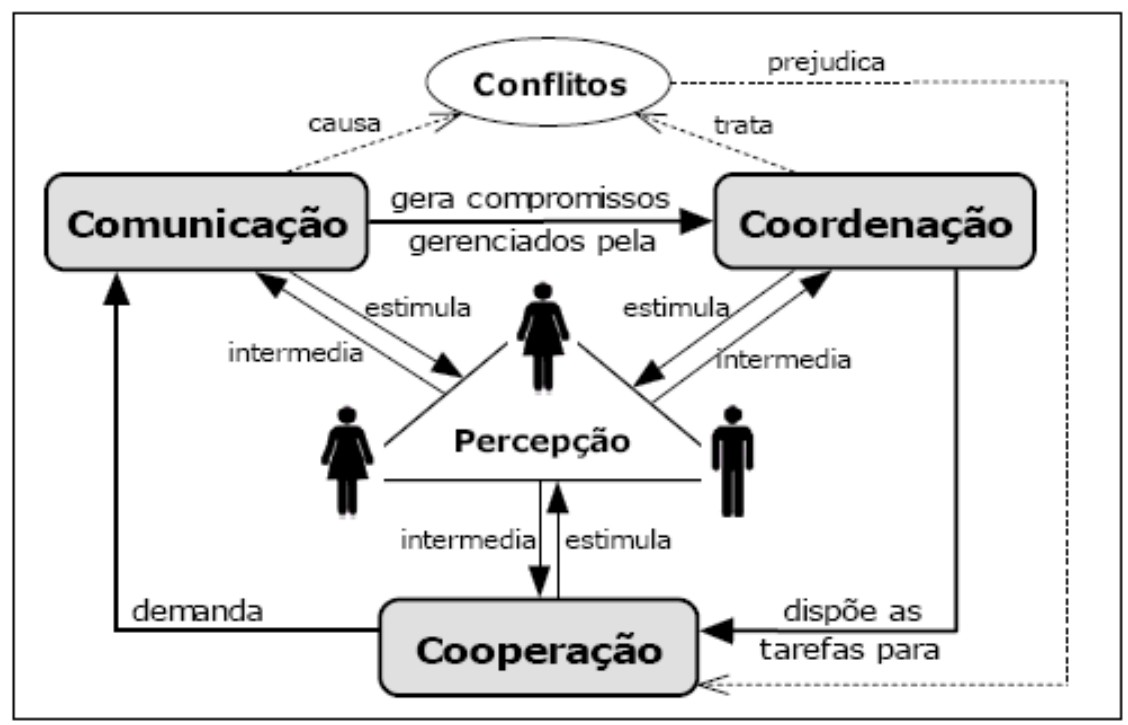

Figura 3. Modelo 3C (Fuks et al., 2004) .

A Percepção pode desencadear os conflitos, pois pode ser distinta de um indivíduo para o outro. O conflito não prejudica a colaboração se não for destrutivo, já que trás ao debate questões que podem ainda não ter sido percebidas pelo resto do grupo, e que enriquecem a discussão.

Mesmo sendo o objetivo compartilhado pelo grupo, surgem posições diversas por parte dos seus integrantes, o que desencadeia o processo de negociação-colaboração. Neste processo temos de um lado a necessidade de consenso, incentivando à colaboração, e do outro lado, o conflito, porque sem conflito as questões debatidas podem não ser suficientemente analisadas (Linhares et al., 2012).

Segundo Mathias (Mathias, 1994), na literatura de conflitos existem distinções de tipos de conflitos: aqueles que beneficiam os objetivos da organização e, os não desejáveis, que são frutos apenas de interesses individuais. O conflito 
desejável é aquele que estimula o interesse e a curiosidade, impede a estagnação e enriquece o debate. São necessários mecanismos que estimulem conflitos "positivos" e para isso é importante contemplar, ao mesmo tempo, a negociação e a colaboração.

Segundo Lewicki e Litterer (Lewicki e Litterer, 1985) os tipos de atitudes que os participantes podem seguir numa situação de conflito são: competição, acomodação, compromisso, colaboração e inação. Esta classificação é baseada no grau de satisfação dos objetivos de cada participante face ao grupo.

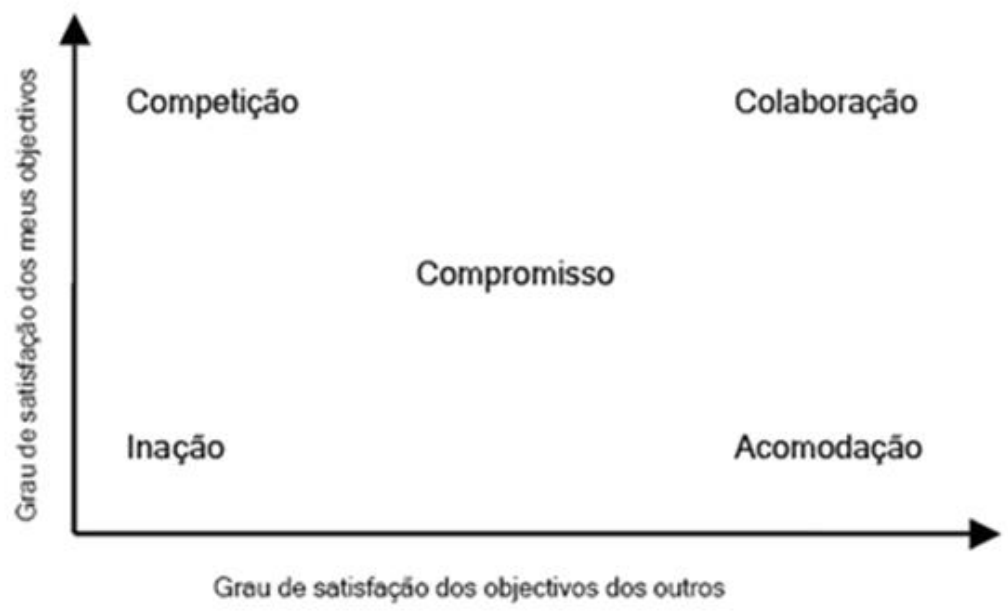

Figura 4. Tipos de Atitudes Durante a Negociação (Ramires, 2004).

O melhor resultado para um processo de qualidade é a colaboração. É importante que haja conflito no início, mediando-se conflitos e superando impasses, para que se chegue à colaboração. A colaboração surge quando as partes se interessam pela qualidade do resultado comum. O que é algo mais que somente obter o resultado pretendido (Linhares et al., 2012).

Suh (Suh, 2009) reforça a ideia de que o desenvolvimento de softwares requer colaboração e negociação para que as decisões sejam tomadas de acordo com as necessidades do cliente. Ele propôs heurísticas para colaboração e negociação com base em algumas premissas, como por exemplo, todos os participantes compreenderem o objetivo geral do projeto, entenderem a estratégia definida para alcançar o objetivo do projeto. 
Para o sucesso da dinâmica de Negociação-Colaboração, não deve haver informações secretas sobre as regras do processo. Se existe o registro de comportamento dos participantes, este deve ser público - princípio da transparência (Leite e Cappelli, 2010; Linhares et al., 2012). Os participantes possuem a mesma liberdade de participação - princípio da igualdade. A negociação deve ser direcionada objetivando o consenso e procurando soluções que satisfaçam ambas as partes - princípio da eficácia ganha-ganha. Outros dois princípios são citados para a qualidade da Negociação-Colaboração, a confidencialidade, que é o princípio que envolve o anonimato dos envolvidos; e a imparcialidade, que é o princípio de não fazer tender a um determinado participante em detrimento dos outros (Linhares et al., 2012).

A dinâmica de Negociação-Colaboração também deve apresentar as seguintes premissas: ser inerentemente apoiado em participação colaborativa, tendo em mente que interagir nem sempre resulta em colaborar; o acesso a fontes de informação ser livre e incentivado; e, existir registros das interações (questionamentos, conflitos, mensagens geradas durante as discussões) (Freitas et al., 2007). O processo proposto de construção colaborativa de RNFs, descrito no Capítulo 4, usa na sua dinâmica, o conceito de Negociação-Colaboração.

Vale ressaltar, que a presente pesquisa trata do tipo de colaboração que ocorre no âmbito das equipes envolvidas em projetos organizacionais de desenvolvimento de produtos ou serviços, que por concorrência de mercado, são mantidos em sigilo até sua comercialização. Diferente portanto, do tipo de colaboração por exemplo, tratada por Knauss et al. em (Knauss et al., 2018), que ocorre em ambientes com abordagem comercial aberta, onde existem comunidades, "ecossistemas", e várias organizações colaborando interconectadas, compartilhando informações. Não obstante, o processo proposto, poderá ser reavaliado no futuro, e adaptado, se caso for, para funcionar de acordo com outros tipos de colaboração.

\subsection{Questões da Pesquisa}

O objetivo central da tese é criar um processo de construção de RNFs de maior qualidade e que fortaleça por consequência, a qualidade dos RNFs produzidos. Para elaborar as questões de pesquisa partimos de duas premissas: a primeira é de que 
um processo bem estruturado gera produtos de maior qualidade. Como já mencionado na introdução deste trabalho, organizações como a ISO (Koscianski, 2007), CMMI (CMMI, 2011) e MPS.Br (Softex, 2020), oferecem guias e regras de normalização para melhorar os processos organizacionais e a habilidade desses em gerenciar o desenvolvimento e a manutenção de produtos e serviços. A segunda premissa é de que sendo bem definidos e implementados corretamente, os RNFs acarretam um impacto positivo na qualidade do software, pois operacionalizam as características de qualidade do software (Chung e Leite, 2009; Boehm , 1996). O objetivo principal portanto é construir um processo eficiente e eficaz (de construção de RNFs) visando um produto (RNFs) de maior qualidade. Como objetivos específicos da tese nos desafiamos a responder três perguntas: Como aumentar a atenção aos RNFs? Como aumentar a qualidade dos RNFs? Como apoiar a construção colaborativa de RNFs?

$\mathrm{Na}$ busca de respostas para essas questões da pesquisa desenvolvemos algumas ações que desencadearam resultados. Para aumentar a qualidade dos RNFs, investimos na criação de um novo processo de construção de RNFs que agrega além de atividades de engenharia de requisitos, mecanismos de NegociaçãoColaboração. Partimos da premissa de que após vários ciclos de discussões em grupo, entendimentos e aprimoramentos, o processo deve resultar em RNFs mais refinados e de maior qualidade. A dinâmica de Negociação-Colaboração é portanto o conceito teórico aproveitado para criação de um processo novo, com intuito de melhorar a qualidade deste processo. Um processo de construção de RNFs de maior qualidade, acarreta maior qualidade dos RNFs produzidos.

Também é englobado ao processo, o debate dos impactos positivos ou negativos existentes entre os requisitos. Uma nova linguagem de representação dos RNFs e suas interdependências - incluindo os impactos em RFs, foi criada para simplificar a comunicação durante o debate e fomentar a análise em grupo dos aspectos transversais dos RNFs. Esta discussão é fundamental para a tomada de decisão com maior qualidade da inclusão, ou não, de um novo RNF em uma especificação.

Para aumentar a atenção aos RNFs criamos um recurso no processo de construção de RNFs para o reuso do conhecimento existente contido nos Catálogos 
de RNFs. No exercício de uso dos Catálogos ocorrem inclusões de novos RNFs detectados e também de novas operacionalizações. Portanto, além do benefício da possibilidade de minimizar a negligencia relativa aos RNFs, temos também a oportunidade de evolução deste conhecimento como efeito do seu reuso.

\subsection{Desenho da Pesquisa}

A pesquisa seguiu os passos representados nos desenhos das figuras 5, 6, 7 e 8 . A forma de desenhar utilizada foi inspirada no desenho de pesquisa (seção 4, página 483) do trabalho de Oliveira (Oliveira et al., 2019). Os passos são detalhados em seguida as figuras.

a.1)

Entendimento

do problema

O problema é a

baixa qualidade

dos RNFs. a.2) Formulação das questões de

pesquisa

Os RNFs são tratados durante as atividades relacionadas à arquitetura do software, e, muitas vezes, até na

implementação, acarretando maiores custos e menor

qualidade dos softwares (Martín et al., 2011; Silva et al., 2016).

Além disso, faltam métodos robustos para se lidar com RNFs ao desenvolver e implementar softwares, principalmente no

tratamento de interdependências entre RNFs (Svensson et al.

2012). Faltam soluções que considerem a relações entre RNFs,

que caso sejam conflitantes, ajudam na priorização dos mesmos (Shah et al., 2019).

Também é difícil processar e reutilizar sistematicamente o conhecimento atual sobre os RNFs (Sadi, 2020).

Ocorre que não há compartilhamento de responsabilidades relacionadas a requisitos, há apenas interações através da transferência de tarefas, dificultando a coesão em torno do objetivo comum (Freitas, et al., 2007).

\section{Figura 5. Entendimento do Problema.}

Como aumentar a atenção aos RNFs?

Como aumentar a qualidade dos RNFs?

Como apoiar a construção colaborativa de RNFs? 


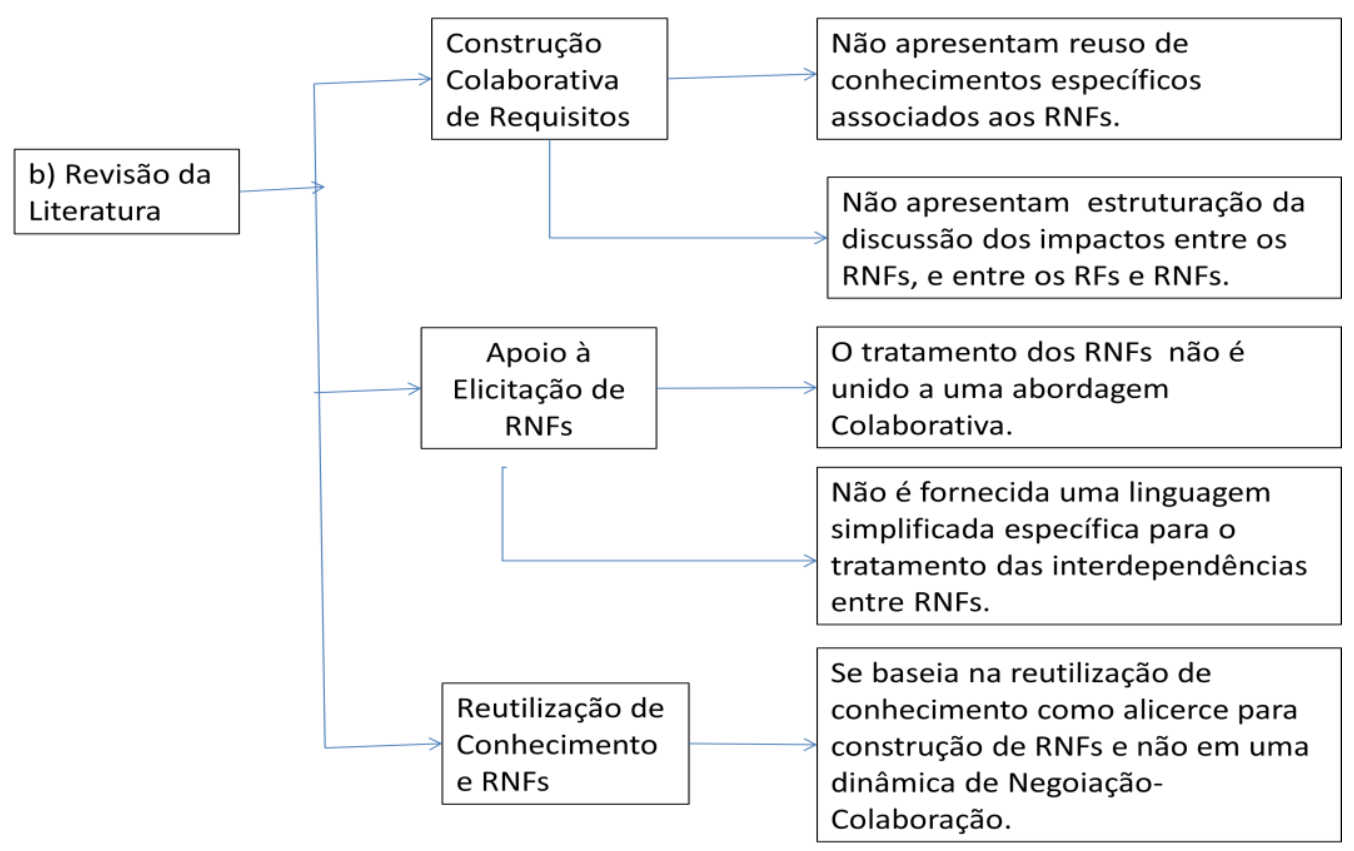

Figura 6. Revisão da Literatura.

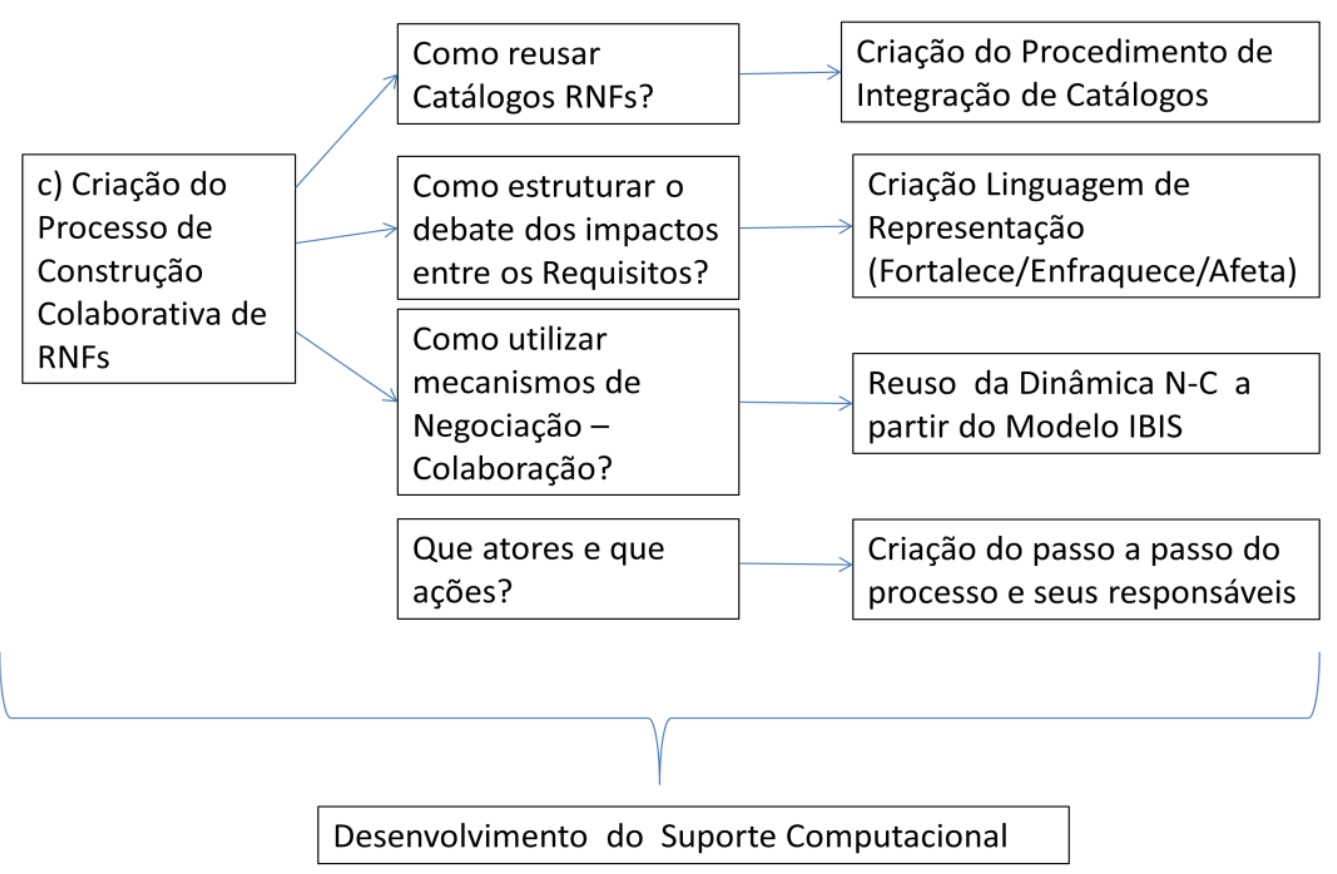

Figura 7. Criação do Processo. 


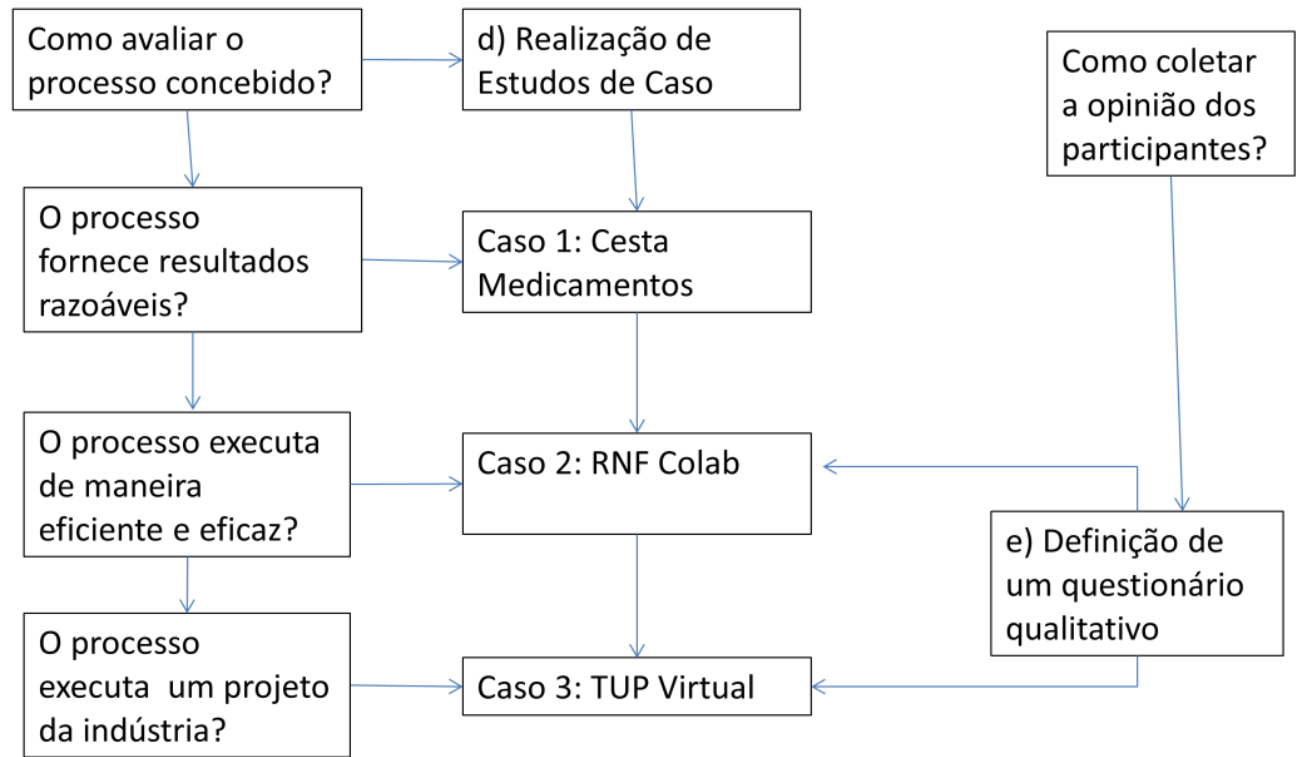

Figura 8. Avaliação.

a) Entendimento do problema.

Este passo foi realizado com o propósito de aprofundar o entendimento do problema em relação a qualidade dos RNFs tratado na tese. Duas ações foram realizadas para cumprir esse passo. A primeira foi a busca de referências na literatura que apontassem problemas relacionados a RNFs e o contato com alguns profissionais da indústria para analisar se a percepção dos mesmos acerca do problema. O conhecimento da literatura é importante para caracterizar o problema. Também é a base para entender os desafios envolvidos e saber o que já foi feito para resolve-los. Pode-se se dizer que nesta ação foi realizado o inicio parte do passo $b$ descrito mais adiante. A segunda ação foi verificarmos a percepção dos profissionais da indústrias contatados com relação ao problema de baixa qualidade dos RNFs. Sob a ponto de vista destes, especialistas em elicitação de RNFs, no contexto de grandes organizações de telecomunicação, esse problema ocorre. Apresentaram inclusive, vários possíveis motivos que desencadeiam a baixa qualidade ou negligencia dos RNFs. Com base nos achados na literatura e a confirmação da existência do problema na prática (ao menos nas opiniões investigadas), refinamos as perguntas para pesquisa.

b) Revisão de literatura relacionada a construção de RNFs.

Este passo foi realizado com o objetivo de entender o que já foi feito em trabalhos anteriores envolvendo o problema pesquisado. Em linhas gerais a 
primeira ação realizada foi definir as chaves de busca (explicitadas no Capítulo 3), isso é, palavras que usaríamos nas consultas; e depois, executar as chaves de buscas no Google Scholar. Selecionamos os textos listados pela ferramenta, lendo o resumo. Caso não fosse suficiente para o entendimento do trabalho, lia-se também a introdução. Se interessava, era selecionado para leitura integral e varredura das referencias em busca de mais referências. No caso de não interessar, descartava-se. Para todos os textos selecionados efetuamos uma leitura completa ou uma "leitura diagonal". Realizamos a extração de dados relativos ao problema e também da solução proposta. Na leitura de cada um dos trabalhos selecionados procuramos a presença de tratamento para característica transversal dos RNFs, abordagem colaborativa para construção, e uma linguagem de representação dos RNFs e seus impactos, fora a presença de recursos de reuso do conhecimento existente (Catálogos de RNFs), o que ajudaria a evitar a negligência dos mesmos. Tais itens tornaram-se critérios de comparação entre os trabalhos selecionados e por fim, realizamos o agrupamento dos trabalhos em três temas: i) construção colaborativa de requisitos, ii) elicitação específica de RNFs, iii) reuso de conhecimento em RNFs. A revisão da literatura realizada está descrita no Capítulo 3 deste texto.

c) Proposição do processo para construção de RNFs.

A partir dos achados literários e respectiva analise, entendemos os desafios, assim como o que já foi feito para resolve-los. Este passo foi realizado com o objetivo de criar tratamentos novos que englobasse aspectos ainda não trabalhados acerca do problema pesquisado na tese. A incorporação de mecanismos de negociação-colaboração já existentes para elicitação específica e com maior qualidade de RNFs foi um deles. Uma nova maneira de integrar os Catálogos de RNFs para reuso do conhecimento existente, ajudando a minimizar o problema da negligência para com os RNFs, foi outro tratamento original. A organização e incentivo ao debate sobre os impactos entre requisitos através de uma nova linguagem cujo a simplicidade estimula o seu uso, também é uma novidade trazida pela pesquisa. na opinião da pesquisadora é a principal novidade, a maior contribuição. Basicamente cinco trabalhos foram desenvolvidos para obtenção dos resultados acima citados: 
- Desenhamos um novo processo de construção de RNFs, passo a passo, vislumbrando papeis, artefatos, entradas e saídas de cada ação a ser realizada pelos atores, nos baseando nas atividades de engenharia de requisitos de elicitação, modelagem e análise (Silva, 2006). Desenhamos cada estado que um RNF pode apresentar dentro do processo criado ("criado", "cancelado", "em negociação", "construído", "descartado")

- Criamos uma nova maneira de integrar os Catálogos de RNFs (Chung et al., 2000) a partir da observação de interseções dos mesmos, isto é, qualidades que pertenciam a mais de um catálogo. E incluímos a consulta aos Catálogos de RNFs integrados no processo de construção de RNFs para reuso do conhecimento existente. Consultando os Catálogos de RNFs os engenheiros de requisitos e também o grupo de participantes podem evitar a negligencia de algum aspecto de qualidade que esteja mapeado nestas bases de conhecimento.

- Desenvolvemos uma nova linguagem "Fortalece/Enfraquece/Afeta" para representação das interdependências entre os requisitos com base no conceito chinês de classificação dos alimentos nos tipos: "quente", "frio" e "neutro" (Kwang, 2009) e no modelo V-Graf (Yu et al., 2004). E incluímos a linguagem na estruturação do debate de impactos entre requisitos (incluindo os RFs e RNFs) dentro do processo de construção de RNFs.

- Reutilizamos conceitos de Negociação-Colaboração de trabalhos anteriores (Antunes et al., 2006; Linhares, 2009) como uma maneira de organizar a dinâmica que acontecerá ao longo do processo de construção de RNFs criado. Adaptamos o modelo IBIs, modificamos os parâmetros da pontuação dos participantes, instanciamos as alternativas ao consenso (voto maioria ou decisão moderador), e incluímos esses mecanismos dentro do processo de construção de RNFs.

- Desenvolvimento de um suporte computacional para apoiar o processo colaborativo de construção de RNFs. Este trabalho foi realizado com o objetivo de facilitar o uso do processo, e torná-lo mais eficiente, 
fomentando desta maneira a sua adoção. Também se justifica desenvolver o software para saber se o processo é implementável computacionalmente.

O processo de construção de RNFs está detalhado no Capítulo 4 deste texto.

d) Avaliação do processo através de 3 estudos de casos.

Este passo foi realizado com o objetivo de avaliar qualitativamente o processo criado. Na Metodologia Empírica para Validação de Processos, descrita no trabalho de Shull et al. (Shull et al., 2001), e apresentada na figura 9, são examinadas primeiramente as questões fundamentais que irão demandar maior esforço para ajustar o processo, pois implicam em maiores mudanças. As questões posteriores são mais de detalhes e exigem menor esforço para ajuste. Assim, a metodologia, obriga investigar desde o início, os problemas mais complicados de resolver, evitando desperdício de esforço (Kalinowski e Travassos, 2007).

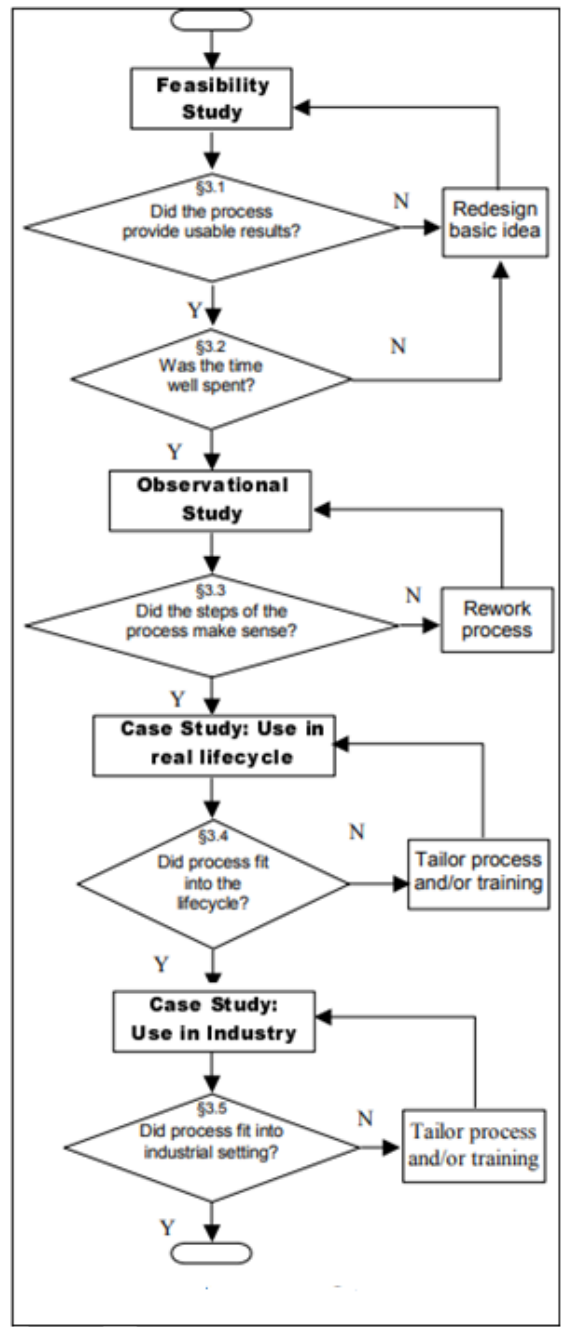

Figura 9. Metodologia Empírica para Validação de Processos (Shull, 2001) 
Estruturamos a avaliação da presente pesquisa baseada nesta metodologia, e realizamos 3 estudos de casos:

- Caso 1 - Cesta de Medicamentos: apurarmos se o processo era viável, isso é, produzia resultados utilizáveis em um tempo aceitável. A aplicação foi para construção de RNFs de um produto IOT, Cesta de Medicamentos.

- Caso 2 - RNF Colab: discutimos os requisitos do software de suporte do próprio processo e verificamos se as atividades envolvidas no processo proposto faziam sentido, isso é, estavam organizadas de maneira eficiente e eficaz.

- Caso 3 - TUP Virtual: sondamos se o processo proposto se adaptava a um projeto da indústria. A aplicação foi para construção de RNFs do projeto TUP Virtual, projeto de uma organização de grande porte na área de Telecomunicações.

A avaliação é principalmente de cunho qualitativo pois se baseia no instrumento de pesquisa de questionário, para a coleta da opinião dos participantes acerca do processo proposto. Contudo é possível agregar alguns elementos quantitativos na análise de seus resultados. Métricas como o número de RNFs construídos, correlações e refinamentos, o número de posicionamento e argumentos, pontuação do participante, dúvidas e sugestões postadas no mural, foram coletadas para análise. Esses elementos quantitativamente indicam o volume de participação e possibilidade de enriquecimento de ideias, desencadeando um processo de construção de requisitos de maior qualidade. A estruturação dos estudos de caso assim como seus resultados estão descritos no Capítulo 5 deste texto.

e) Coleta da opinião dos participantes dos estudos de caso acerca da qualidade do processo concebido.

Este passo foi realizado com o objetivo de coletar opiniões dos participantes das atividades de avaliação. Primeiramente, definimos as perguntas do questionário com base nos aspectos que gostaríamos de analisar, acerca da própria atividade de avaliação, e sobre o processo proposto. As perguntas foram definidas elencando as características do processo como apoio a negociação, colaboração, debate de 
impactos entre requisitos, reuso do conhecimento existente e etc. A intenção foi saber se tais características do processo foram percebidas pelos participantes.

$\mathrm{O}$ artefato pronto e revisado pela pesquisadora e seu orientador, foi encaminhado para avaliação do Câmara de Ética em Pesquisa (CEP) da universidade, órgão independente do Departamento do Informática. A CEP analisou o questionário, assim como o Termo de Consentimento Livre e Esclarecido (Anexo I) a ser assinado pelos participantes. O referido documento também foi preparado pela pesquisadora com base no procedimento encontrado na página da Vice-Reitoria para Assuntos Acadêmicos (http://vrac.puc-rio.br). Os dois artefatos faziam parte do Projeto de Pesquisa 552020 encaminhado à CEP.

O parecer favorável foi emitido para o Projeto de Pesquisa 552020, liberando o uso do questionário para a pesquisa. Após a execução das atividades de avaliação, o questionário foi enviado individualmente para resposta anônima dos participantes. Vale lembrar que durante o treinamento dos participantes, os termos e objetivos do questionário foram explicados. O questionário compõe o Anexo II deste texto e a analise das respostas estão contidas na seção 5.4 do Capítulo 5 de avaliação do processo proposto. Os questionários respondidos foram disponibilizados no link: https://github.com/gbribeirol/RNFColab.git.

Por fim, cabe aqui salientar que optamos por questionário ao invés de outras técnicas de coleta de opiniões, como por exemplo "focus groups"1 (Stewart and Shamdasani, 2014), para uma pessoa não ser influenciada por outra pessoa no momento de explicitar sua opinião. Com o questionário anônimo, e de preenchimento individual, promovemos a eliminação de constrangimentos que o participante poderia sofrer para fornecer suas respostas, fora a influência de opiniões de outros participantes. Entretanto, o uso do Mural no estudo de caso 2 RNF Colab de certa maneira emprega uma visão de focus group.

\footnotetext{
1 O Focus Group ou Grupo Focal é uma técnica utilizada em pesquisas qualitativas para as mais diversas finalidades. São entrevistas em grupo onde é possível observar a interação entre os participantes, que podem manifestar uma opinião comum coletiva ou se dividirem em subgrupos com ideias opostas. Neste tipo de técnica os participantes levam em consideração a opinião dos outros para formular a sua própria opinião.
} 


\section{Trabalhos Relacionados}

Neste Capítulo analisamos trabalhos relacionados ao presente tema, selecionados na literatura pesquisada nas duas últimas décadas.

A busca dos trabalhos relacionados à pesquisa foi realizada qualitativamente, baseando-se na técnica de "Bola de Neve" (Vinuto, 2014). Nas consultas através do software Google Scholar, foram utilizadas as combinações, tanto em Português quanto em Inglês, das seguintes palavras: Negociação, Colaboração, Elicitação, Requisitos, Requisitos Não Funcionais, RNFs, Negociação-Colaboração, Engenharia de Requisitos. A cada trabalho selecionado se buscava nas referências do achado outros títulos de interesse. Também buscamos referências junto aos professores de universidades brasileiras, especialistas nos assuntos de RNFs e Negociação-Colaboração.

Utilizamos, conforme mencionado no Capítulo 2, os seguintes critérios de comparação para análise dos trabalhos relacionados: estruturação da discussão dos impactos entre os RNFs, e entre os RFs e RNFs; abordagem colaborativa; linguagem simplificada específica para o tratamento das interdependências entre RNFs; e, reuso de conhecimentos específicos associados aos RNF. Tais critérios, ao mesmo tempo, configuram propriedades do processo proposto nesta pesquisa.

O processo proposto reutiliza a integração do modelo de argumentação com mecanismos para promover a colaboração e negociação de Linhares (Linhares, 2009), no entanto os processos criados são totalmente distintos. Além disso, para a construção de RNFs a integração ao modelo IBIS parte da ideia de que o próprio RNF é uma questão. Também as correlações entre os RNFs, tomam lugar da questão no modelo de argumentação. Em (Linhares, 2009) os comentários dos revisores são transformados em questões por um facilitador e integram o modelo de argumentação.

O processo proposto também se assemelha ao método Delphi (Grisham, 2009), desenvolvido a partir da década de cinquenta. No método, especialistas ao 
longo das diferentes rodadas de discussões, apresentam as suas opiniões, comparando com as do grupo, argumentando e defendendo as suas posições e, ao mesmo tempo, estão abertos a reconsiderar e a alterá-las perante os argumentos de outros colegas ou a tendência geral do grupo. As características comuns que definem o método são: a) anonimato; b) retorno das contribuições individuais; c) construção e apresentação da resposta do grupo como um todo; d) possibilidade de revisão e alteração das respostas (Marques e Freitas, 2018). O processo no entanto é completamente distinto da dinâmica da presente proposta. As discussões são feitas através de questionários anônimos trocados entre os pesquisadores e os especialistas. A longa duração do processo é outra diferença. A fase das rodadas do Delphi pode durar vários meses, e cada nova versão do questionário se demanda mais tempo dos participantes.

Além dos processos, o anonimato existente no método Delphi Grisham, 2009) e também no trabalho de Negociação-Colaboração nas Revisões Técnicas Formais (Linhares, 2009) é mais um fator que os distinguem do processo proposto, que não adota o anonimato, conforme detalharemos no Capítulo 4.

Nas próximas seções listaremos os outros trabalhos selecionados, e suas respectivas contribuições, agrupando cada trabalho a um tema principal em função de suas principais características: i) abordagem colaborativa, ii) tratamento de especificidades dos RNFs, e, iii) reuso do conhecimento existente em RNFs.

\subsection{Construção Colaborativa de Requisitos}

- Togneri et al., (Togneri et al., 2002) investigam como as soluções da área de Suporte por Computador ao Trabalho Cooperativo (SCTC) pode apoiar nas atividades de Engenharia de Requisitos. Apresentam CRETA, uma ferramenta de suporte cooperativo à Engenharia de Requisitos, visando integrar os aplicativos de groupware em aplicativos que suportam elicitação de requisitos.

- O sistema EasyWinWin (Briggs; Grunbacher, 2002) é uma metodologia de negociação de requisitos, tendo por base a aproximação de negociação WinWin (Herzwurm et al., 1999), sendo suportada por um GSS promovendo o envolvimento e a interação das partes interessadas mais importantes. A 
aproximação Win-Win baseia-se na Teoria-W (Boehm et al.,1989), em que o princípio fundamental é que seja condição necessária e suficiente, para que um projeto tenha sucesso, que todas as partes interessadas sejam vencedores.

- A ferramenta MEG construída por Ramires (Ramires, 2004; Antunes et al., 2006), é, simultaneamente, um sistema de suporte à negociação (NSS) e um sistema de suporte à decisão em grupo (GDSS), baseado no modelo de desenvolvimento de software SQFD e fomentando uma perspectiva de negociação e colaboração. Esta integração de modelos é utilizada para questões que envolvam Quality Function Deployment (QFD), que pode ser definida como uma matriz de correlação entre requisitos do usuário e especificação técnica. Na célula da matriz QFD é imputado pelo usuário um valor (0 - vazio, 1 - fraco, 3 - médio ou 9 - forte) que representa a opinião (preferência) deste acerca da correlação entre as duas variáveis: requisitos do usuário e especificação técnica. Os autores descrevem a integração dos modelos de argumentação, que possuem as variáveis - questão, posição e argumentos - com o modelo de negociação, que possui as variáveis posição inicial, preferência e valor final -, na implementação da MEG. Um estudo de caso foi realizado envolvendo negociação na validação de requisitos de software em uma organização.

- O artigo de Freitas et al.. (Freitas et al., 2007) aborda as atividades de construção de requisitos, e apresenta um processo estruturado e colaborativo de elicitação de requisitos e sua ferramenta de apoio RECOLAB. Reforça que a dinâmica da Negociação-Colaboração aplicada à construção de requisitos, desencadeia a cada ciclo de discussões do grupo, uma maior qualidade dos requisitos elaborados.

- Laporti et al. (Laporti et al., 2009) apresenta ATHENA, uma abordagem baseada em conhecimento coletivo para construir progressivamente os requisitos do sistema, desde uma narrativa de histórias do usuário até a definição de casos de uso. A solução consiste em um modelo de conhecimento baseado em histórias sobre o sistema, um método de construção coletiva e uma ferramenta para apoiar as interações. 
- Jureta et al. (Jureta et al., 2009) abordaram o tema relativo a construção de requisitos, mais especificamente a validação dos requisitos pelas partes interessadas. Os atores estudaram as discussões entre as partes interessadas e os engenheiros de requisitos. No trabalho é proposta ACE, uma linguagem para a representação de informações trocadas em discussões sobre a validação de um artefato contendo requisitos. Também são abordadas as condições de aceite do artefato, e proposto um procedimento de raciocínio para checagem automática de tais condições de aceitabilidade.

- Pinto et al. (Pinto et al., 2020), apresentam em seu artigo um sistema de informação para elicitação de requisitos, baseado em criatividade, que é capaz de gerenciar um grande número de participantes. A ferramenta IdEASY é um ambiente configurável que implementa um processo de elicitação usando uma técnica combinatória de criatividade.

\subsection{Apoio à Elicitação de RNFs}

- Serrano e Leite (Serrano e Leite, 2011) abordam o tema de RNFs e um framework de argumentação. A proposta do trabalho foi capturar padrões de RNFs, mais especificamente de Transparência, através de uma estruturação da dinâmica de argumentação ao longo de discussões entre engenheiros de requisitos e as partes interessadas no software.

- Ameller et al. (Ameller et al., 2012) apresentam em seu artigo algumas conclusões de um estudo empírico baseado em treze entrevistas com arquitetos de software. Aborda questões como: quem decide as RNFs, quais tipos de RNFs são importantes para os arquitetos, como são documentadas as RNFs, e como as RNFs são validadas.

- Kopczyńska e Nawrocki (Kopczyńska e Nawrocki, 2014), aborda a questão do equilíbrio entre o custo e o valor da elicitação de requisitos. No artigo, investigam o método de Elicitação Estruturada de Requisitos Não Funcionais (SENoR). O método é composto por uma seqüência de sessões curtas de brainstorming, conduzidas pelas características de qualidade da ISO25010. É feito um estudo utilizando sete projetos de desenvolvimento WEB, sobre o custo e a eficácia do método. 
- Carvallo et al. (Carvallo et al., 2015), apresenta em seu artigo uma abordagem baseada em reutilização, para obter modelos de qualidade de software compostos para orientação a quantificação de RNFs. A abordagem implementa a ideia de uso de métodos bem conhecidos, padrões e notações como ISO/IEC25010, e o i *.

- Em Silva et al. (Silva et al., 2016), é proposto um processo para a criação de um guia de elicitação que auxilie os engenheiros de requisitos na identificação dos RNFs. Ele se concentra em um mecanismo que facilita a obtenção e validação desses requisitos com especialistas em domínio e clientes.

- Myloupolos (Myloupolos, 2018) desenvolve uma estratégia de refinamento de requisitos, através de uma dinâmica cíclica de "ataques" aos requisitos, com sustentação por argumentação. As sucessivas críticas acarretam alterações nos requisitos desencadeando a cada ciclo, uma maior qualidade dos mesmos. Os tipos de ataques são: não atômico, ambíguo, intangível, injustificado, rejeitado, incompletos, conflitante, rejeitado. E os operadores são: reforçar, enfraquecer, reduzir, adicionar, rejeitar.

\subsection{Reutilização de Conhecimento em RNFs}

- Em Balushi et al. (Balushi et al., 2007), é apresentada a ferramenta ElicitO, uma ferramenta de elicitação de requisitos que visa apoiar os engenheiros de requisitos a partir de um repositório de conhecimento de RNFs. A ferramenta é usada para estruturar entrevistas de elicitação, e orientar quanto aos aspectos importantes da qualidade relacionados a alguns tipos de aplicações, baseados em características e métricas disponíveis.

- Em Araújo et al., (Araújo et al., 2014) é proposta e descrita a ferramenta NDR-Tool, baseada no uso do NFR-Framework, para apoio ao engenheiro de software no processo de elicitação e modelagem de requisitos. Essa ferramenta propõe o uso de ontologias e técnicas de Web Semântica para facilitar o armazenamento e a recuperação de conhecimentos. 
- Buitron et al. (Buitron et al., 2017) trabalha no seu artigo a questão das partes interessadas possuírem conhecimentos distintos, dependendo dos papéis dos envolvidos, da experiência profissional, das perspectivas e níveis de formação técnica. A estrutura MERliNN foi criada, fortalecendo a relação entre as disciplinas de Gestão de Conhecimento e Engenharia de Requisitos. A modelagem explicita o conhecimento tácito dos envolvidos, em cenários no processo de elicitação de RNFs.

- Veleda e Cysneiros (Veleda e Cysneiros 2019), apresentam o QRFramework, que usa uma abordagem baseada em ontologia para apoiar a coleta de conhecimento. Mecanismos de busca preliminares são fornecidos para facilitar a identificação RNFs e seus RNFs relacionados. Enfatizam que a reutilização do conhecimento de RNF pode levar os engenheiros de software a obter um conjunto mais próximo de soluções possíveis para resolver problemas de qualidade. 


\section{A Construção de RNFs}

Neste Capítulo apresentamos o processo de construção de RNFs. O processo colaborativo é permeado por negociações para a tomada de decisão da entrada, ou não, de um RNF em uma especificação. Também faz parte do processo, o uso de catálogos de RNFs e uma nova linguagem simplificada para representação dos impactos entre requisitos. Por último, apresentamos a implementação do processo proposto, o software RNF Colab.

\subsection{Modelo de Discussão de RNFs}

Desenvolvemos um processo para a construção de RNFs, baseada na dinâmica de Negociação-Colaboração, buscando trazer uma maior qualidade para os RNFs. Operacionalizamos a reutilização de Catálogos de RNFs, para facilitar o acesso ao conhecimento existente, com base na estrutura de RNF proposta por Chung et al. (Chung et al., 2000). Por fim, listamos os requisitos discutidos em grupo, mapeando suas interdependências, através de uma nova linguagem simples que facilitou a organização do debate.

O Modelo IBIS (Issue-based information system), representado na Figura 10, foi criado por Rittel e Kunz em 1970 (Touchstone, 2000). Por ser de simples entendimento e fácil aplicação, o reuso do modelo IBIS foi percebido como uma oportunidade de apoio ao processo colaborativo permeado por negociação de construção de RNFs. Adaptamos o modelo utilizado em trabalhos anteriores (Antunes et al., 2006; Linhares 2009) para melhor servir aos objetivos de organização da construção de RNFs. 


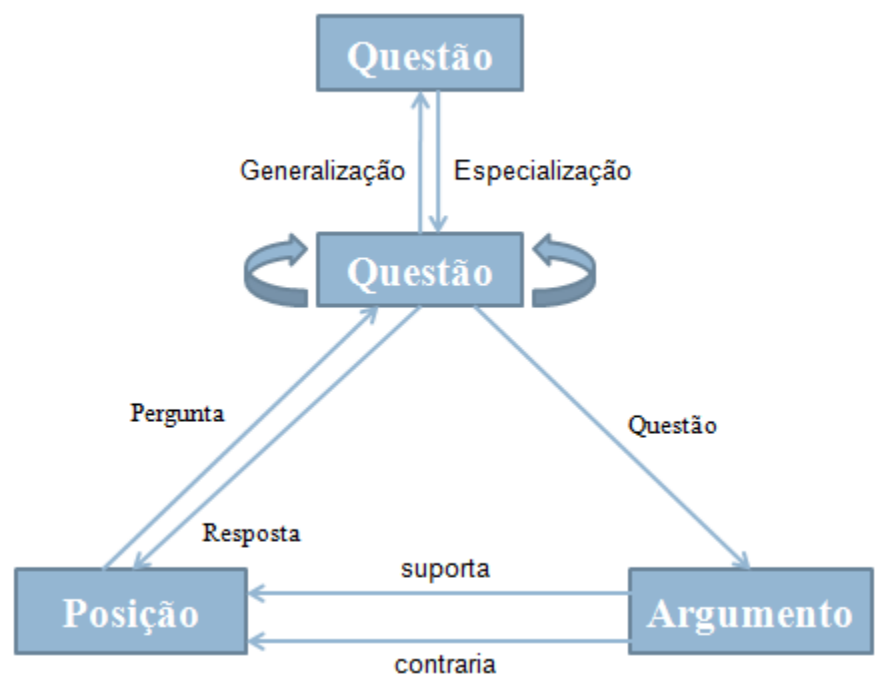

Figura 10. Modelo IBIS (Touchstone, 2000; Wikipedia, 2020).

O modelo IBIS propõe a categorização das mensagens em Questão (ou Tema), Posição e Argumentação. A mensagem do tipo Questão é utilizada para propor perguntas e tópicos para discussão; A Posição é utilizada para expressar uma opinião e responde a uma questão; e a Argumentação é utilizada para fornecer as razões onde se apoiam as posições. A ideia vislumbrada durante o estudo, foi de adaptar o modelo, com uma simples substituição, da "Questão" pelo "RNF"2. Temos portanto, a representação da abordagem proposta (uma reinterpretação do modelo IBIS) ilustrada na Figura 11.

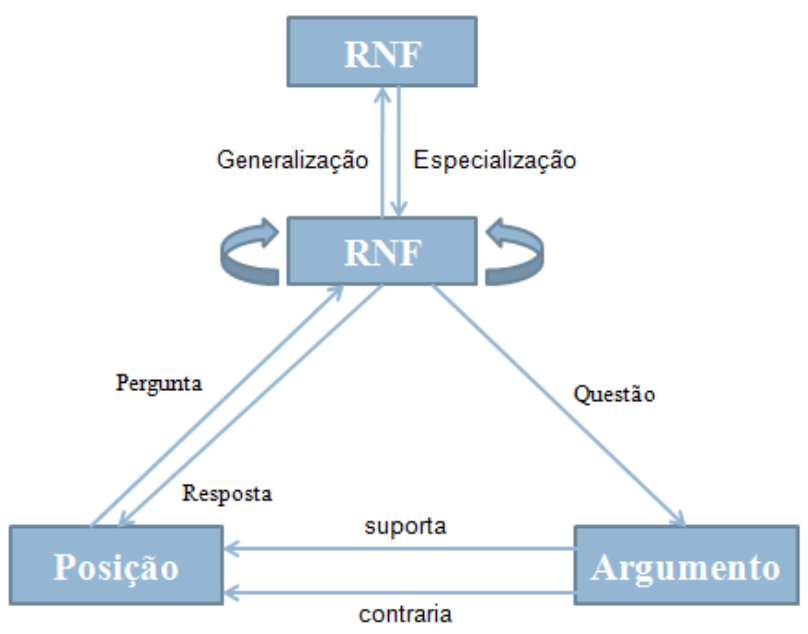

Figura 11. Modelo IBIS adaptado (Linhares e Leite, 2020).

\footnotetext{
2 O RNF é uma sentença no formato: "O Sistema deve" + verbo + objeto + "para" + complemento + ["quando" / "se"] + condição (Leite, 2007).
} 
Partindo da adaptação do modelo IBIS, e a unindo com mecanismos de Negociação-Colaboração (que serão apresentados mais adiante no texto), desenhamos um novo processo para apoiar a construção colaborativa de RNFs. Acreditamos que o processo proposto, detalhado nos parágrafos seguintes, responde às questões de pesquisa apresentadas na seção 1.3: como aumentar a atenção nos RNFs durante toda a construção do software, como aumentar sua qualidade e como fornecer suporte à construção com tais objetivos.

Em linhas gerais, a ideia é que um processo de debate em grupo, estruturado e iterativo, desencadeie uma maior qualidade dos RNFs, a cada rodada de discussões. Isso se justifica pelo fato de que, em grupo, os perfis de conhecimento podem ser complementados e uma mesma questão pode ser vista por seus vários "ângulos" (Leite, 1988). Por exemplo, durante as discussões, os membros de um grupo podem encontrar lacunas e procurar novas idéias, novas informações e novas referências para ajudar a criar RNFs de maior qualidade. O desejo pela construção colaborativa se justifica inclusive pela lei de Linus: "Dados olhos suficientes, todos os erros são óbvios" (Himanen et al, 2001).

O processo de construção RNFs é realizado por um grupo de pessoas que a) reutilizam RNFs existentes no catálogos de RNFs; b) definem RNFs partindo de uma lista inicial sugerida pelo Engenheiro de Requisitos; c) relacionam esses RNFs entre si mesmos e entre os RFs, discutindo os impactos positivos e negativos provocados uns pelos outros; e, d) negociam os RNFs que devem entrar na especificação e suas prioridades. Na seção 4.2 detalharemos cada ação envolvida no processo, assim como seus atores.

\subsection{Processo para Construção de RNFs}

O processo se inicia com o Moderador selecionando a equipe que trabalhará em grupo para a construção colaborativa de RNFs. Os Engenheiros de Requisitos convocados elaboram uma lista preliminar de RNFs com base nas fontes de informação (UdI), lista de RFs recebida e uso de Catálogos de RNFs existentes. O Engenheiro de Requisitos portanto, analisa a lista de RFs e observa os Catálogos Integrados de RNFs existentes. Essa observação dos Catálogos é análoga a uma verificação em um "checklist" para trazer à memória do responsável pela tarefa, a 
gama de qualidades desejadas para um software. Consultando os Catálogos de RNFs o Engenheiros de Requisitos pode evitar a negligencia de algum aspecto de qualidade que esteja mapeado nestas bases de conhecimento. Vale ressaltar que o Engenheiro de Requisitos também cria a lista preliminar de RNFs com base na sua experiência profissional, assim como no seu conhecimento do domínio do negócio e do contexto do projeto em questão.

Durante a dinâmica de Negociação-Colaboração disparada ao longo da construção de RNFs, cada participante (usuários, desenvolvedores, arquitetos, testadores), simultaneamente, informa a sua posição em relação ao requisito criado, isto é, informa seu julgamento acerca da inclusão, ou não, do mesmo na

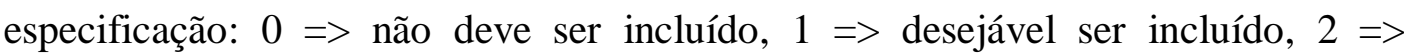
essencial ser incluído. O participante poderá informar também sua argumentação relativa a posição tomada. $\mathrm{O}$ participante tem a possibilidade de abster-se, mas mesmo assim deve se manifestar-se, escolhendo a posição "nulo" ao invés de 0,1 ou 2.

Os Engenheiros de Requisitos também apontarão os respectivos impactos entre os requisitos no momento de sua criação. Tanto entre RNFs e RFs quanto entre RNFs em si. Ou seja, a criação de requisitos inclui a atribuição de impactos entre o novo RNF e os requisitos existentes. Por exemplo, os requisitos de segurança afetam os requisitos de usabilidade. Também existe a possibilidade de fornecer argumentos para os impactos detectados; portanto, além de se posicionar sobre os RNFs, os participantes também discutirão os impactos entre requisitos (incluindo impactos em RFs). Consideramos que esclarecer os tipos de impactos entre requisitos, principalmente os conflitantes, ajudam a priorizar os RNFs. Classificamos os impactos em três tipos: Fortalece (impacto positivo), Enfraquece (impacto negativo) e Afeta (existe impacto, mas não se sabe se é positivo ou negativo). Essa classificação foi baseada na estrutura do modelo V-Graph (Yu et al., 2004). Nós detalharemos esse ponto mais adiante na seção 4.4. Importante ficar claro que os RFs que foram recebidos no inicio do processo de construção dos RNFs são incluídos no debate para que as correlações entre estes e os RNFs criados sejam analisadas, mais tais requisitos em si não são o foco do processo de construção. 
Com base na estrutura IBIS, sob cada RNF são gerados posicionamentos e argumentações. Essa dinâmica é feita até a compreensão integral dos requisitos pelos participantes, com o objetivo de chegar a um consenso da posição a ser adotada pelo grupo em relação ao RNF debatido. Isso significa que um RNF (e seus impactos) serão refinados - especialização e generalização no modelo IBIS, quantas vezes forem necessárias, para que seu conteúdo e nível de detalhe sejam compreensíveis e aceitáveis para todos os participantes (do usuário ao desenvolvedor). O requisito pode passar por vários graus de abstração ao longo de sua construção. Quando o consenso é alcançado, o refinamento chega ao fim e temos o RNF construído.

O cálculo das posições (quantos veredictos foram 0 e quantos foram 1 e 2) é realizado e divulgado, requisito a requisito. Caso não exista divergência para um dado requisito, este passa para o estado "construído" e deve ser incluído na lista de RNFs construídos. Nem sempre o consenso será obtido em todos os requisitos. Todos os requisitos são votados, mas, se não há consenso, e também não existe uma posição que tenha recebido a maioria de votos, isso é, ocorre empate na votação, um participante escolhido para o papel de "Moderador" poderá finalizar a construção com requisitos ainda no estado "em negociação" e dar resultado da lista de RNFs que entrarão na especificação, com apenas os que forem vontade da maioria ou obtiveram consenso. Também há a opção de convocar uma nova dinâmica, dando continuidade à discussão dos requisitos "em negociação".

Espera-se a convergência em direção ao consenso com a exposição dos argumentos, ao longo das discussões. O voto da maioria configura a primeira alternativa quando não ocorre o consenso em uma única posição. Porém outros mecanismos poderão ser utilizados para forma de decisão sobre um requisito. Variáveis como o tempo, escopo do projeto frente capacidade da equipe, custo, recursos tecnológicos e a decisão conforme desejo do cliente, podem ser fundamentais em determinados casos, e nestes, o Moderador assume a decisão e justifica sua escolha com base em uma ou mais variáveis. ${ }^{3}$ A forma de decisão

\footnotetext{
${ }^{3}$ Ao longo da avaliação da pesquisa, descrita no Capítulo 7, foi sugerida a confecção de um guia para o moderador, com a descrição das ações precisas a serem tomadas de acordo com cada cenário e variável. O guia do Mediador, faz parte da lista de trabalhos futuros. Um Guia base, pois tais atuações do Moderador podem variar de acordo com cada organização.
} 
acerca dos RNFs visa ser obtida através do consenso, mas também pode ser alcançada pela decisão da maioria, ou através da decisão do Moderador.

Portanto, temos que, depois de avaliar os argumentos associados a um requisito, um participante pode, ou não, mudar de posição sobre ele. Este procedimento pode ser realizado repetidamente pelos participantes, em vários requisitos, até que um valor seja atingido em consenso. Neste sentido, o moderador deverá controlar o tempo das discussões para que as mesmas não se alonguem mais do que o necessário. Seguindo o princípio de transparência do processo de Negociação-Colaboração, as mudanças de posição ao longo da dinâmica devem ser explicitadas. $\mathrm{O}$ rastro entre o histórico do debate e cada RNFs debatido é registrado. Isto é de suma importância para entendimento futuro dos motivos de construção ou descarte de um RNF. Também é relevante para a aquisição de conhecimento de novos membros da equipe. A rastreabilidade e estruturação do histórico das discussões relativas a cada RNF é uma das contribuições da presente pesquisa.

A relevância do tema para o grupo, e, o perfil do grupo, são variáveis que também podem influenciar qualidade da Negociação-Colaboração. Pode ocorrer, se o assunto abordado for relevante apenas para parte do grupo, que não haja a participação global. É também de responsabilidade do Moderador analisar a relevância dos assuntos para com os membros do grupo, certificando-se de que é o grupo adequado. Em contrapartida, o grupo de trabalho deve possuir o perfil "alinhado" ao tema. Um grupo, cujo perfil seja bastante heterogêneo, pode desencadear maior tempo de discussão, porém o debate pode vir a ser enriquecido, aumentando assim a qualidade de seus resultados. O Moderador deve criar grupos com participantes específicos de acordo com suas especialidades, e pode reduzir ou aumentar o número de participantes de um grupo. Não é rara a detecção da necessidade de conhecimentos específicos ao longo das discussões e análises, ou no sentido contrário, do envolvimento desnecessário de alguns especialistas. Esses ajustes são benéficos para alcançar a qualidade e agilidade da dinâmica. A Figura 12 resume os atores e ações na construção de RNFs. 


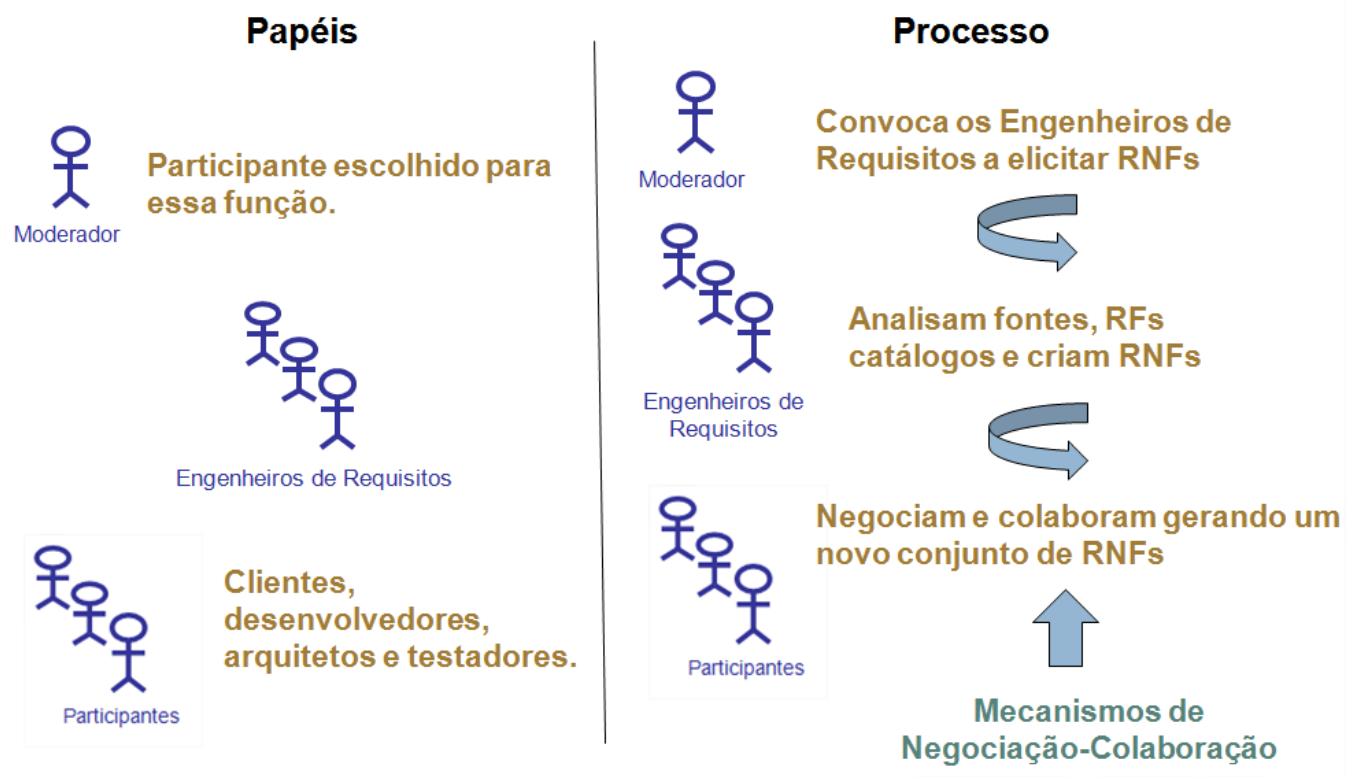

Figura 12. Atores e suas Ações (Linhares de Leite, 2019).

Nota-se que tanto o papel do Moderador, quanto o do Engenheiro de Requisitos não possuem ação de posicionamento perante os RNFs. O Engenheiro cria os RNFs e justifica a criação dos mesmos, assim como dos impactos entre eles durante os respectivos cadastros. Já o Moderador só toma decisões acerca dos RNFs caso os mesmos não tenham sido objeto de consenso.

A construção de um RNF pode ter estados diferentes: "criado", "em negociação", "cancelado", "construído", "descartado" - conforme ilustrado na figura 13. É importante reforçar que a criação de requisitos é simultânea e incremental, novos requisitos podem ser criados a qualquer momento, por exemplo, enquanto outros requisitos estão sendo negociados. Como mencionado anteriormente, várias versões do mesmo requisito podem ser geradas ao longo das discussões, até que os participantes cheguem a um consenso. 


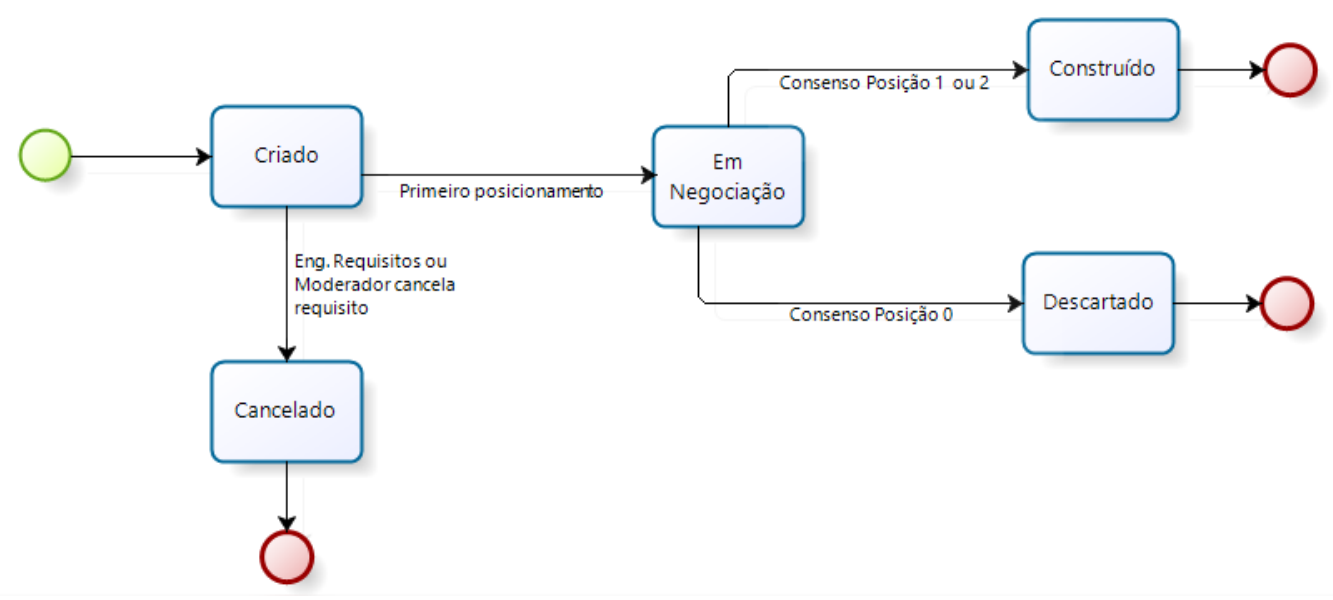

Figura 13. Os estados do RNF (Linhares e Leite, 2019).

Horkoff et al. (Horkoff et al., 2014) tratam da análise interativa de modelos de metas para a engenharia de requisitos. O trabalho proposto demonstra que, interativamente, as discussões estruturadas do grupo de trabalho visando maior refinamento dos requisitos, desencadeiam por consequência, maior qualidade dos resultados produzidos. Myloupolos (Myloupolos, 2018) desenvolve uma estratégia de refinamento de requisitos, através de uma dinâmica cíclica de "ataques" aos requisitos. As sucessivas críticas acarretam alterações sugeridas pelos "operadores" nos requisitos desencadeando a cada ciclo, uma maior qualidade dos mesmos ${ }^{4}$.

Após uma série de aprimoramentos do requisito, espera-se um melhor entendimento entre os participantes, em particular os desenvolvedores, que farão uso dos RNFs para suas respectivas implementações. A dinâmica colaborativa estruturada, após vários ciclos de discussões, entendimentos e aprimoramentos, deve resultar em RNFs de maior qualidade.

\footnotetext{
${ }^{4}$ Os tipos de ataques são: não atômico, ambíguo, intangível, injustificado, rejeitado, incompletos, conflitante, rejeitado. Os tipos de operadores são: reforçar, enfraquecer, reduzir, adicionar, rejeitar.
} 


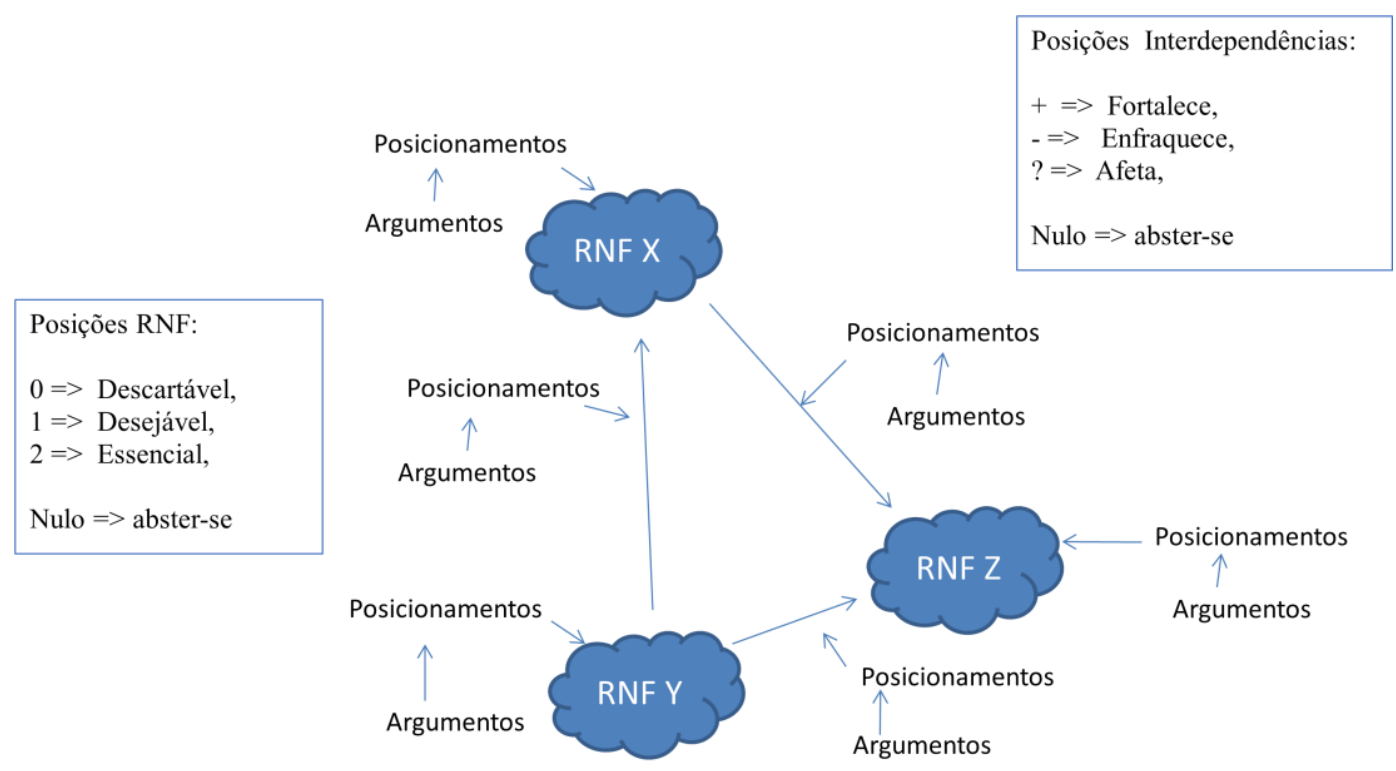

Figura 14. Dinâmica de Negociação-Colaboração (Linhares e Leite, 2019).

A Figura 14 ilustra a dinâmica proposta, onde temos três RNFs (X, Y e Z), e suas respectivas interdependências. Entre o RNFY e o RNFX, e entre o RNFY e o RNFZ, podemos obter consenso dos posicionamentos para impactos positivos ("Fortalece"). Entre o RNFX e o RNFZ podemos obter consenso de que impacto é negativo ("Enfraquece").

Vale lembrar que o conflito não prejudica a colaboração se não for destrutivo. Por exemplo, o exercício do "advogado do diabo" pode aumentar a qualidade de uma decisão, pois traz ao debate questões que talvez não tenham sido levantadas antes e enriquece a discussão. O "bom conflito" possibilita o surgimento de ideias (Camacho, 2005). Para avaliar o comportamento dos participantes é necessário manter o controle das mudanças de posição em relação a um determinado RNF, que sinaliza o caminho deste membro do grupo em direção ao consenso, ou ao desacordo.

Adaptamos de Antunes e Linhares (Antunes et al.2006, Linhares, 2009) um mecanismo de pontuação dos participantes ${ }^{5}$, de acordo com seu comportamento, como uma maneira de incentivar posturas de conciliação e de suprimir comportamentos desagregadores. Modificamos a maneira de calcular um parâmetro

\footnotetext{
${ }^{5}$ Em Antunes et al (Antunes et al, 2006) construiu-se um jogo de benefícios e resistências para influenciar as atitudes dos participantes. No trabalho estabelecem benefícios para ações "ganhaganha" e restrições para ações "ganha-perde" ou "perde-perde".
} 
e criamos um novo. Além disso, aperfeiçoamos o mecanismo incluindo o "Aviso de Pontuação Baixa", enviado ao participante durante a construção, isso é, em tempo de execução. O aviso de "pontuação baixa" é enviado alertando o participante para que o mesmo reflita sobre sua participação e tenha chances de melhorá-la, ainda em tempo do projeto. O mecanismo original, pontuava o participante apenas no final de cada reunião de revisões técnicas formais, e não sinalizava em tempo de influenciar mais efetivamente o comportamento do participante. Não obstante, saber que sua participação está sendo medida já é um fator de influência. O comprometimento individual, que pode interferir na participação efetiva dos envolvidos e com isso afetar a negociação (pode ser "enriquecida" ou não pelos participantes), também é tratado por esse mecanismo de pontuação.

A pontuação leva em conta: posicionamento (nível de participação); abstenção (quantidade de posicionamentos igual a nulo) - parâmetro incluído; pontualidade (tempo de início da participação) - parâmetro alterado; nível de contribuição dos argumentos ("relevante", "informativo" ou "inconsistente"); número de argumentos incluídos; atitude de "block" ou "firm" (se, em qualquer RNF, todos assumem uma posição e o participante vota em outra posição, impedindo o consenso, é uma atitude "firm"; se nessa mesma situação, o participante se abstém, é uma atitude "block") e mudança de posição para convergir com a maioria. Essas informações devem apoiar o moderador no ajuste do grupo para que as discussões sejam o máximo possível proveitosas na direção de RNFs de maior qualidade.

Também concebemos a ideia de disponibilizar um espaço como um "mural" ou um "quadro de avisos" ou até mesmo um "quadro de rascunho" para ideias, dúvidas e esclarecimentos. $\mathrm{O}$ espaço deve facilitar a interação entre os participantes, onde novos RNFs possam ser sugeridos, dúvidas compartilhadas; e no qual os Engenheiros de Requisitos possam esclarecer questionamentos, e coletar novas ideias de requisitos, refinamentos e correlações. Onde ocorra uma troca de informações e uma comunicação livre, porém estruturada e passível de registro histórico para consultas futuras.

O "mural" é um mecanismo de incentivo a colaboração. Fomentando e facilitando a participação dos membros da equipe na discussão dos requisitos. 
Também a partir desse espaço, a participação poderá ser medida. Como por exemplo, o número de sugestão de novos requisitos para debate. Poderá ser observada a inclusão, ou não, de sugestões, dúvidas, comentários, por parte dos participantes. Não obstante, é um recurso de percepção. Constam ali as "ultimas noticias", compartilhadas e publicadas; os assuntos gerais do projeto que estão sendo explicitados naquele momento pelos participantes. Mantendo-se o histórico de maneira organizada. O "mural" ainda servirá como fonte de informação para atuação do Moderador na mediação de conflitos para a condução do processo em direção ao consenso, e na busca de razões dos impasses.

Resumimos o processo proposto nas atividades ilustradas na figura 15 . Sucintamente, um processo abarca a tarefa, o ator que desempenha a tarefa, as entradas, que são insumos (ações, informações ou documentos) para que se execute a tarefa; e as saídas, produtos ou informações resultantes da execução da tarefa. Lembrando que após iniciada uma construção de RNFs de um projeto, todas as tarefas podem ser executadas simultaneamente pelo grupo, e de maneira incremental. A implementação de elementos de percepção, descrita na seção 4.6 deste Capítulo, é fundamental para o sucesso das atividades colaborativas.

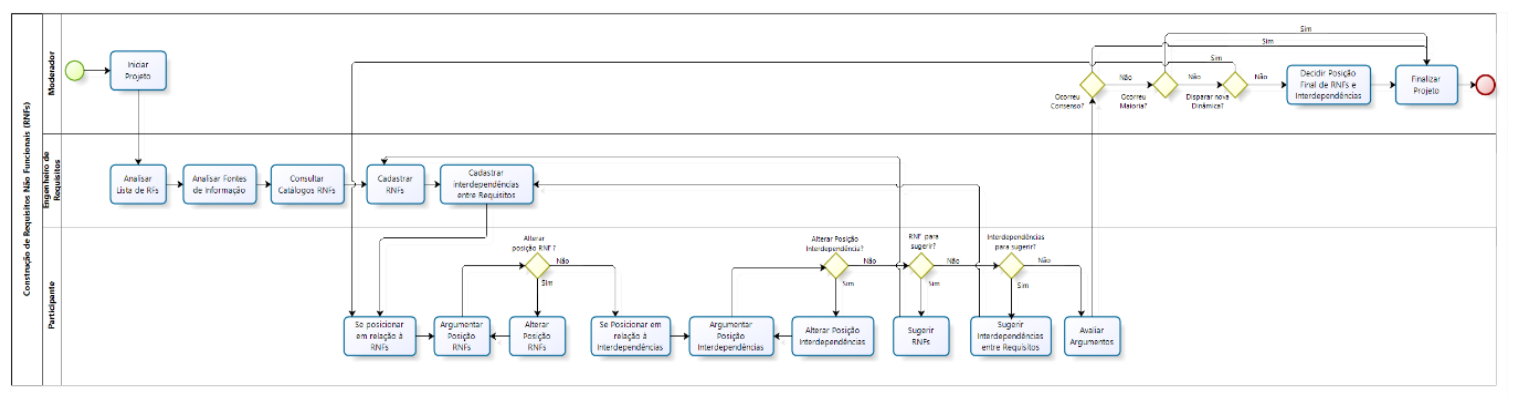

Figura 15. Macro Processo de Construção de RNFs. ${ }^{6}$

1. Moderador inicia o projeto. Tarefa: Iniciar projeto. Ator: Moderador. Entrada: dados nova construção de RNF (título projeto, descrição do projeto, data início e data fim, participantes e papeis associados a cada participante). Saída: Projeto criado e equipe convocada ao trabalho.

\footnotetext{
6 Para facilitação do entendimento, foi representado no diagrama o fluxo do processo sem cancelamento da construção. Não obstante, o recurso de cancelamento da construção foi implementado no software que apóia o processo.
} 
2. Engenheiro de Requisitos analisa RFs: Tarefa: Analisar RFs. Ator: Engenheiro de Requisitos. Entrada: lista de RFs. Saída: lista de RFs analisada.

3. Engenheiro de Requisitos Analisa UdI: Tarefa: Analisar Fontes de Informação (UdI). Ator: Engenheiro de Requisitos. Entrada: Fontes de Informação (UdI), lista de RFs analisada. Saída: Fontes de Informação analisadas.

4. Engenheiro de Requisitos Consulta Catálogos de RNFs: Tarefa: Consultar Catálogos de RNFs. Ator: Engenheiro de Requisitos. Entrada: Catálogos de RNFs, lista de RFs analisada, Fontes de Informação analisadas. Saída: Catálogos de RNFs analisados e lista inicial de RNFs.

5. Engenheiro de Requisitos cadastra RNFs: Tarefa: Cadastrar RNFs. Ator: Engenheiro de Requisitos. Entrada: RNFs. Saída: RNFs cadastrados.

6. Engenheiro de Requisitos cadastra interdependências entre RNFs: Tarefa: Cadastrar interdependências entre RNFs. Ator: Engenheiro de Requisitos. Entrada: interdependências entre RNFs / RFs. Saída: interdependências entre RNFs criadas, incluindo também entre RNFs e RFs.

7. Participante se posiciona acerca dos RNFs (descartável, desejável, essencial): Tarefa: Posicionar RNFs. Ator: Participante. Entrada: RNFs. Saída: RNFs posicionados.

8. Participante se posiciona acerca das Interdependências entre RNFs ou RNFs e RFs (fortalece, enfraquece, afeta): Tarefa: Posicionar interdependências. Ator: Participante. Entrada: Interdependências entre RNFs. Saída: Interdependências posicionados.

9. Participante argumenta posição RNFs: Tarefa: Argumentar posições. Ator: Participante. Entrada: RNFs. Saída: argumentos associados aos posicionamentos de RNFs explicitados. 
10. Participante argumenta posição Interdependências: Tarefa: Argumentar Interdependências. Ator: Participante. Entrada: Interdependências. Saída: argumentos associados às Interdependências explicitados.

11. Participante altera posição RNFs: Tarefa: Alterar posições RNFs. Ator: Participante. Entrada: RNFs posicionados. Saída: RNFs com posicionamentos alterados.

12. Participante altera posição Interdependências: Tarefa: Alterar posições Interdependências. Ator: Participante. Entrada: Interdependências posicionadas. Saída: Interdependências com posicionamentos alterados.

13. Participante avalia argumentos (relevante, informativo ou inconsistente): Tarefa: Avaliar argumentos. Ator: Participante. Entrada: RNFs e interdependências posicionados. Saída: Argumentos associados aos posicionamentos avaliados.

14. Participante sugere RNFs: Tarefa: Sugerir RNFs. Ator: Participante. Entrada: Lista atual de RNFs e seus argumentos. Saída: RNFs sugeridos.

15. Participante sugere Interdependências: Tarefa: Sugerir Interdependências. Ator: Participante. Entrada: Lista atual de RNFs e seus argumentos. Saída: Interdependências sugeridas.

16. Moderador Decide Posição Final de RNFs e Interdependências: Tarefa: Decidir Posição Final. Ator: Moderador. Entrada: RNFs e Interdependências que não obtiveram consenso e nem voto da maioria. Saída: Posição Final Decidida pelo Moderador para RNFs e Interdependências que não obtiveram consenso e nem voto da maioria.

17. Moderador finaliza Projeto: Tarefa: Finalizar Projeto. Ator: Moderador. Entrada: projeto. Saída: Lista de RNFs e Interdependências construídos.

Temos sete pontos de controle (decisão) no macro processo:

- "Alterar posição RNF?": Esse controle ocorre logo após a argumentação relacionada aos RNFs. Se o participante decidir alterar posicionamento, 
ele o faz, e segue para a tarefa de argumentação. Caso contrário, segue o fluxo para se posicionar com relação as interdependências.

- "Alterar Posição Interdependência?": Esse controle ocorre logo após a argumentação relacionada as Interdependências. Se o participante decidir alterar posicionamento relativo as interdependências, ele o faz, e segue para a tarefa de argumentação. Caso contrário, o fluxo segue para o controle de sugestão de novos RNFs.

- "RNF para sugerir?": Esse controle ocorre logo após o controle de "Alterar Posição Interdependência?". Se o participante decidir sugerir novo RNF, ele o faz, e o fluxo segue para a tarefa de "Cadastrar RNFs", na raia do Engenheiro de Requisito. Caso contrário, o fluxo segue para o controle de sugestão de novas Interdependências.

- "Interdependências para sugerir?": Esse controle ocorre logo após o controle de " RNF para sugerir?". Se o participante decidir sugerir nova Interdependência, ele o faz, e o fluxo segue para a tarefa de "Cadastrar Interdependências entre Requisitos", na raia do Engenheiro de Requisito. Caso contrário, o fluxo segue para a tarefa "Avaliar Argumentos".

- "Ocorreu Consenso?": Esse controle ocorre logo após a avaliação dos argumentos pelos participantes. Se ocorreu consenso em todos os itens debatidos, o Moderador finaliza o projeto na tarefa "Finalizar Projeto". Caso contrário, o fluxo segue para o controle "Ocorreu Maioria?".

• "Ocorreu Maioria?": ?": Esse controle ocorre logo após o controle "Ocorreu Consenso?". Se ocorreu decisão pela maioria em todos os itens debatidos onde não se chegou a um consenso, o Moderador finaliza o projeto na tarefa "Finalizar Projeto". Caso contrário, o fluxo segue para o controle "Disparar nova dinâmica?".

• "Disparar nova dinâmica?": Esse controle ocorre logo após o controle "Ocorreu Maioria?". Se o Moderador decidir, para os itens onde não ocorreu consenso e nem maioria, ele toma a decisão em relação aos itens 
que permaneceram em negociação, na tarefa "Decidir Posição Final de RNFs e Interdependências", e finaliza o projeto na tarefa "Finalizar Projeto". Caso contrário, o fluxo segue para a tarefa "Se posicionar em relação à RNFs". Neste caso, ocorre uma continuação de um projeto já existente, onde serão debatidos os RNFs e Interdependências que permaneceram "em negociação". Todas as informações já registradas nas dinâmicas anteriores, vão compor a nova dinâmica de construção.

Por fim, informamos que o processo não adota o anonimato. Segundo Kayo e Securato (Kayo e Securato, 1997), o anonimato permite ultrapassar barreiras na comunicação como, por exemplo, capacidade de persuasão e domínio psicológico de alguns membros do grupo sobre outros, ou relutância natural em exprimir opiniões impopulares, minoritárias ou contrarias. O anonimato também assegura a redução dos efeitos de vieses pessoais (Grisham, 2009). Em contra partida, é importante que os perfis - principalmente os dos clientes, que colaboram entre si, sejam conhecidos, para que haja transparência de todo o contexto do debate, em todas suas dimensões. Inclusive o conhecimento da área de atuação e especialidade de cada membro do grupo, visando fundamentar, até mesmo esclarecer e justificar, o ponto de vista de cada indivíduo. Além disso o anonimato pode levar os participantes a conformarem-se, optando simplesmente por seguir a resposta do grupo. Por isso, não adotamos o anonimato em nosso processo. Optamos pela plena transparência em detrimento de algumas vantagens que o anonimato oferece. Os efeitos colaterais negativos ocorridos pela não adoção do anonimato, podem ser atenuados com os outros mecanismos existentes, de estimulo a igualdade e a imparcialidade.

\subsection{Integração de Catálogos de RNFs}

O processo proposto abrange a integração de SIGs ("Softgoal Interdependence Graph" - SIG (Chung et al., 2000)), que são representação para catálogos de RNF. Criamos uma estrutura para integrar os vários catálogos existentes, em uma base de conhecimento para reuso. É portanto, oferecido aos Engenheiros de Requisitos, e também o grupo de participantes, a capacidade de reutilizar esses catálogos. Consultando os Catálogos de RNFs os Engenheiros de Requisitos e também o grupo de participantes, podem evitar a negligencia de algum aspecto de qualidade 
que esteja mapeado nestas bases de conhecimento. Portanto o trabalho foi feito com o objetivo de minimizar o problema de negligência dos RNFs.

Inicialmente foram integrados os catálogos de Consciência de Software, Transparência, Confiança (Cunha, 2014; Cappelli, 2009; Leal et al., 2009). Essa escolha foi feita com base na palestra de Leite (Leite, 2019) no WER2019, que considera o conjunto, básico para a qualidade do software.

Tabulamos os três catálogos citados acima listando para cada meta flexível de cada catálogos, suas respectivas metas flexíveis ascendentes e descendentes. Assim sendo, o conteúdo dos catálogos foi organizado do nível de maior abstração (ascendentes) para o de menor abstração (descendentes). No momento em que identificava-se qualidades que pertenciam a mais de um catálogo, isso é, em duplicação, os itens eram marcados como interseções entre os Catálogos, e tornavam-se ligações entre os mesmos. As informações tabuladas alimentaram a base de dados do software de apoio ao processo que será descrito na seção 4.6 deste Capítulo. Observemos, por exemplo, a Meta Flexível "Informativo". Tal qualidade é encontrada tanto no Catálogo de Transparência quanto no Catálogo de Confiança conforme mostra a figura 16.
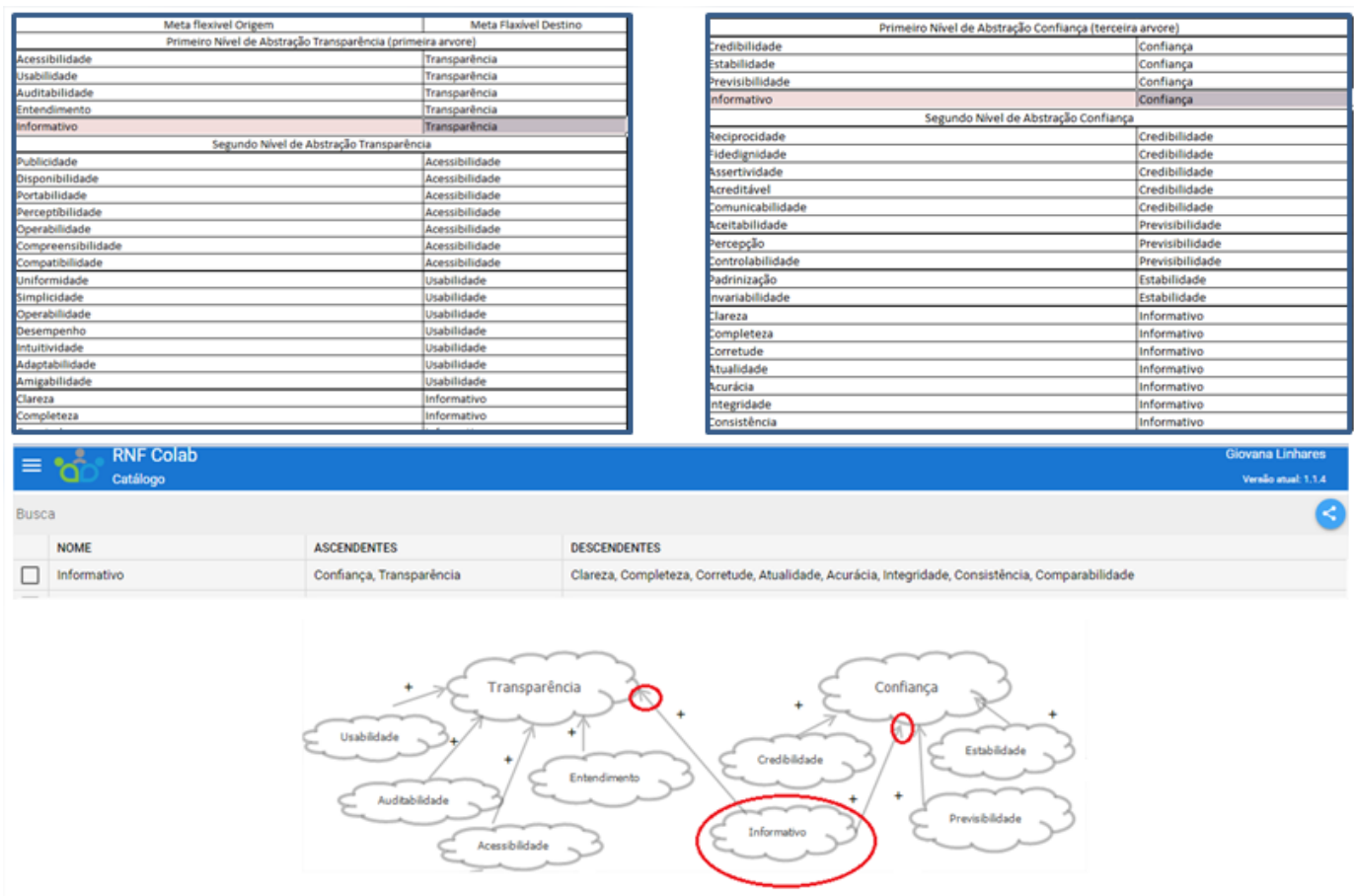

Figura 16. Exemplo Integração Transparência e Confiança: Informativo. 
A qualidade Informativo tornou-se uma ligação entre os dois catálogos, integrando-os, assim como qualquer qualidade que se apresente em mais de um Catálogo. Ao final do trabalho de integração, temos os catálogos interligados, com metas flexíveis não duplicadas, disponível para o armazenamento em um repositório de dados. Por exemplo, um RNF relativo a disponibilização de informações possui uma correlação com a Meta Flexível "Informativo" que por sua vez, está correlacionada ao atendimento das qualidades de Transparência e Confiança.

Abordar as interdependências entre RNFs e integrar os catálogos de RNF existentes para consulta e reutilização, constituem um tratamento específico para os RNFs e é uma das contribuições para diminuição da negligencia dos mesmos. A intenção é que esta base de conhecimento aumente ao longo do tempo e uso do processo, não apenas com conhecimento já existente mas também com desenvolvimento de novas versões de catálogos. Tornando-se instrumento para além de minimizar a negligencia, apoiar a construção dos RNFs, guiando e facilitando o trabalho dos Engenheiros de Requisitos.

\subsection{Representação dos Impactos entre Requisitos}

Para diagramação dos RNFs e suas interdependências simplificamos o modelo V$\mathrm{Graph}^{7}$ proposto originalmente por $\mathrm{Yu}$ et.al (Yu et al., 2004) e adaptado posteriormente por Silva (Silva, 2006); e criamos uma nova linguagem de representação.

A figura 17 a ilustra a representação original do V-Graph: possui três elementos, cujo vértice inferior é a tarefa que operacionaliza as metas e objetivos programáticos (RNF). A figura $17 \mathrm{~b}$ ilustra a adaptação, explicitando todos os relacionamentos possíveis entre os elementos do modelo, como uma maneira de lidar com o entrelaçamento de requisitos funcionais e não funcionais.

\footnotetext{
${ }^{7}$ V-graph é um modelo de metas, proposto como uma simplificação do Modelo RNF (Chung, 2000).
} 


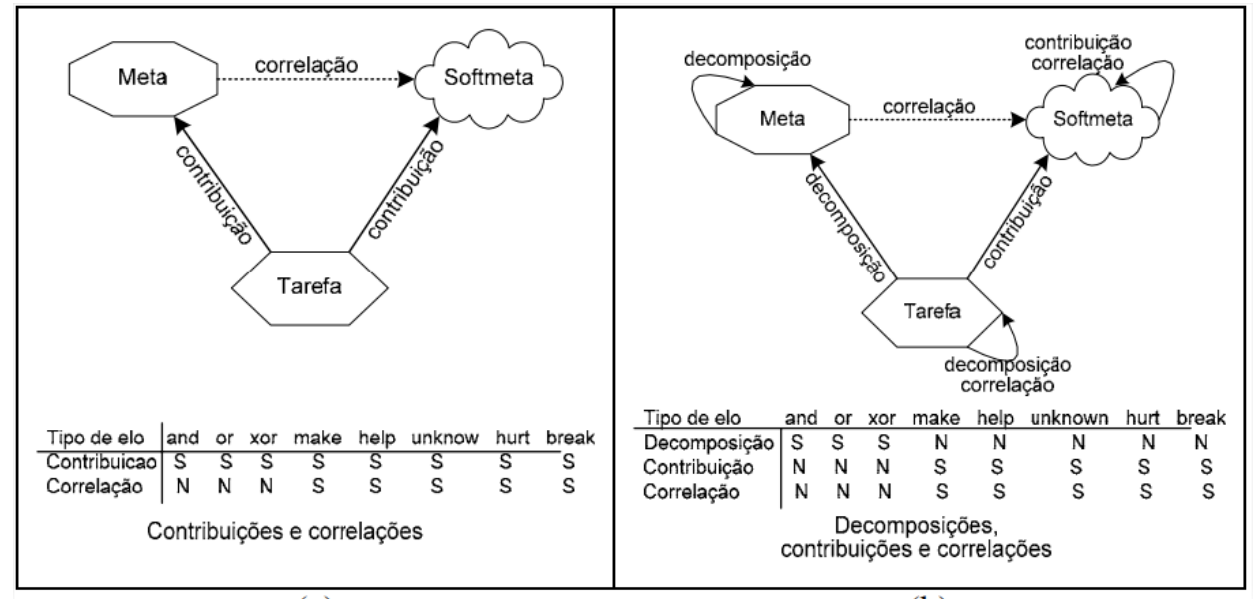

(a)

(b)

Figura 17 a, b. V-GRAF Original (a) e Adaptado (b) (Silva, 2006).

Nós partimos da análise destes dois modelos e criamos um terceiro, que simplifica ambos. Em relação a adaptação de Silva (Silva, 2006), tratamos a "decomposição" como um "refinamento", e mesclamos a "correlação" e "contribuição". Isso porque toda decomposição de um requisito, é na verdade um refinamento do mesmo. Já as "contribuições" e "correlações" foram unificadas como "correlações", pois são em última instância, correlações entre dois requisitos; independentemente de serem entre requisitos da mesma hierarquia de requisitos ou de hierarquias separadas. Em relação ao modelo original proposto por $\mathrm{Yu}$ et al. ( $\mathrm{Yu}$ et al., 2004), comparativamente mais simples que o adaptado, tratamos as contribuições como refinamentos de requisitos.

Em relação a ambos modelos, original e adaptado, apenas as metas flexíveis e as operacionalizações das mesmas são representadas, já que nosso foco é em RNFs. Porém, no processo e referido suporte computacional devem ser incluídos também os RFs para que as correlações entre os RFs e RNFs sejam da mesma forma debatidas. Os tipos de elos também foram simplificados em: Fortalece, Enfraquece, Afeta, E e OU exclusivo ${ }^{8}$.

O "Não afeta" não é representado no gráfico pois, se não há impacto, não há relação (seta) ${ }^{9}$. Resumido: as interdependências entre os RNFs são tratadas como Refinamentos (E , Ou), ou como Correlações (Fortalece, Enfraquece, Afeta).

${ }^{8} \mathrm{O}$ OU inclusivo não influencia na busca otimizada de alternativas, já que apenas o caminho mais próximo do ótimo será o caminho escolhido.

9 Entretanto, foi detectado ao longo da avaliação do processo descrita no Capítulo 7, que é importante a alternativa "não afeta" implementada no apoio computacional, para posicionamento 


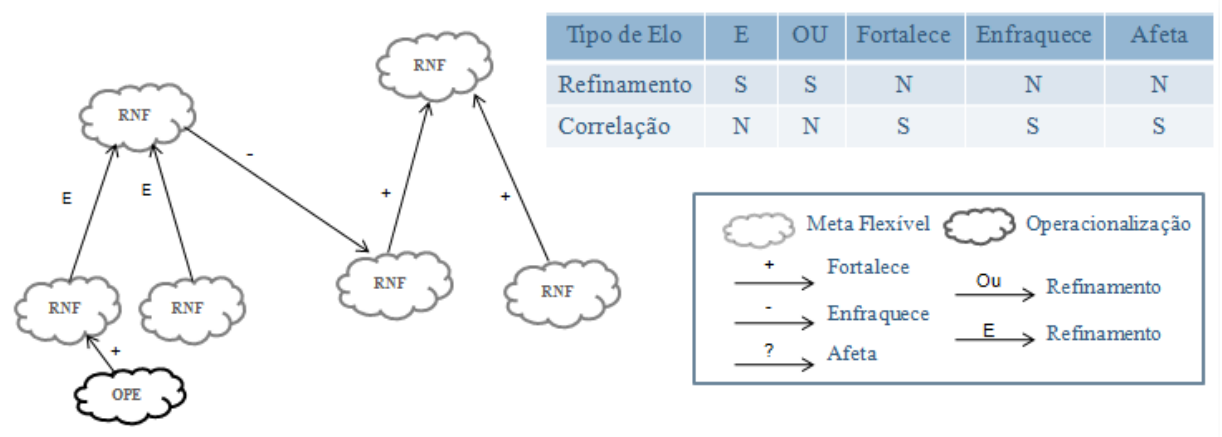

Figura 18. Simplificação do V-GRAF (Linhares e Leite, 2020).

A Figura 18 explica a simplificação do V-Graph: Meta Flexível (representação do RNF), Operacionalizações (alternativas de solução técnica para "satisfação a contento" do RNF), Correlações (Fortalece, Enfraquece, Afeta) e Refinamentos (E e OU).

Importante salientar que devem ser cadastrados também os RFs presentes como entrada do processo, no suporte computacional, para que as correlações entre os RFs e RNFs sejam da mesma forma debatidas e mapeadas.

\subsection{O Exemplo "Atualização Cadastral"}

Utilizaremos um exemplo fictício, chamado "Atualização Cadastral", para ilustração do passo a passo do processo, auxiliando no entendimento do mesmo. Vamos imaginar que estamos tratando de um projeto em telefonia celular. No exemplo, uma equipe discutirá os RNFs necessários para atendimento de um projeto que pretende implantar a atualização de informações cadastrais por meio de captura de imagem.

O primeiro passo é moderador formar a equipe de trabalho para a construção de RNFs. O moderador elege o Engenheiro de Requisitos (poderá ser mais de um Engenheiro) assim como o restante da equipe de acordo com o escopo de projeto, contexto de negócio e especialidades dos profissionais. O Moderador seleciona 4 pessoas além do Engenheiro de Requisitos. Os profissionais escolhidos são dois especialistas de desenvolvimento da plataforma pré-pago, um analista de testes, e um arquiteto. Os dois clientes solicitantes do projeto também irão 
participar da dinâmica colaborativa de construção de RNFs. Integrando portanto, um grupo de trabalho de 8 pessoas para a construção. Um projeto poderá ter mais de uma dinâmica de Negociação-Colaboração para se atingir o consenso de todos os RNFs construídos. O Moderador controla a necessidade de convocação de uma ou mais dinâmicas de discussão ao longo do projeto.

Após a convocação do Moderador, o Engenheiro de Requisitos inicia a criação da lista preliminar de RNFs. Porém, para isto, necessita receber a lista inicial de RFs elicitada, anteriormente, junto as Fontes de Informações (UdI) e clientes solicitantes. Os RFs apontados foram: a) o software deve possibilitar a atualização cadastral através de captura de imagem; b) o software deve validar a imagem; c) o software deve criar mecanismo de bloqueio do cliente por pendência de validação de imagem.

O Engenheiro de Requisitos cria 4 RNFs. No Catálogo de Confiança (Leal et al., 2009), o Engenheiro de Requisitos seleciona a qualidade "Integridade", na hierarquia da qualidade "Informativo" e cria o RNF: o software deve garantir $a$ integridade no armazenamento das imagens. Já que a partir do projeto será possível realizar as atualizações de cadastro a partir de imagens. No Catálogo de Transparência (Cappelli, 2009), o Engenheiro seleciona "Auditabilidade" e em seguida "Rastreabilidade", e cria o RNF: o software deve garantir registro de auditoria. Já que tratando-se de cadastro de clientes e documentação deve haver rastro para futuras auditorias. No Catálogo de Consciência de Software (Cunha, 2014), seleciona "Consciência de Contexto", e em seguida "Ambiente Computacional" e cria o RNF: o software deve possibilitar o aumento de filesystem. Pois a possibilidade de atualização de cadastro utilizando imagens pode elevar o número de transações assim como, o armazenamento de imagens pode gerar maior necessidade de espaço. Também no Catálogo de Consciência de Software, o Engenheiro seleciona "Consciência de Contexto Social" e em seguida "Consciência do Usuário", e cria o RNF: o software deve possibilitar mecanismos de autenticação do usuário. Pois a atualização do cadastro apenas poderá ser feita pelo cliente autenticado no sistema. O debate então é aberto aos outros participantes e os 4 RNFs criados pelo Engenheiro de Requisitos são discutidos. 
Após os 4 RNFs serem postos para debate, cada participante se posicionou e argumentou sua posição em relação a cada um dos RNFs. Não se discordou muito de que cada RNFs deveria ser construído, foram unânimes e o consenso ocorreu em 3 dos 4 RNFs para a posição $=2$, isso é, RNFs essenciais. Porém um dos participantes entendeu que o requisito referente ao aumento de filesystem era desejável (posição $=1$ ) e não essencial (posição $=2$ ). Para esse caso, o estado do RNF permaneceu "Em negociação" até o final da construção. Dentro do período destinado a construção, os argumentos apontados não foram suficientes para o convencimento do participante, e ele não mudou de ideia.

O Moderador decidiu finalizar a construção e optar pelo voto da maioria no caso do RNF de aumento de filesystem. Essa ação pode ser configurada no suporte computacional para ser automática, isso é, assumir a posição da maioria para a decisão relacionada a um determinado RNFs, cujo o consenso não ocorreu.

Foi detectada, ao longo dos ciclos de discussões, a interdependência entre os RNFs de autenticação do usuário e integridade no armazenamento das imagens. Justifica-se pelo fato de que apenas usuários autenticados no sistemas possuem autorização para atualizar o cadastro, e isso ajuda a garantir a integridade das informações armazenadas. As correlações entre os RFs e RNFs também são do tipo "fortalece". Por exemplo, o RNF para garantir a integridade no armazenamento das imagens fortalece o RF de atualização cadastral por captura de imagem, pois sem integridade no armazenamento, a funcionalidade de atualização cadastral corre risco de ocorrer de maneira insatisfatória. Outra ocorrência, associada ao RNF de integridade das imagens armazenadas, foi a solução técnica sugerida para captura de imagem com criptografia. Desencadeando dois refinamentos: Captura de Imagem com criptografia para armazenamento e Captura de Imagem com criptografia para tráfego. As sugestões foram colocadas em votação e o consenso foi alcançado.

No caso da Atualização Cadastral, tivemos um exemplo de postura "firm" relacionada ao RNF de aumento de filesytem. Apenas um participante escolheu a posição 1 (desejável), enquanto o restante dos participantes optaram pela posição 2 (essencial). A postura impediu o consenso e a construção finalizou com o RNF no estado "Em negociação". Em geral a pontuação dos participantes no exemplo dado 
foi alta, pois, exceto esse caso de postura "firm", a colaboração em direção ao consenso foi dominante na dinâmica.

Durante o debate um novo RNF foi postado no mural, coletado pelo Engenheiro de Requisitos para sua redação padronizada e incluído no debate: $o$ software deve possibilitar mecanismos de 'sanitização de entrada' das imagens esperados. Ligado a qualidade de Segurança, o RNF foi construído ao longo da dinâmica como essencial para o projeto. A correlação entre os RNFs de autenticação do usuário e integridade no armazenamento das imagens também foi sugerida através do espaço para discussões chamado Mural.

Resumindo, no exemplo da Atualização Cadastral temos a construção de 5 RNFs e 1 correlação entre os RNFs de autenticação do usuário e integridade no armazenamento das imagens. A correlação é do tipo fortalece (+). Também são positivos os impactos junto aos RFs. Ao longo da construção colaborativa, o RNF relacionado a integridade das imagens armazenadas foi operacionalizado em "captura de imagem com criptografia" e recebeu dois refinamentos (E): Captura de Imagem com criptografia para armazenamento e Captura de Imagem com criptografia para tráfego. A figura 19 ilustra o SIG construído no exemplo "Atualização Cadastral".

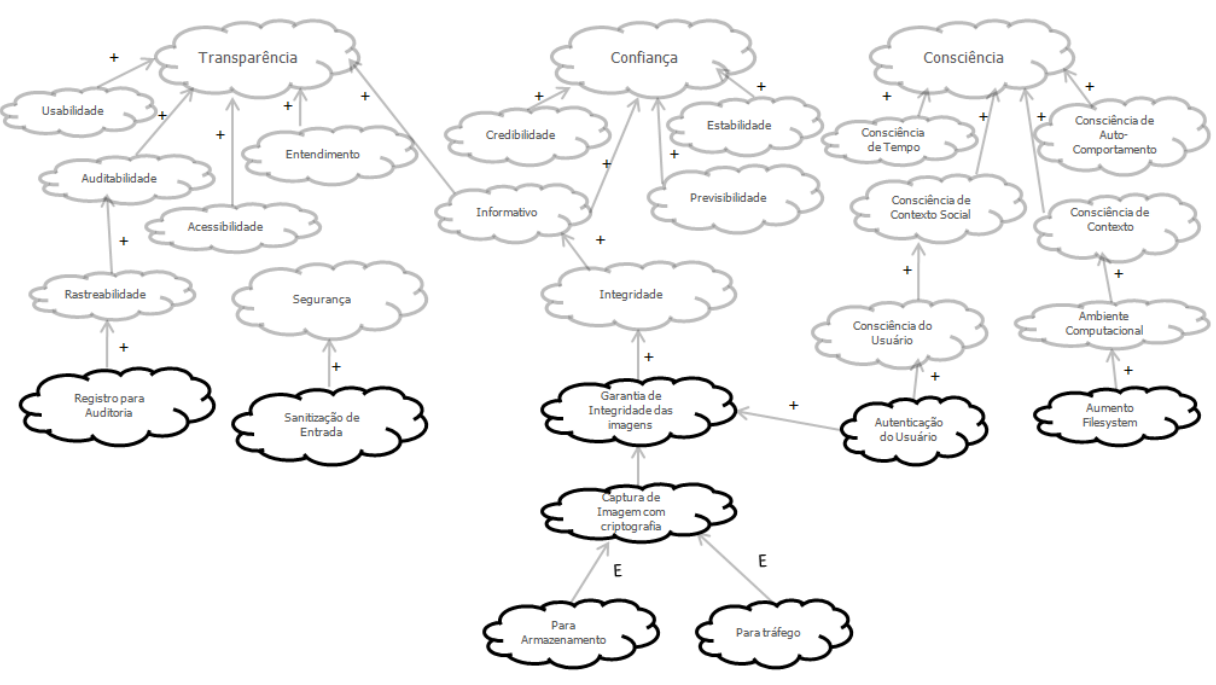

Figura 19. SIG da Atualização Cadastral ${ }^{10}$

${ }^{10} \mathrm{O}$ RNF relativo à sanitização dos dados de entrada é ligado a qualidade de Segurança, qualidade à parte dos 3 catálogos abordados (Transparência, Confiança e Consciência de Software). 


\subsection{Suporte Computacional}

Os softwares de suporte a modelagem colaborativas, que facilitam o engajamento do grupo de trabalho, são fundamentais para a qualidade final do produto gerado. $\mathrm{O}$ uso de softwares colaborativos viabiliza a coleta efetiva de dados sobre as atividades para análise futura (Rittgen, 2012). A necessidade da presença de várias partes interessadas, potencialmente distribuídas espacialmente, durante trabalho de criação em grupo, requer um infra-estrutura para facilitar e registrar o processo de colaboração durante o processo de modelagem (Forster, 2013). São muitas as formas de impacto do uso de softwares colaborativos nos trabalhos produzidos, para se ter sucesso na pratica, tais softwares precisam ser entendidas como sendo de natureza social (Prilla, 2015).

\subsubsection{RNF Colab}

Para apoiar a construção colaborativa proposta, desenvolvemos o software "RNF Colab" (figura 20), assíncrono e para usuários distribuídos geograficamente. Tal suporte diminuirá os problemas de disponibilidade dos participantes para reuniões em um mesmo local ou horário fixo. O suporte computacional não é essencial para o exercício do processo, mas o torna mais eficiente e isto estimula a sua adoção. Pode ser acessado via celular, tablet, laptop ou desktop. Através do endereço: https://snc-rnf.firebaseapp.com.

Utilizando o usuário "visitante@gmail.com" e senha "123456". Os relatórios produzidos durante a atividade de avaliação e o código do software estão em: https://github.com/gbribeirol/RNFColab.git.

Os usuários podem ao final de cada ciclo de discussão, visualizar a lista de RNFs construídos, bem como os RNFs descartados. É possível obter um histórico organizado das discussões relativa a cada requisitos construído ou descartado (posicionamentos, argumentos, dúvidas e esclarecimentos). Além disso, é disponibilizado um painel que permite visualizar os refinamentos e as correlações entre os requisitos. Também é disponibilizado o registro do comportamento dos participantes durante a Negociação-Colaboração (pontualidade, participação, grau de abstenção, colaboração positiva e negativa e contribuição de argumentos) . 


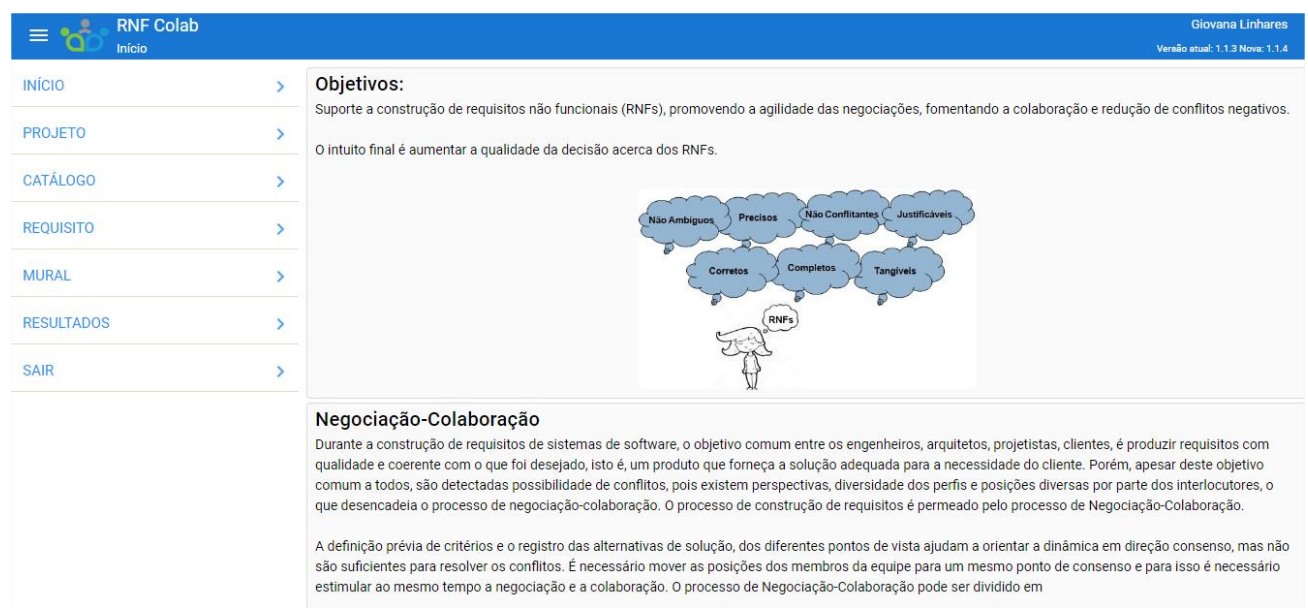

Figura 20. Tela Inicial do Software RNF Colab.

\subsubsection{Requisitos do Software}

\subsubsection{Lista de Requisitos}

Na tabela 1 temos listados os RFs do item 1 ao 10, e os RNFs do item 11 ao 20.

Do item 21 ao 24, são listados os resultados esperados gerados através do software. As informações geradas são também RFs do software RNF Colab, mas apresentamos separadamente na lista, para destacar o que o software oferece de informações organizadas já "filtradas" para consulta. Tais itens são descritos na seção 4.6.2.3.

Tabela 1. Requisitos da RNF Colab

\begin{tabular}{|c|l|}
\hline 1 & O sistema deve possibilitar a construção colaborativa de RNFs. \\
\hline 2 & O sistema deve possibilitar o tratamento de interdependências entre RNFs. \\
\hline 3 & $\begin{array}{l}\text { O sistema deve possibilitar o acesso facilitado à catálogos de RNFs para } \\
\text { consulta e reuso de todo o conhecimento já existente. }\end{array}$ \\
\hline 4 & $\begin{array}{l}\text { O sistema deve possibilitar a criação e divulgação de um padrão de processo } \\
\text { único e detalhado, com regras igualitárias (participantes com mesmos direitos } \\
\text { de participação). }\end{array}$ \\
\hline 5 & $\begin{array}{l}\text { O sistema deve possibilitar a equalização do entendimento de conceitos, } \\
\text { vocabulários, compreensão de termos compartilhada. A lista por exemplo, de } \\
\text { características de qualidade desejadas para um RNF. }\end{array}$ \\
\hline 6 & $\begin{array}{l}\text { O sistema deve possibilitar local para postagem de comentários, } \\
\text { dúvidas/esclarecimentos e sugestões (mensagens de texto, voz, inclusão de } \\
\text { documentos e imagens). }\end{array}$ \\
\hline
\end{tabular}




\begin{tabular}{|c|c|}
\hline 7 & $\begin{array}{l}\text { O sistema deve possibilitar a interação do software e o participante, com o } \\
\text { objetivo de melhorar desempenho do mesmo (avisos, alertas). }\end{array}$ \\
\hline 8 & $\begin{array}{l}\text { O Sistema deve possibilitar a avaliação do "grau" de qualidade da Negociação- } \\
\text { Colaboração contabilizando as quantidades de requisitos, interdependências, } \\
\text { argumentos, posicionamentos, e fornecendo uma pontuação aos participantes. }\end{array}$ \\
\hline 9 & $\begin{array}{l}\text { O Sistema deve possibilitar a identificação de razões de conflitos, e a condução } \\
\text { do processo para o consenso. }\end{array}$ \\
\hline 10 & $\begin{array}{l}\text { O Sistema deve possibilitar o incentivo à posturas conciliadoras e repreensão à } \\
\text { condutas desagregadoras. }\end{array}$ \\
\hline 11 & $\begin{array}{l}\text { O sistema deve possibilitar a comunicação da equipe a qualquer hora e de } \\
\text { qualquer lugar. }\end{array}$ \\
\hline 12 & $\mathrm{Si}$ \\
\hline 13 & $\begin{array}{l}\text { O Sistema deve impossibilitar danos a outros componentes do dispositivo onde } \\
\text { for instalado. }\end{array}$ \\
\hline 14 & $\begin{array}{l}\text { O Sistema deve possibilitar uma interface que se comporte adequadamente } \\
\text { independente do front-end que será utilizado para acesso (Browser, Smartphone } \\
\text { ou Tablet). }\end{array}$ \\
\hline 15 & $\begin{array}{l}\text { O Sistema deve possibilitar uma interface com facilidade de entendimento e } \\
\text { uso. }\end{array}$ \\
\hline 16 & $\begin{array}{l}\text { O Sistema deve possibilitar funcionamento } 24 \text { x } 7 \text { (vinte e quatro horas por dia, } \\
\text { sete dias por semana), e utilização em modo "off-line". }\end{array}$ \\
\hline 17 & $\begin{array}{l}\text { O Sistema deve possibilitar telas e funcionalidades acessíveis apenas conforme } \\
\text { perfil do usuário. }\end{array}$ \\
\hline 18 & $\begin{array}{l}\text { O Sistema deve possibilitar autenticação em nível do servidor e em nível da } \\
\text { aplicação. }\end{array}$ \\
\hline 19 & $\begin{array}{l}\text { O Sistema deve possibilitar apenas criação de componentes segundo padrão de } \\
\text { projeto conhecido para reuso. }\end{array}$ \\
\hline 20 & $\begin{array}{l}\text { O Sistema deve possibilitar programação modularizada e com comentários e } \\
\text { nomes de métodos e variáveis auto explicativos. }\end{array}$ \\
\hline 21 & $\mathrm{OSi}$ \\
\hline 22 & pendências entre os requisitos. \\
\hline 23 & $\begin{array}{l}\text { O Sistema deve prover o histórico organizado das discussões (argumentos, } \\
\text { posições, dúvidas, esclarecimentos). }\end{array}$ \\
\hline 24 & $\begin{array}{l}\text { O sistema deve prover a pontuação do participante de acordo com o } \\
\text { comportamento do mesmo durante a dinâmica de Negociação-Colaboração } \\
\text { (participação intensa ou ausente, pontualidade, tempo de escolha de posição, } \\
\text { classificação dos argumentos recebida, alteração de posicionamento para } \\
\text { convergir com a maioria ou posicionamento impedindo do consenso). }\end{array}$ \\
\hline
\end{tabular}




\subsubsection{Regras de Uso}

A tabela 2 lista as ações e os atores que as executam. As ações que não possuem atores são efetuadas pelo software.

Tabela 2. Ações X Atores

\begin{tabular}{|c|c|c|c|c|}
\hline & Ações & Moderador & \begin{tabular}{|c|} 
Engenheiro \\
de Requisitos \\
\end{tabular} & Participante \\
\hline 1 & Cadastrar projeto & $\mathrm{x}$ & & \\
\hline 2 & $\begin{array}{l}\text { Cadastrar participantes e seus } \\
\text { papeis }\end{array}$ & $\mathrm{x}$ & & \\
\hline 3 & Iniciar construção & $\mathrm{x}$ & & \\
\hline 4 & Finalizar construção & $\mathrm{x}$ & & \\
\hline 5 & Cancelar construção & $\mathrm{x}$ & & \\
\hline 6 & $\begin{array}{l}\text { Criar requisito (e faz utilização do } \\
\text { catálogo) }\end{array}$ & $\mathrm{x}$ & & \\
\hline 7 & Alterar requisito & & $\mathrm{x}$ & \\
\hline 8 & Cancelar requisito & & $\mathrm{x}$ & \\
\hline 9 & $\begin{array}{l}\text { Escolher posição Requisito e } \\
\text { Incluir argumento }\end{array}$ & & $\mathrm{x}$ & \\
\hline 10 & Alterar Posição & & & $\mathrm{x}$ \\
\hline 11 & Criar correlações e refinamentos & & & $\mathrm{x}$ \\
\hline 12 & $\begin{array}{l}\text { Escolher posição correlações e } \\
\text { Incluir argumento }\end{array}$ & & $\mathrm{x}$ & \\
\hline 13 & Classificar argumentos & & & $\mathrm{x}$ \\
\hline 14 & $\begin{array}{l}\text { Exibir posicionamentos, } \\
\text { requisitos e argumentos }\end{array}$ & & & $\mathrm{x}$ \\
\hline 15 & $\begin{array}{l}\text { Somar votos posições ou marcar } \\
\text { para decisão Moderador }\end{array}$ & & & \\
\hline 16 & $\begin{array}{l}\text { Exibir Lista de RNF e seus } \\
\text { estados }\end{array}$ & & & \\
\hline 17 & $\begin{array}{l}\text { Disponibilizar espaço para } \\
\text { dúvidas e sugestões }\end{array}$ & & & \\
\hline 18 & $\begin{array}{l}\text { Disponibilizar Pontuação do } \\
\text { Participante }\end{array}$ & & & \\
\hline 19 & $\begin{array}{l}\text { Disponibilizar Histórico } \\
\text { Organizado das Discussões }\end{array}$ & & & \\
\hline 20 & $\begin{array}{l}\text { Disponibilizar Requisitos e suas } \\
\text { Interdependências }\end{array}$ & & & \\
\hline 21 & $\begin{array}{l}\text { Disponibilizar Resumo } \\
\text { Quantitativo da Negociação- } \\
\text { Colaboração }\end{array}$ & & & \\
\hline
\end{tabular}




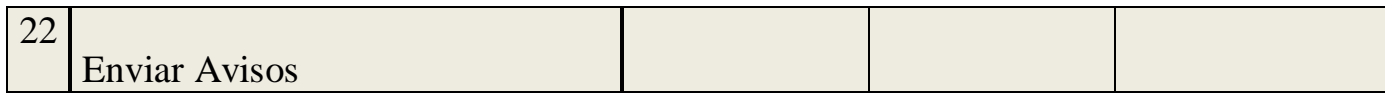

Vale mencionar que o administrador do sistema realiza ações como preencher parâmetros de configurações, cadastrar os tipos RNF, tipos papéis, moderador, tipos posições e cadastrar catálogos.

Durante o planejamento da implementação do RNF Colab, nos deparamos com a necessidade de estabelecer algumas regras associadas as ações realizadas pelos usuários. Essas regras foram implementadas para que o processo fosse refletido no apoio computacional.

a) Uma construção é a criação e um ciclo de discussão de uma lista de RNFs e suas interdependências. Um projeto pode conter uma ou várias dinâmicas de Negociação-Colaboração, até se atingir o consenso de uma lista final de RNFs.

b) Novas dinâmica de Negociação-Colaboração podem ser agendadas pelo Moderador caso o ciclo atual de debate não tenha atingido consenso.

c) Na criação de uma nova dinâmica de Negociação-Colaboração, dentro de um mesmo projeto, o histórico das posições e argumentos da construção anterior é mantido, para continuação das discussões, dos requisitos selecionados para a nova dinâmica.

d) O Moderador pode reduzir o número de participantes da construção, porém, as posições e argumentações relacionadas a estes participantes não são excluídas, pois fazem parte do histórico daquele projeto.

e) Numa mesma construção uma pessoa não poderá acumular o papel de Moderador e Participante ou Engenheiro de Requisitos.

f) Apenas o Moderador pode cancelar uma construção.

g) A construção dos RNFs e suas correlações é colaborativa, porém a redação final e cadastro no software é de responsabilidade do Engenheiro de Requisitos. 
h) Um RNF ou uma correlação ou um refinamento podem ser cadastrados após o início de uma construção e ao longo de todo o processo. Todos os participantes recebem um aviso via e-mail de que há um novo requisitos/correlação/refinamento para ser negociado.

i) Um requisito pode estar associado a várias dinâmicas de NegociaçãoColaboração de um projeto (reuso) ${ }^{11}$.

j) O Engenheiro de Requisitos pode alterar um requisito, caso este ainda esteja no estado "criado".

k) O Engenheiro de Requisitos pode cancelar um requisito, caso este ainda esteja no estado "criado".

1) As posições acerca dos requisitos podem ser: (0) Descartável, (1) Desejável, (2) Essencial, (Nulo) Abster-se. Essa classificação é configurável.

m) As posições acerca das correlações entre requisitos podem ser: (+) Fortalece, (-) Enfraquece, (?) Afeta, (Nulo) Abster-se. Essa classificação não é configurável, pois faz parte da linguagem proposta na presente pesquisa. $^{12}$

n) No momento do primeiro posicionamento para um determinado requisito, o requisito entra no estado "em negociação".

o) Pode se iniciar a posicionamento/argumentação de um requisito enquanto outros ainda estão sendo posicionados ou até sendo criados.

p) A cada posição incluída, vai sendo somada na votação das posições. No ato de alterar a posição escolhida o cálculo será refeito.

q) As correlações não possuem "estado", pois elas fazem parte da discussão como um todo de um requisito. No final da construção, também é calculada uma posição decidida pelo grupo em relação as Correlações.

${ }^{11}$ Consta na lista de trabalhos futuros o reuso de requisitos entre os projetos.

12 Durante a avaliação do processo os participantes sugeriram, na ferramenta a opção de "não afeta", quando se discorda da existência de uma correlação. Essa inclusão foi implementada para prover a discussão, porém para a linguagem de representação gráfica não precisa existir, pois se ficar definido que não existe uma correlação, a associação não será representada. 
r) Os argumentos podem ser classificador em: "Relevante", "Informativo", ou "Inconsistente". "Relevante" é um argumento capaz de refutar conceitos até o momento defendidos por parte dos participantes. "Informativo" é um argumento que não altera os conceitos discutidos, porém agrega a estes informações importantes que podem reforçá-los ou enfraquecê-los. "Inconsistente" é um argumento que não é inteligível, ou que não é relevante ou relativo à discussão. Além de não agregar ao esclarecimento dos conceitos, este último tipo de argumento confunde os participantes, retardando o processo como um todo. Essa classificação é configurável.

s) A votação contabilizada internamente pelo software, deve ser apresentada aos participantes desde o início da negociação.

t) Votação é calculada pelo software até obtenção do consenso, ou até data de prazo final da dinâmica de Negociação-Colaboração. Se não forem necessárias novas dinâmicas, a construção é finalizada.

u) O consenso a respeito de um requisito só é contabilizado no final da dinâmica de Negociação-Colaboração, pois até o final dela os participantes podem mudar de posição, e a posição que estava em comum acordo de todos pode deixar de ficar.

v) Os estados que um requisito pode assumir são: "criado", "em negociação", "construído" ou "descartado". Na sua posição final "construído" deve ser apresentada em conjunto a informação "desejado" ou "essencial", e a informação da forma de decisão, se automática ou por decisão do moderador.

w) No caso de impasses perdurarem, o moderador deve atuar nas causas dos conflitos para mediar e possivelmente sanar problemas, auxiliando na busca de soluções para os impasses. 
x) Quando não há consenso e nem maioria ${ }^{13}$, o Moderador assume a tomada de decisão. A justificativa da escolha realizada deve esclarecer os motivos da decisão do Moderador.

\subsubsection{Informações Geradas}

Os relatórios são informações registradas ao longo do uso do processo, que são apresentadas de maneira organizada, em tempo de execução, isso é, não são geradas apenas no final da construção. Os relatórios do software também foram planejados de acordo com alguns critérios. A seguir detalharemos um pouco mais esses resultados esperados.

No relatório de "Históricos das Discussões", por projeto e por requisito, são listada as posições e argumentos de cada participante. São listadas também todas as dúvidas e esclarecimentos, assim como sugestões de melhorias ou relato de erros. Essa rastreabilidade das discussões envolvidas na construção dos requisitos, servirá para aquisição de conhecimento, por exemplo, por novos membros contratados para equipe, ou para recuperação de discussões efetuadas, onde as razões para a implementação, ou não, de um determinado requisito são identificadas.

No relatório de "Requisitos e suas Interdependências" para cada requisito deve ser apresentada suas correlações, refinamentos e associações aos catálogos de Requisitos Não Funcionais (nível de abstração mais alto). Esse relatório materializa o tratamento dado as interdependências entre os requisitos. A partir dele, poderão ser diagramados os Diagramas Orientados a Objetivos relacionados a cada projeto $^{14}$.

No "Resumo quantitativo" é possível avaliar o "grau" de qualidade da Negociação-Colaboração. Através deste resumo quantitativo advindo da construção, temos as quantidades de requisitos construídos, as suas interdependências (correlações e refinamentos) e, a quantidade de argumentos e de posicionamentos. Juntamente com a pontuação dos participantes (relatório a parte) essas informações são insumos das dinâmicas ocorridas a serem analisados e

\footnotetext{
${ }^{13}$ Deve-se levar em conta nesse cenário a possibilidade de configuração de pesos distintos (maior) para o voto do cliente da área de negócio que demanda o projeto. Sugestão dos participantes da avaliação do processo descrita no Capítulo 7.

${ }^{14}$ A geração de Diagramas Orientados a Objetivos consta na lista de trabalhos futuros.
} 
comparados. Poderão ser detectados fatores de influência nas negociações, razões de impasses, que tornam as construções mais ou menos produtivas. A partir desta análise novos mecanismos para fomentar a colaboração podem ser traçados.

Para um entendimento melhor do relatório de Pontuação do Participantes, apresentamos na tabela 3 a lista os parâmetros utilizados. Lembrando, que tais parâmetros são configuráveis, de acordo com a escolha da organização ou da equipe que utilizará o software. A pontuação poderá ser Alta, Média ou Baixa. Conforme faixas percentuais e fórmulas de cálculo. Temos 5 parâmetros de medição: Abstenção, Participação, Pontualidade, Colaboração e Contribuição de Argumentos. Para cada parâmetro é calculada a pontuação, e um aviso é enviado, quando um dos parâmetros obtiver pontuação baixa.

Tabela 3. Parâmetros para Pontuação dos Participantes

\begin{tabular}{|c|c|c|c|c|c|c|c|c|}
\hline \multicolumn{2}{|c|}{ Avaliação Participantes } & \multirow{2}{*}{$\begin{array}{c}\text { Peso } \\
-\end{array}$} & \multicolumn{2}{|c|}{ Baixa } & \multicolumn{2}{|c|}{ Média } & \multicolumn{2}{|c|}{ Alta } \\
\hline Abstenção & $\%$ de Null & & 51 & 100 & 11 & 50 & 0 & 10 \\
\hline \multirow[t]{2}{*}{ Participação } & $\begin{array}{l}\text { \%RNFs/correlações } \\
\text { Posicionados }\end{array}$ & - & 0 & 50 & 51 & 90 & 91 & 100 \\
\hline & $\begin{array}{l}\text { \%Argumentos } \\
\text { Preenchidos }\end{array}$ & - & 0 & 10 & 11 & 20 & 21 & 100 \\
\hline Pontualidade & $\begin{array}{l}\text { \% Tempo } \\
\text { posicionamento }\end{array}$ & - & 51 & 100 & 21 & 50 & 0 & 20 \\
\hline \multirow[t]{2}{*}{ Colaboração } & $\begin{array}{l}\% \text { alterar } \\
\text { posicionamento } \\
\text { para convergir }\end{array}$ & - & 0 & 20 & 21 & 50 & 51 & 100 \\
\hline & $\begin{array}{l}\% \text { posicionamento } \\
\text { Block ou Firm }\end{array}$ & - & 51 & 100 & 1 & 50 & 0 & 0 \\
\hline \multirow{4}{*}{$\begin{array}{l}\text { Contribuição } \\
\text { Argumentos }\end{array}$} & \%Inc.,Inf., Rel. & - & 0 & 20 & 21 & 50 & 51 & 100 \\
\hline & Inconsistentes & 0 & & & & & & \\
\hline & Informativos & 3 & & & & & & \\
\hline & Relevantes & 5 & & & & & & \\
\hline
\end{tabular}


Detalhamento:

- $\quad$ Abstenção (\% de null): qtd de posição = "null" efetuados pelo participante /total de posicionamentos efetuados pelo participante.

- Participação:

○ posições preenchidas pelo participante/total de requisitos/correlações da construção.

○ argumento incluídos pelo participante/total argumentos cadastrados na construção.

- Pontualidade: tempo para início do preenchimento dos posicionamentos e argumentos com relação ao prazo total da construção. Por exemplo: iniciou preenchimento 3 dias após o início da construção que possui o prazo total igual a 10 dias. $3 / 10=30 \%$. É classificado como pontualidade média.

- Colaboração: Relembrando, se em algum requisito, todos queriam uma posição e o participante votou em outra posição impedindo o consenso, é atitude "firm". Se, se absteve nesta mesma situação, é atitude "block".

○ qtd de atitudes block ou firm do participante / qtd de atitudes block ou firm do total de participantes.

○ qtd de atitudes para convergir com a maioria do participante / qtd de atitudes para convergir com a maioria do total de participantes.

- Contribuição de argumentos: Contribuição do argumento = ((número de argumentos do participante com maioria votos ${ }^{15}$ como contribuição relevante /total de argumentos que tiveram maioria votos como relevante) * 5 + (número de argumentos do participante com maioria votos como informativo/total de argumentos que tiveram maioria votos como informativo) $* 3+$ (número de argumentos do participante com maioria votos como inconsistente /total de argumentos que tiveram maioria votos

\footnotetext{
${ }^{15}$ Um mesmo argumento poderá ser classificado por vários membros do grupo. A classificação final será a classificação que a maioria atribuiu. No caso de empate, a classificação de maior peso é a que pontua. Para estimular a prática de argumentação.
} 
como inconsistente) * 0) /8. O argumento classificado como inconsistente não tem peso, isso é feito para não desestimular a inclusão de argumentos.

A tabela 4 lista os avisos padrões do RNF Colab e respectivos momentos de disparo. Os avisos podem ser configurados conforme as necessidades das organizações e equipes.

Tabela 4. Avisos X Momento Disparo

\begin{tabular}{|l|l|}
\hline \multicolumn{1}{|c|}{ Avisos } & \multicolumn{1}{c|}{ Quando é disparado } \\
\hline Aviso de início construção de RNF & $\begin{array}{l}\text { Na confirmação da operação "iniciar } \\
\text { construção" realizada pelo Moderador }\end{array}$ \\
\hline Aviso de RNF criado & $\begin{array}{l}\text { Na criação de novos requisitos realizada pelo } \\
\text { Eng. de Requisitos (pode ser em lote, avisar um } \\
\text { grupo novo criado) }\end{array}$ \\
\hline Aviso de final construção de RNF & $\begin{array}{l}\text { Na confirmação da operação "finalizar } \\
\text { construção" realizada pelo Moderador }\end{array}$ \\
\hline $\begin{array}{l}\text { Aviso de tempo que falta para o final } \\
\text { construção de RNF }\end{array}$ & Um dia antes do prazo final da construção. \\
\hline Aviso pontuação baixa & $\begin{array}{l}\text { Depois da metade do prazo total da construção, } \\
\text { caso o participante possua algum parâmetro } \\
\text { com pontuação baixa. É enviado uma única vez } \\
\text { por parâmetro. }\end{array}$ \\
\hline Aviso argumento classificado ${ }^{16}$ & $\begin{array}{l}\text { Diariamente, com a lista de argumentos do } \\
\text { participante que foram classificados }\end{array}$ \\
\hline
\end{tabular}

\subsubsection{Rastreabilidade entre N-C e o RNF Colab}

Durante o planejamento da implementação do software RNF Colab, os princípios da Negociação-Colaboração mencionados no Capítulo 2, também foram analisados. A tabela 5 relaciona os princípios da Negociação-Colaboração ao respectivo tratamento do RNF Colab.

Tabela 5. Princípios da Negociação-Colaboração X RNF Colab

\begin{tabular}{|l|l|}
\hline \multicolumn{1}{|c|}{ Conceito } & \multicolumn{1}{c|}{ Tratamento RNF Colab } \\
\hline $\begin{array}{l}\text { Transparência: Não possuir } \\
\text { regras/cálculos/processos secretos }\end{array}$ & $\begin{array}{l}\text { Regras e funcionamento do Processo de } \\
\text { Construção dos RNFs são publicadas para o } \\
\text { conhecimento de todos. }\end{array}$ \\
\hline $\begin{array}{l}\text { Igualdade: Todos os participantes } \\
\text { possuem os mesmos direitos de } \\
\text { intervir, argumentar }\end{array}$ & $\begin{array}{l}\text { Estabelecimento de Regras para a } \\
\text { Construção dos Requisitos, onde não haja } \\
\text { constrangimentos para a participação, que é }\end{array}$ \\
\hline
\end{tabular}

16 O aviso "Argumento Classificado" foi incluído por sugestão dos participantes durante a avaliação do software RNF Colab. A avaliação é descrita no Capítulo 7. 


\begin{tabular}{|l|l|}
\hline $\begin{array}{l}\text { Confidencialidade: Participantes } \\
\text { têm sua identidade preservada para } \\
\text { liberdade de escolha de posição }\end{array}$ & $\begin{array}{l}\text { Esse princípio não foi adotado no processo. } \\
\text { Optamos pela transparência ao invés do } \\
\text { anonimato, pois é importante que os perfis } \\
\text { dos participantes que colaboram entre si } \\
\text { sejam conhecidos, apoiando e fundamentando } \\
\text { o ponto de vista de cada indivíduo. }\end{array}$ \\
\hline $\begin{array}{l}\text { Eficácia ganha - ganha: Direcionar } \\
\text { o processo de negociação do nível } \\
\text { mais alto de conflito para o mais } \\
\text { baixo, objetivando o consenso }\end{array}$ & $\begin{array}{l}\text { A coleta de dados como participação intensa } \\
\text { ou ausente, pontualidade, classificação dos } \\
\text { argumentos recebida, alteração de } \\
\text { posicionamento para convergir com a maioria } \\
\text { ou posicionamento impedindo do consenso, } \\
\text { visa identificar as razões de problemas. O } \\
\text { aviso de pontuação baixa ainda durante a } \\
\text { execução da dinâmica, alerta um participante } \\
\text { para que o mesmo reflita sobre sua } \\
\text { participação e tenha chances de melhorá-la. }\end{array}$ \\
\hline $\begin{array}{l}\text { Imparcialidade : Não fazer tender a } \\
\text { discussão para um determinado } \\
\text { participante ou perfil de participante }\end{array}$ & $\begin{array}{l}\text { A pontuação atingida pelo participante é } \\
\text { informada apenas ao mesmo. A cada reunião, } \\
\text { este histórico é apagado. }\end{array}$ \\
\hline
\end{tabular}

Por fim, salientamos que além da atenção aos princípios da NegociaçãoColaboração mencionados no Capítulo 2, em Linhares (Linhares, 2009) também são apresentadas variáveis que podem influenciar a dinâmica e a qualidade da negociação-colaboração. Selecionamos as que consideramos mais relevantes para comentá-las.

Equivocidades é um engano no que diz respeito ao assunto da discussão. Incertezas é a existência de pontos de vistas diferentes sobre um mesmo assunto. Para essas duas variáveis temos que no software, estão disponíveis para consulta de todos, as regras e o processo de construção de RNF. Também são sugeridos atributos de qualidade para um RNF. Para cada projeto são cadastradas a sua descrição e objetivo. É importante evitar que o desconhecimento ou pouco conhecimento sobre as regras e do passo a passo do processo de negociação possa desencadear um esforço adicional para evolução do processo, elevando o tempo 
total da negociação em virtude de esclarecimento de dúvidas ou de discussões sobre o processo em si.

A variável percepção é sem dúvida de suma importância num software colaborativo assíncrono. Como mecanismo de percepção temos a exibição dos posicionamentos recebidos para cada requisito, e seus respectivos argumentos. As dúvidas, esclarecimentos e sugestões feitas pelos participantes, isso é, assuntos levantados durante as discussões, são publicadas para o conhecimento de todos no "Mural". As mensagens do Moderador relativas aos assuntos da dinâmica de construção também são públicas. Os avisos padrões de início e fim de construção; aviso de novo requisitos ou correlações a serem debatidos, aviso de pontuação baixa, são enviados por e-mail ou mensagens para celular.

\subsubsection{Arquitetura}

A estrutura de arquitetura do software RNF Colab é ilustrada na figura 21. Os RNFs do software RNF Colab são mapeados cada um deles dentro da solução de arquitetura adotada. O software possui padrão aberto, e código fonte livre e grátis. A aplicação executa no servidor Firebase (serviço do Google) e no cliente (browser no dispositivo).

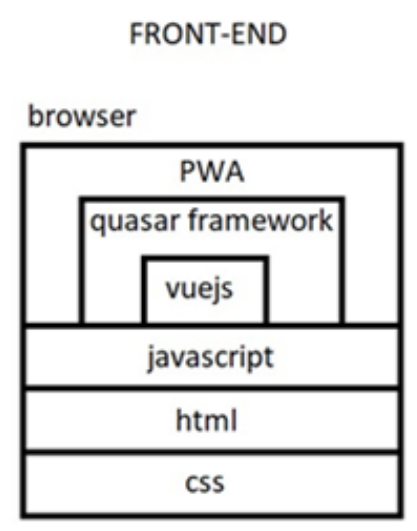

BACK-END
firebase (bas)
\begin{tabular}{|l|}
\hline authentication \\
\hline host (web server) \\
\hline firestore (banco de dados) \\
\hline functions \\
\hline
\end{tabular}

Figura 21. Arquitetura do RNF Colab.

\section{Front-End}

- PWA é abreviatura de "progressive web app". É um aplicativo da web, tipo de página da web ou site, que funciona em qualquer plataforma que use um navegador padrão. Entre as suas funcionalidades temos execução offline, 
notificações e acesso ao hardware do dispositivo. Utilizando o PWA não é necessário que os desenvolvedores ou usuários instalem os aplicativos da web em seus dispositivos. Portanto, a utilização não é feita por distribuição digital como Apple App Store ou Google Play.

- "quasar" é um framework, baseado no "vuejs", que contém uma biblioteca de componentes visuais.

- "vuejs" é um framework para criar componentes reativos (de atualização sincronizada entre a estrutura de dados da memória RAM e a interface).

- As linguagens de programação utilizadas são: javascript (linguagem de fato do programa), html e css (linguagens voltadas para interface).

\section{$\underline{\text { Back-End }}$}

BAS é a sigla de "back end as service". Está dividido em 4 partes:

- Authentication: onde ficam as funções para a autenticação dos usuários.

- Host (web server): servidor onde fica hospedada a aplicação WEB, que executa no cliente (browser).

- Functions: onde ficam hospedados e são executados, os procedimentos relativos aos avisos. O "relógio" que verifica de tempos em tempos o momento de enviá-los também está hospedado neste local.

- Firestore: é o banco de dados orientado a documentos. Esse tipo de banco de dados contém coleções que possuem documentos (objetos). Essas coleções, por sua vez podem conter outras coleções e assim por diante.

Mapeando os RNFs listados com a arquitetura apresentada, temos as seguintes correspondências:

- RNF11 - O sistema deve possibilitar a comunicação da equipe a qualquer hora e de qualquer lugar. 
○ É operacionalizado através do servidor Firebase, que garante o acesso livre às aplicações que estão nele "hospedadas", a partir de qualquer localidade e horário.

- RNF12 - O Sistema deve possibilitar execução em sistemas operacionais distintos.

○ É operacionalizado através das linguagens de programação que são executadas "dentro" de qualquer browser.

- RNF13 - O Sistema deve impossibilitar danos a outros componentes do dispositivo onde for instalado.

○ É operacionalizado através das linguagens de programação que são executadas 'dentro" do qualquer browser. Os mecanismos de defesa dos próprio browser protegem os dispositivos. Não há necessidade de instalação de nenhum ".exe".

- RNF14 - O Sistema deve possibilitar uma interface que se comporte adequadamente independente do front-end que será utilizado para acesso (desktop, laptop, smartphone ou tablet).

- É operacionalizado do uso da linguagem css com a definição do estilos responsivos que permitem a adaptação das telas e seus elementos de acordo com a resolução do dispositivos alvo.

- RNF15 - O Sistema deve possibilitar uma interface com facilidade de entendimento e uso.

○ É operacionalizado através da camada front-end, na estrutura de Quasar, que fornece padrão de Interface gráfica amigável. A biblioteca contém componentes visuais de fácil entendimento e uso. A forma de utilização dos componentes na programação é crucial para que o resultado seja bem sucedido.

- RNF16 - Funcionamento 24 x 7 (vinte e quatro horas por dia, sete dias por semana), utilização também em modo "off-line". 
○ É operacionalizado através da camada back-end, na estrutura de Firebase, que permite acesso e funcionamento $24 \times 7$.

○ É operacionalizado através da camada front-end, na estrutura de service worker (interna do browser), que fornece execução offline.

- RNF17 - O Sistema deve possibilitar telas e funcionalidades acessíveis apenas conforme perfil do usuário.

- É operacionalizado através da camada front-end, na programação das regras para acesso de telas e funcionalidades, através da linguagem javascript e framework vuejs.

- RNF18 - Autenticação em nível do servidor e em nível da aplicação.

- É operacionalizado através da camada back-end, na estrutura de Authentication.

- RNF19 - Os componentes criados devem seguir padrão de projeto conhecido para reuso.

○ É operacionalizado através da camada front-end, nas estruturas de framework Quasar e Vuejs, bibliotecas padrões. O uso dos componentes já implica em padrão para reuso, porém para possibilitar o reuso efetivo, a programação deve ser planejada com esse objetivo.

- RNF20 - Programação modularizada e com comentários e nomes de métodos e variáveis auto explicativos.

○ É operacionalizado através da camada front-end, nos códigos implementados, que seguiram a diretriz de nomes de métodos e variáveis auto explicativos e inclusão de comentários esclarecedores. Além disso, a programação foi organizada com modularização.

É importante enfatizar que os RNFs do software RNF Colab foram construídos em conjunto com os RFs, isto é, antes da atividade de estruturação da arquitetura. A lista de RNFs foi utilizada como insumo para a atividade de 
estruturação da arquitetura do software. Segue na tabela 6 o "batimento" dos RNFs e atendimento no RNF Colab.

Tabela 6. Requisitos X RNF Colab

\begin{tabular}{|c|c|c|c|}
\hline$\#$ & Requisito & Tipo & RNF Colab \\
\hline RNF11 & $\begin{array}{l}\text { O sistema deve possibilitar a } \\
\text { comunicação da equipe a } \\
\text { qualquer hora e de qualquer } \\
\text { lugar. }\end{array}$ & Comunicabilidade & Arquitetura Firebase \\
\hline RNF12 & $\begin{array}{lcr}\text { O Sistema } & \text { deve } & \text { possibilitar } \\
\text { execução } & \text { em } & \text { sistemas } \\
\text { operacionais distintos. }\end{array}$ & Portabilidade & $\begin{array}{c}\text { Arquitetura } \\
\text { Linguagens Browser }\end{array}$ \\
\hline RNF13 & $\begin{array}{l}\text { O Sistema deve impossibilitar } \\
\text { danos a outros componentes do } \\
\text { dispositivo onde for instalado. }\end{array}$ & Confiabilidade & $\begin{array}{c}\text { Arquitetura } \\
\text { Linguagens Browser }\end{array}$ \\
\hline RNF14 & $\begin{array}{l}\text { O Sistema deve possibilitar } \\
\text { uma interface que se comporte } \\
\text { adequadamente independente } \\
\text { do front-end que será utilizado } \\
\text { para acesso (Browser, } \\
\text { Smartphone ou Tablet). }\end{array}$ & Usabilidade & Arquitetura CSS \\
\hline RNF15 & $\begin{array}{l}\text { O Sistema deve possibilitar } \\
\text { uma interface com facilidade } \\
\text { de entendimento e uso. }\end{array}$ & Usabilidade & Arquitetura Quasar \\
\hline RNF16 & $\begin{array}{l}\text { O Sistema deve possibilitar } \\
\text { funcionamento } 24 \text { x } 7 \text { (vinte e } \\
\text { quatro horas por dia, sete dias } \\
\text { por semana), e utilização em } \\
\text { modo "off-line". }\end{array}$ & Disponibilidade & $\begin{array}{c}\text { Arquitetura Firebase } \\
\text { Browser }\end{array}$ \\
\hline RNF17 & $\begin{array}{l}\text { O Sistema deve possibilitar } \\
\text { telas e funcionalidades } \\
\text { acessíveis apenas conforme } \\
\text { perfil do usuário. }\end{array}$ & Segurança & $\begin{array}{c}\text { Arquitetura } \\
\text { Javascript Vuejs }\end{array}$ \\
\hline RNF18 & \begin{tabular}{lrrr} 
O Sistema & deve & \multicolumn{2}{c}{ possibilitar } \\
autenticação & em & nível & do \\
servidor e em & nível & da \\
aplicação. & & & \\
\end{tabular} & Segurança & $\begin{array}{c}\text { Arquitetura } \\
\text { Authentication }\end{array}$ \\
\hline RNF19 & $\begin{array}{l}\text { O Sistema deve possibilitar } \\
\text { apenas criação de componentes } \\
\text { segundo padrão de projeto } \\
\text { conhecido para reuso. }\end{array}$ & Reusabilidade & $\begin{array}{c}\text { Arquitetura Quasar } \\
\text { Vuejs }\end{array}$ \\
\hline RNF20 & $\begin{array}{l}\text { O Sistema deve possibilitar } \\
\text { programação modularizada e } \\
\text { com comentários e nomes de } \\
\text { métodos e variáveis auto } \\
\text { explicativos. }\end{array}$ & Manutenabilidade & $\begin{array}{l}\text { Arquitetura } \\
\text { Programação }\end{array}$ \\
\hline
\end{tabular}

A Figura 22 mostra o esquema do banco de dados para o RNF Colab. 


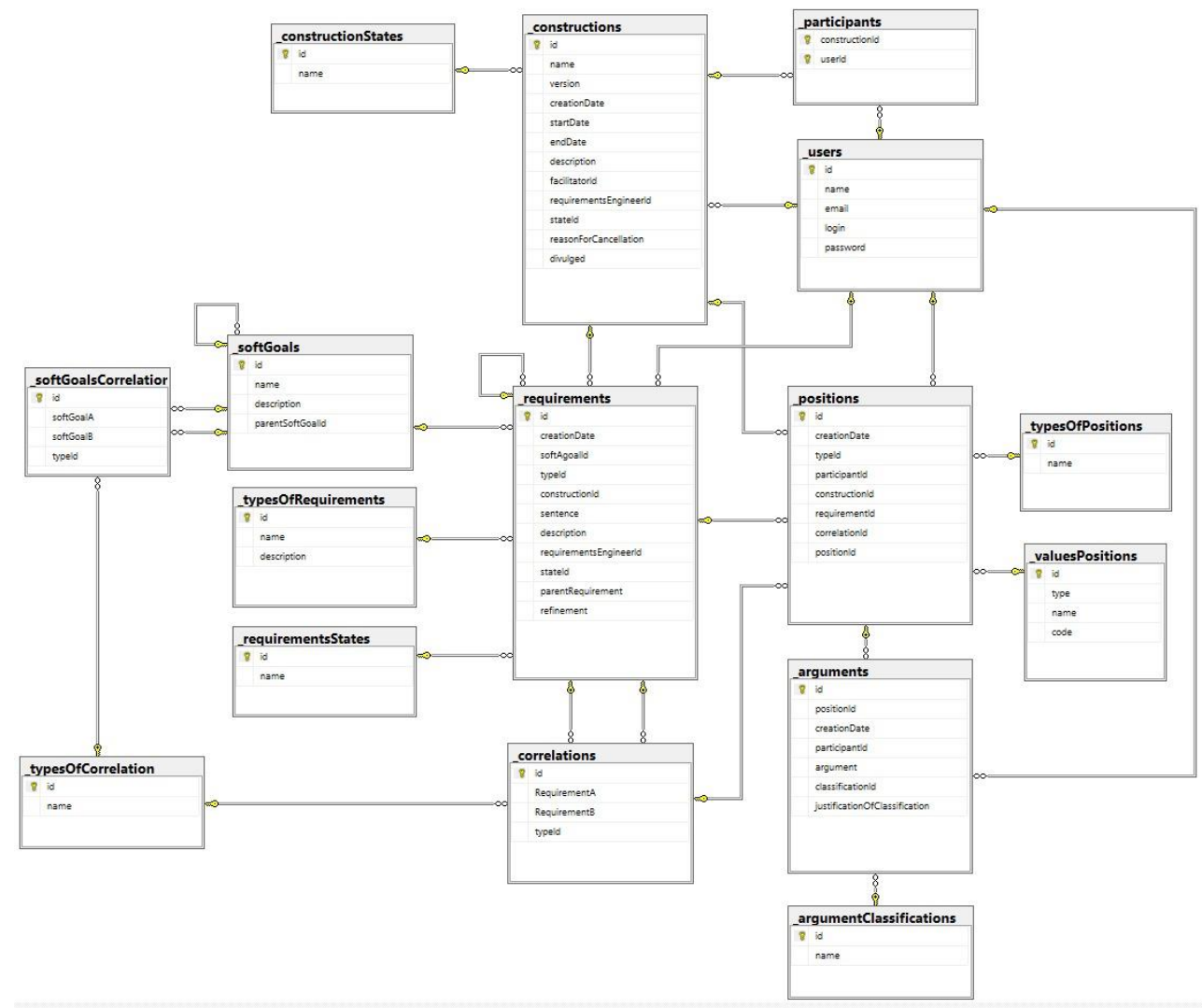

Figura 22. Esquema Lógico do Banco de Dados do RNF Colab. 


\title{
5 Estudos de Casos
}

\begin{abstract}
Neste Capítulo apresentamos uma avaliação do processo proposto. São descritos três estudos de casos: o uso do processo na construção de requisitos de um produto IOT, Cesta de Medicamentos; o uso do processo com apoio computacional na construção dos requisitos do software RNF Colab - software de suporte ao próprio processo; e finalmente, o uso do processo e apoio computacional em um projeto de uma organização real de grande porte.
\end{abstract}

A avaliação foi realizada com o intuito de verificar se objetivos específicos de pesquisa foram atendidos pela solução proposta. A avaliação, portanto, pretendeu buscar indícios de que o processo proposto primeiramente, é viável de ser utilizado e além disso possibilita o direcionamento da atenção dos profissionais envolvidos para os RNFs; promove um impacto positivo na qualidade dos RNFs produzidos e mais além, possibilita o debate e tratamento de suas interdependências. Esse Capítulo foi estruturado com base nos procedimentos de documentação de estudos de caso sugeridos por Runeson e Höst (Runeson e Höst, 2008).

O estudo de caso Cesta de Medicamentos é um exemplo de uso do processo e uma prova de conceito do software RNF Colab. Não foi realizada a coleta da opinião dos participantes acerca do processo. Mas foi possível a coleta de algumas métricas como número de RNFs construídos, correlações, argumentos, dúvidas e sugestões.

O estudo de caso RNF Colab se difere dos demais por ser uma avaliação focada na retroalimentação, isto é, a aplicação do processo para avaliação do próprio processo. Além da coleta da opinião dos participantes a respeito do processo via questionário, durante a execução da atividade, os participantes explicitaram suas opiniões sobre o processo através do software, no espaço voltado para o debate em grupo: o Mural.

O estudo de caso TUP Virtual é um exemplo de uso do processo com apoio do software em um projeto da indústria. Foi realizada a coleta de opinião dos participantes através de questionário. 
Como abordado na seção 2.1, na Engenharia de Software busca-se melhorar o processo de produção para se adquirir maior confiança na qualidade do produto final. Também discutimos, na seção 2.3, que em muitos casos na indústria de software, uma avaliação do processo é considerada como "garantidora" da qualidade dos produtos e citamos a ISO (Koscianski, 2007), CMMI (CMMI, 2011) e MPS.Br (Softex, 2020). A avaliação, portanto, é majoritariamente do processo proposto de construção de RNFs. Não obstante, foi observado no uso do processo e também minerado nas respostas ao questionário, afirmações sobre os RNFs resultantes das construções, isto é, sobre o produto. No estudo de caso 2 e 3 , o uso do Mural do RNF Colab traz também avaliações sobre o produto, isto é, afirmações à respeito dos RNFs resultantes da construção. Lembrando que o Caso 2 os requisitos debatidos no Mural eram relativos ao apoio computacional do próprio processo proposto.

Por fim, vale ressaltar que cada estudo de caso acarretou uma evolução tanto do processo quanto do software de apoio, e tais aprimoramentos foram utilizados nos estudos de caso seguintes.

\subsection{Descrição dos Casos e Participantes}

Nesta seção detalhamos o conteúdo dos projetos envolvidos em cada um dos estudos de caso. Informamos também o perfil dos participantes e as ações realizadas com as respectivas durações.

\section{Caso 1 - Cesta de Medicamentos}

Experimentamos o processo proposto em um caso real de um produto IoT em fase de desenvolvimento de protótipo e registro de patente pertencente a uma StartUp brasileira. O produto IoT, "Cesta Automática de Medicamentos", consiste em um dispositivo acoplado a um sistema de software e conectado a uma rede. Ele é leve, portátil, operado por bateria e/ou conectado a uma tomada elétrica. Possui reservatório adequado para armazenar medicamentos. $\mathrm{O}$ produto destina-se a diversos tipos de usuários, não necessariamente idosos ou pessoas com limitações físicas ou doenças crônicas.

Os RF iniciais eram cinco: 
1. o software deve separar os medicamentos por dia e hora;

2. o software deve alertar os pacientes que é hora de tomar uma medicação;

3. o software deve disponibilizar a medicação ao paciente;

4. o software deve confirmar a ingestão da medicação;

5. o software deve enviar um alarme, aos parentes registrados, em caso de falha de ingestão ou necessidade de reabastecimento.

Os critérios para escolha dos participantes da Cesta de Medicamentos foram:

- pessoas sem formação em informática, para analisar essencialmente os requisitos do produto

- pessoas com necessidade de uso de medicação contínua, para obtermos a posição de clientes do produto

- pessoas com diferentes perfis de clientes (jovens, idosos, transplantados), para obtermos pontos de vistas distintos acerca dos requisitos do produto

- ao menos uma pessoa com formação na área de saúde (medicina, enfermagem ou farmácia), para obtermos a posição de especialistas no assunto que envolve o produto

O uso do processo envolveu cinco pessoas. Um Engenheiro de Requisitos, que também atuou como Moderador e quatro participantes. A mesma pessoa atuou como Engenheiro de Requisitos e Moderador (a pesquisadora) ${ }^{17}$.

Tabela 7. Perfil dos Participantes: Cesta de Medicamentos

\begin{tabular}{|c|c|}
\hline Identificação & Perfil \\
\hline Participante 1 & farmacêutico \\
\hline Participante 2 & doente crônico \\
\hline Participante 3 & mãe de transplantado \\
\hline Participante 4 & filho de idosa \\
\hline
\end{tabular}

17 Pelas regras do processo, um participante não pode em uma mesma construção atuar como Moderador e Engenheiro de Requisitos. Por ser uma pesquisa, foi aberta a exceção de que o Moderador e o Engenheiro de Requisitos fossem a mesma pessoa, a pesquisadora. Esse ponto é comentado no final deste Capítulo quando são abordadas as ameaças à avaliação. 
No que se refere a treinamento dos participantes, foi realizado presencialmente. Tivemos uma exposição das regras e funcionamento da dinâmica, realizada no início da atividade. Essa apresentação esclarecendo a atividade, tomou uma hora das seis horas totais da reunião. A tabela 8 apresenta as atividades envolvidas no estudo do caso.

Tabela 8. Atividades e Durações: Cesta de Medicamentos

\begin{tabular}{|l|c|c|}
\hline \multicolumn{1}{|c|}{ Atividades } & Período & Responsável \\
\hline Reunião de abertura da Cesta & 1 hora & Pesquisadora \\
\hline Construção RNFs da Cesta & 5 horas & Participantes \\
\hline Prova de Conceito Cesta de Medicamentos & 7 dias & Pesquisadora \\
\hline
\end{tabular}

\section{Caso 2 - RNF Colab}

Experimentamos o processo proposto no projeto RNF Colab, software de apoio ao próprio processo proposto nesta tese. Desde modo foi possível usar o processo para melhorar o próprio processo. Em si, a auto aplicação, é interessante porque ao funcionar, a atividade ao mesmo tempo avalia e evolui o processo.

Os RF iniciais eram 14 (citados no Capítulo 4):

1. O sistema deve possibilitar a construção colaborativa de RNFs.

2. O sistema deve possibilitar o tratamento de interdependências entre RNFs.

3. O sistema deve possibilitar o acesso facilitado à catálogos de RNFs para consulta e reuso de todo o conhecimento já existente.

4. O sistema deve possibilitar a criação e divulgação de um padrão de processo único e detalhado, com regras igualitárias (participantes com mesmos direitos de participação).

5. O sistema deve possibilitar a equalização do entendimento de conceitos, vocabulários, compreensão de termos compartilhada. A lista por exemplo, de características de qualidade desejadas para um RNF.

6. O sistema deve possibilitar local para postagem de comentários, dúvidas/esclarecimentos e sugestões (mensagens de texto, voz, inclusão de documentos e imagens). 
7. O sistema deve possibilitar a interação do software e o participante, com o objetivo de melhorar desempenho do mesmo (avisos, alertas).

8. O Sistema deve possibilitar a avaliação do "grau" de qualidade da Negociação-Colaboração contabilizando as quantidades de requisitos, interdependências, argumentos, posicionamentos, e fornecendo uma pontuação aos participantes.

9. O Sistema deve possibilitar a identificação de razões de conflitos, e a condução do processo para o consenso.

10. O Sistema deve possibilitar o incentivo à posturas conciliadoras e repreensão à condutas desagregadoras.

11. O Sistema deve prover a lista de RNFs construídos.

12. O Sistema deve prover a matriz de interdependências entre os requisitos.

13. O Sistema deve prover o histórico organizado das discussões (argumentos, posições, dúvidas, esclarecimentos).

14. O sistema deve prover a pontuação do participante de acordo com o comportamento do mesmo durante a dinâmica de Negociação-Colaboração (participação intensa ou ausente, pontualidade, tempo de escolha de posição, classificação dos argumentos recebida, alteração de posicionamento para convergir com a maioria ou posicionamento impedindo do consenso).

Os critérios para escolha dos participantes RNF Colab foram:

- profissionais com mais de quinze anos de experiência profissional

- profissionais com experiência na área de Engenharia de Software ou Engenharia de Requisitos

- profissionais em atividade

- profissionais pertencentes a empresas de grande porte 
O uso do processo envolveu sete pessoas. Um Engenheiro de Requisitos, que também atuou como Moderador e seis participantes. A mesma pessoa atuou como Engenheiro de Requisitos e Moderador (a pesquisadora).

Tabela 9. Perfil dos Participantes: RNF Colab

\begin{tabular}{|c|c|c|c|}
\hline $\begin{array}{c}\text { Identificação } \\
\text { do Participante }\end{array}$ & Perfil & $\begin{array}{c}\text { Experiência } \\
\text { Profissional } \\
\text { de TI }\end{array}$ & $\begin{array}{c}\text { Experiência em } \\
\text { Construção de } \\
\text { Requisitos }\end{array}$ \\
\hline 4801 & $\begin{array}{c}\text { Engenheiro de } \\
\text { Requisitos }\end{array}$ & 25 anos & 15 anos \\
\hline 4802 & $\begin{array}{c}\text { Engenheiro de } \\
\text { Requisitos }\end{array}$ & 20 anos & 17 anos \\
\hline 4803 & $\begin{array}{c}\text { Engenheiro de } \\
\text { Requisitos }\end{array}$ & 16 anos & 10 anos \\
\hline 4804 & $\begin{array}{c}\text { Engenheiro de } \\
\text { Requisitos }\end{array}$ & 20 anos & 10 anos \\
\hline 4805 & $\begin{array}{c}\text { Engenheiro de } \\
\text { Requisitos }\end{array}$ & 22 anos & 15 anos \\
\hline 4806 & $\begin{array}{c}\text { Engenheiro de } \\
\text { Requisitos }\end{array}$ & 17 anos & \\
\hline
\end{tabular}

Para o treinamento dos participantes, foram confeccionados oito filmes de em torno três minutos cada um. Os filmes continham a explicação do processo colaborativa e a navegação pelo software, explicando as principais funcionalidades. Isso assim foi feito para atender a ideia de que toda a experiência deveria ser efetuada assíncrona e distribuída geograficamente. Cada participante realizou a atividade, incluindo a atividade de treinamento, no local e no horário que escolheu, via computador ou celular.

Tabela 10. Atividades e Durações: RNF Colab

\begin{tabular}{|l|c|c|}
\hline \multicolumn{1}{|c|}{ Atividades da Avaliação Qualitativa } & Período & Responsável \\
\hline Cadastro dos dados RNF Colab & 4 dias & Pesquisadora \\
\hline Preparação treinamento & 5 dias & Pesquisadora \\
\hline Treinamento participantes & 3 dias & Participantes \\
\hline Construção RNF Colab & 15 dias & Participantes \\
\hline $\begin{array}{l}\text { Preenchimento do questionário pelos } \\
\text { participantes }\end{array}$ & 3 dias & Participantes \\
\hline
\end{tabular}

A atividade relacionada ao projeto RNF Colab contou com quinze dias para ser realizada pelos participantes.

\section{Caso 3 - TUP Virtual}


Experimentamos o processo proposto no projeto "TUP Virtual para Novos Distribuidores". O projeto de pequeno escopo, possuía cronograma adequado para o período disponível dos participantes e da pesquisa ${ }^{18}$. A sigla TUP significa Telefone de Uso Publico. Os celulares podem apresentar defeitos, serem furtados ou ficarem sem carga de energia, por este motivo até hoje os orelhões ou TUP são mantidos em locais como, shoppings, escolas públicas, postos de saúde, hospitais públicos, bibliotecas, museus, terminais rodoviários, aeroportos e órgãos dos poderes Executivo, Legislativo e Judiciário.

No projeto era necessário configurar a "Recarga do Cartão de Orelhão Recarregável" com o "Integrador", homologando os principais distribuidores de Minas Gerais. No cenário em questão, o Produto "Cartão de Orelhão Recarregável" já era ativo em outros distribuidores. O projeto visava portanto, aumentar a lista de parceiros de recarga, utilizando a malha de recarga do Integrador, para facilitar a aderência ao produto como um todo.

Os RF iniciais eram quatro:

1) O Sistema de gestão de recarga deve possibilitar o cadastro do produto TUP Virtual aos distribuidores Regionais do estado de Minas Gerais para venda de recarga on line, na região 1 , através do modelo compra e venda (utilizando o integrador).

2) O Sistema de gestão de recarga deve possibilitar a carga no saldo do TUP Virtual de Recarga on line realizada pelos Distribuidores.

3) O Sistema de gestão de recarga deve possibilitar a parametrização da interface entre Sistema de contabilização e o Sistema de gestão de recarga.

4) O Sistema de gestão de recarga deve possibilitar a parametrização de cada parceiro na plataforma TUP virtual afim de disponibilizar consultas e relatórios.

18 O projeto TUP Virtual fora implantado no ano de 2016. No seu cronograma foram planejados 15 dias para a atividade que, pelo processo da organização, são apontados os RF e RNFs. A lista de requisitos do projeto apresentava um total de 4 requisitos, utilizados na atividade de avaliação da presente pesquisa. Nenhum dos requisitos era RNF. 
Os seis participantes do estudo de caso 2 e 3 são as mesmas pessoas. Portanto os mesmos critérios de escolha dos participantes do caso 2, foi aplicado no estudo de caso 3. Serem os mesmos participantes, trouxe para o caso 3 a vantagem de um maior conhecimento, por parte dos participantes, no uso do processo e software. $\mathrm{O}$ estudo de caso 3 portanto, diverge do 2 não só por ser um projeto de uma organização real de grande porte, mas também pelo fato de que os participantes já se encontravam em um nível de aprendizado mais profundo que o apresentado no caso 2. Os seis participantes responderam o questionário qualitativo relativo ao processo proposto uma única vez, após a execução do estudo de caso 3.

O projeto TUP Virtual foi sugerido por um dos participantes que possuía envolvimento direto. Dos outros 5 participantes, 1 integrava a mesma área do projeto mas não foi designado para atuar no mesmo. Outros 2 participantes trabalham na TI da mesma organização, porém em outras áreas - Testes e PMO. E outros 2 participantes são fornecedores da mesma área do projeto, mas não foram designados para atuar no mesmo.

Outro ponto relevante é que, como já mencionado na seção 5.1, durante o caso 2 foi possível usar o processo para melhorar o próprio processo. Trazendo para o uso no projeto TUP Virtual novos requisitos implementados no software RNF Colab, como os de percepção do usuário e usabilidade. Não obstante erros detectados em produção, pelos então participantes e usuários, também foram prontamente corrigidos. O caso 3 "recebeu" um processo mais esmiuçado e um apoio computacional de melhor qualidade.

Tabela 11. Atividades e Durações: TUP Virtual

\begin{tabular}{|l|c|c|}
\hline \multicolumn{1}{|c|}{ Atividades da Avaliação Qualitativa } & Período & Responsável \\
\hline Cadastro dos dados TUP Virtual & 4 dias & Pesquisadora \\
\hline Construção TUP Virtual & 10 dias & Participantes \\
\hline $\begin{array}{l}\text { Preenchimento do questionário pelos } \\
\text { participantes }\end{array}$ & 3 dias & Participantes \\
\hline
\end{tabular}

A atividade no projeto TUP Virtual, contou com 10 dias para ser realizada pelos participantes. Foi posto da mesma forma que o trabalho seria realizado, por escolha dos participantes, nos momentos e locais mais adequados para a rotina de cada um. 
Observa-se na tabela 11 que não ocorreu atividade relativa à treinamento, pois como já mencionado os participantes eram as mesmas pessoas do estudo de caso 2. Lembrando que o preenchimento do questionário foi realizado pelos participantes uma única vez após o caso 3, com base na vivencia dos participantes nos estudos de caso 2 e 3.

\subsection{Procedimentos de Coleta de Dados}

Nesta seção descrevemos como foi realizada a coleta de dados de cada estudo de caso. Ressaltamos que o uso do apoio computacional ao processo, isto é, o uso do software RNF Colab, foi importante no procedimento de coleta nos estudos de caso 2 e 3 . Além de agilizar a coleta, garantiu a integridade dos dados preenchidos pelos participantes e assegurou que os mesmos não sofreram nenhum tipo de redação, tradução ou interpretação por parte da pesquisadora.

\section{Caso 1 - Cesta de Medicamentos}

Primeiramente deve ficar claro que para o estudo de caso 1 não ocorreu o uso do software RNF Colab. O processo foi executado sem o apoio computacional. Durante a reunião presencial foram anotados pela pesquisadora todos os dados relativos a dinâmica, como as sugestões de RNFs, dúvidas e esclarecimentos, interdependências entre requisitos, posicionamentos e argumentações. No final da reunião os participantes também enviaram o que haviam anotado para a pesquisadora. Todas as informações após consolidação e registro único foram compartilhadas com os participantes para confirmação, evitando assim possíveis registros de informações equivocadas por parte da pesquisadora. Apenas após a execução do processo, todos os dados coletados foram inseridos no software RNF Colab, executando uma prova de conceito do software.

Após o cadastro dos dados, foi possível gerar os relatórios com a lista de requisitos, suas interdependências e o histórico das discussões, contendo os posicionamentos de cada participante, argumentos, além das dúvidas e sugestões. Para este caso não ocorreu registro de classificação dos argumentos. Também a pontuação do participante não foi apurada. E também não foi utilizado o instrumento de coleta questionário.

\section{Caso 2 - RNF Colab}


Os participantes utilizaram o software RNF Colab durante 15 dias de atividade. Após o uso, foram exportados os relatórios com a listagem de requisitos, histórico das discussões e pontuação dos participantes e armazenados para analise das informações. A quantificação de alguns itens (requisitos, correlações, refinamentos, argumentos, posicionamentos e pontuação do participante) já é calculada automaticamente pelo software. Para outros itens, nós tabulamos e quantificamos a partir dos relatórios, como por exemplo, as dúvidas e esclarecimentos.

A coleta de opinião dos participantes a respeito do processo proposto foi feita através do questionário de 14 perguntas abertas - ver Anexo II. O questionário foi enviado aos participantes via e-mail, foram preenchidos de forma anônima, e armazenados em diretório compartilhado para futura análise.

O questionário foi dividido em duas partes. Uma parte contendo 6 perguntas abertas a respeito da opinião dos participante sobre a atividade da avaliação em si, e outra parte com 8 perguntas abertas a respeito da opinião dos participantes sobre o do processo proposto e software de apoio.

Na primeira parte eram coletadas as opiniões dos participantes acerca das variáveis da avaliação. Para apurar a percepção dos participantes quanto ao entendimento sobre o objetivo da avaliação, e as adequabilidades do escopo do projeto escolhido, do tempo requerido para a atividade, do perfil dos participantes, do material de apoio e do treinamento.

$\mathrm{Na}$ segunda parte eram coletadas opiniões acerca do processo proposto propriamente dito. Os participantes foram indagados quanto aos pontos fortes e fracos do processo, percepção da presença de variáveis de negociação, de variáveis de colaboração, do debate dos impactos entre requisitos, no processo. Também fora questionado o entendimento do papel do software de apoio. Além disso, a segunda parte do questionário era composta de perguntas sobre a influência do processo na lista de RNFs produzidos,e sobre a minimização ou não da negligência dos RNFs com o uso do processo, e se recomendariam ou não, o processo proposto em suas organizações.

Vale ressaltar que, para este segundo estudo de caso, também foi possível coletar as impressões dos participantes sobre o processo e software propostos 
através do Mural do RNF Colab, uma aproximação da técnica de "focus groups" (Stewart and Shamdasani, 2014), pois todas as opiniões ali postadas foram visualizadas por todos os participantes. Aqui destacamos mais uma vez, que foram coletadas não só impressões dos participantes acerca do processo proposto, como também impressões acerca dos RNFs resultantes do processo, isto é, o produto da construção de RNFs.

\section{Caso 3 - TUP Virtual}

Os participantes utilizaram o software RNF Colab durante 10 dias de atividade. Após o uso, foram exportados os relatórios com a listagem de requisitos, histórico das discussões e pontuação dos participantes e armazenados para analise das informações. A quantificação de alguns itens (requisitos, correlações, refinamentos, argumentos, posicionamentos e pontuação do participante) já é calculada automaticamente pelo software. Para outros itens, a quantidade foi calculada pela pesquisadora a partir dos relatórios, como por exemplo, as dúvidas e esclarecimentos.

A coleta de opinião dos participantes a respeito do processo proposto foi feita através do mesmo questionário utilizado no caso 2. O questionário foi enviado aos participantes via e-mail, foram preenchidos de forma anônima, e armazenados para futura análise. Como os participantes eram os mesmos no caso 2 e 3 , o questionário foi preenchido uma única vez, pós a execução do estudo de caso 3.

\subsection{Procedimentos de Análise de Dados}

Nesta seção descrevemos os procedimentos para analisar os resultados de cada estudo de caso.

\section{Caso 1 - Cesta de Medicamentos}

Primeiramente foi realizada pela pesquisadora, uma leitura integral dos relatórios de requisitos e suas correlações e refinamentos, e do relatório de histórico das discussões. Observou-se também as quantidades de itens como numero de requisitos iniciais e finais (construídos colaborativamente), correlações, refinamentos, argumentos, posicionamentos, dúvidas e esclarecimentos. 
Foram comparados os números iniciais e finais de requisitos, para se apurar se ocorreu uma evolução quantitativa dos mesmos. Também foram apuradas a quantidades de posicionamentos com relação ao numero de requisitos debatidos para se medir o nível de participação, já que não é obrigatório se posicionar. Nesta análise incluímos a quantificação de abstenções com relação ao total de posicionamentos, para avaliar a contribuição destes posicionamentos na decisão final relativa ao RNF discutido. Também foram verificados da mesma forma o número de argumentos postados, para saber o nível de engajamento e contribuição dos participantes nas discussões. A quantidade de posicionamentos de correlações ("Fortalece", "Enfraquece", "Afeta") também foram analisados para se avaliar a presença, ou não, do debate relativo as interdependências entre requisitos. Por último quantificamos as dúvidas e esclarecimentos para se averiguar além da participação, o nível geral de entendimento dos participantes sobre o objetivo do processo executado ou sobre o objetivo do software a ser construído.

Para este caso não ocorreu coleta de dados através de questionário, por tanto a analise dos resultados qualitativa com base na opinião dos participante não foi realizada. A análise se baseou nas métricas quantitativas acima citadas, lembrando que a prova de conceito também se configura em um resultado do estudo de caso, em cujo o software de apoio ao processo foi evoluído.

\section{Caso 2 - RNF Colab}

Primeiramente foi realizada pela pesquisadora, uma leitura integral dos relatórios de requisitos e suas correlações e refinamentos, e do relatório de histórico das discussões e para este caso, também do relatório de pontuação dos participantes. Além das apurações das mesmas métricas quantitativas realizadas no caso 1, foram possíveis também realizar análises relativas a pontuação dos participantes, isto é, os parâmetros de pontualidade, ocorrência de atitudes "block" ou "firm", alteração de posicionamento em direção ao consenso, avaliação da classificação recebida pelos participantes acerca dos argumentos postados ("Relevantes", "Informativos", "Inconsistentes"). Neste último parâmetro a analise foi no intuito de investigar, além da participação, o nível de contribuição dos participantes nas discussões no julgamento do próprio grupo. 
A análise de dados qualitativos foi realizada pela pesquisadora, com base nas respostas ao questionário. Inicialmente as respostas coletadas foram tabulada em 4 tabelas (Tabelas 16, 17, 18 e 19) conforme o assunto tratado, relativos à características do processo proposto. Após esta ação, analisou-se cada uma das respostas tabuladas e observamos tanto opiniões favoráveis quanto pontos de atenção. A análise realizada buscou detectar pontos de melhoria apontados pelos participantes, assim como uma confirmação dos tratamentos percebidos como positivos para a qualidade do processo de construção de RNFs.

No Caso 2 também foi possível analisar dados imputados pelos participantes sobre o processo proposto através do Mural do software RNF Colab. Uma aproximação de "Focus Group" (Stewart and Shamdasani, 2014), pois todas as opiniões ali postadas foram visualizadas por todos participantes. Foram dadas 17 sugestões de novos requisitos para o processo e para o software de apoio. A pesquisadora analisou a discussão entre os participantes, constatando as questões onde a opinião era reforçada ou minimizada.

\section{Caso 3 - TUP Virtual}

Os procedimentos de análise deste caso foram idênticos aos do caso 2 , com a diferença de que os dados explicitados pelos participantes e analisados pela pesquisadora caso 2, compunham uma retroalimentação para o próprio processo proposto.

\subsection{Resultados}

Nesta seção detalhamos os resultados de cada um dos estudos de caso. É reportado o uso do processo, e os resultados obtidos neste uso, assim como são expostas as observações e análises feitas pela pesquisadora. Também são exploradas as respostas dos participantes ao questionário aplicado.

\subsubsection{O Uso do Processo}

\section{$\underline{\text { Caso } 1 \text { - Cesta de Medicamentos }}$}

Três catálogos de RNFs existentes foram integrados e utilizados: Consciência de Software, Transparência, Confiança (Cunha, 2014; Cappelli, 2009; Leal et al., 
2009). Como mencionado no Capítulo 4, essa escolha foi feita com base na palestra de Leite (Leite, 2019) no WER2019.

O Engenheiro de Requisitos analisou os 3 catálogos conjuntamente em busca da criação de RNFs. No catálogo de Consciência de Software, temos: "identificação do usuário" e "características dos usuários". Para "identificação dos usuários", foi selecionado o uso de "autenticação biométrica". Podendo ser refinado nas operacionalizações de "reconhecimento de rosto, voz e impressão digital". Para as "características dos usuários", considerou-se as operacionalizações: "solicitar características ao usuário" e "inferir características do usuário". Em Acessibilidade, no catálogo de Transparência, e na sua extensão (Oliveira et al., 2016), duas opções interessaram: "conteúdo perceptível" e "conteúdo operável". Para tornar o conteúdo perceptível para diversos tipos de usuários, ele deve ser apresentado de várias maneiras. Para operacionalidade, o aplicativo pode fornecer acesso via voz, tanto para autenticação quanto para acesso aos conteúdos ou funções. Esse tipo de possibilidade é importante para os idosos que têm dificuldade em gerenciar o toque em aplicações de tela ou mesmo dificuldade para ler, devido a problemas de visão. No catálogo de Confiança, foi encontrada a qualidade da "controlabilidade". Alternativas para a segurança de acesso aos medicamentos, que por sua vez, reforçam a confiança dos usuários no produto em questão.

Com base nas qualidades selecionadas através da análise dos catálogos, o Engenheiro criou os quatro RNFs:

1. o software deve se adaptar a diferentes tipos de usuários (incluindo aqueles com limitações físicas, como baixa visão ou dificuldades motoras);

2. o software deve identificar usuários (via reconhecimento de rosto, voz e impressão digital);

3. o software deve fornecer acesso via comando de voz a qualquer função ou conteúdo;

4. o software deve proteger o reservatório com uma função de autenticação na tampa de abertura para o reabastecimento de estoque da medicação. 


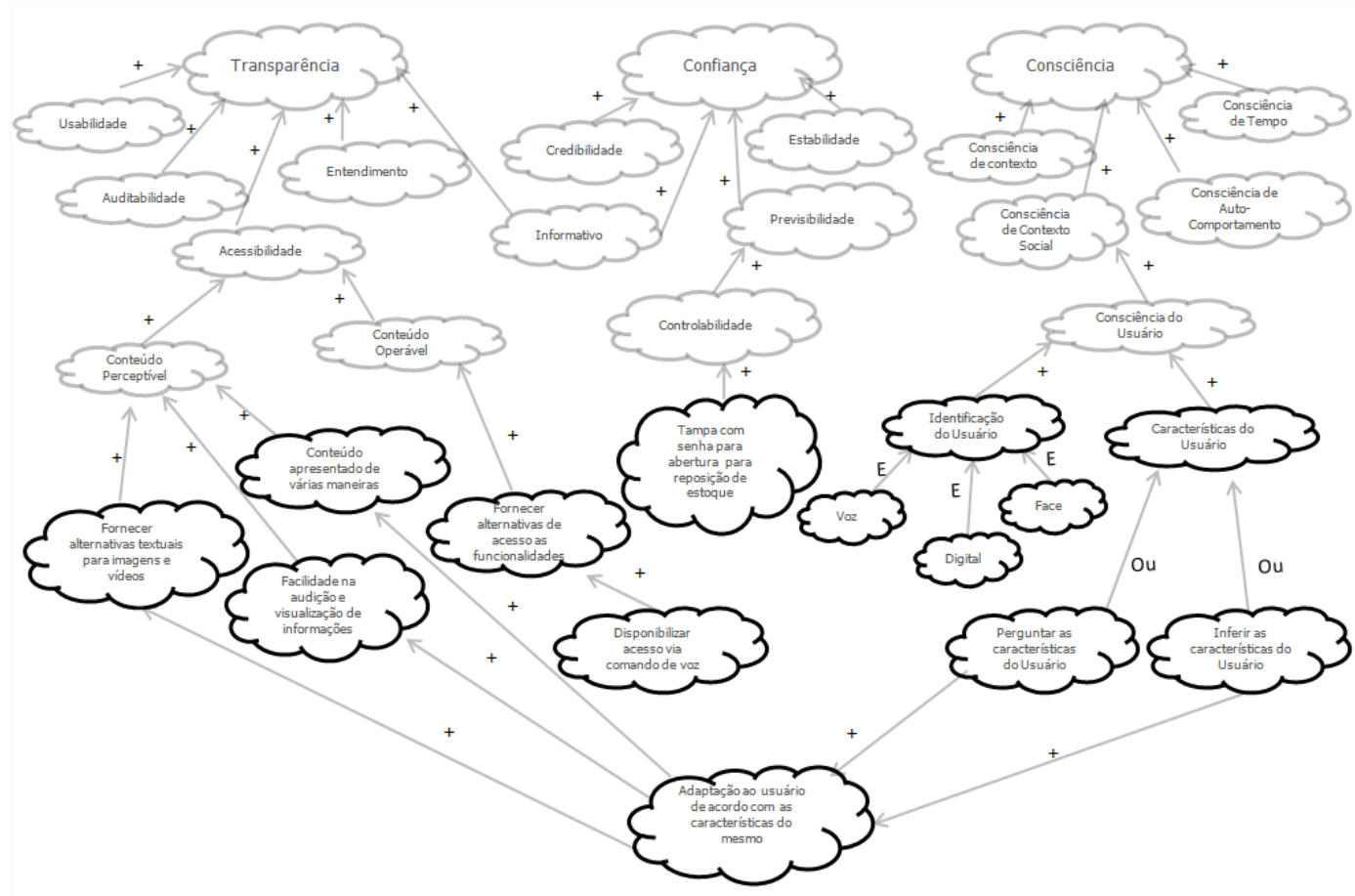

Figura 23. SIG Inicial Cesta de Medicamentos

A lista com os nove requisitos relacionados ao produto, foi posta para debate do grupo. Os catálogos também foram utilizados como fonte de referência para análise de grupo.

A primeira rodada da dinâmica durou cerca de cinco horas. Como mencionado, um treinamento foi realizado com a apresentação da visão geral do processo e teve a duração de uma hora. No início da dinâmica, todos os participantes leram os nove requisitos listados pelo engenheiro de requisitos. Após esta tarefa, os participantes levantaram questões sobre os requisitos criados e possíveis interdependências entre os mesmos. Durante o debate do grupo, os participantes forneceram ideias para novos requisitos.

Para cada requisito anterior ou novo listado, a votação era aberta. Todos os nove requisitos listados inicialmente foram acordados como Essenciais (posição $\Rightarrow$ 2). Os requisitos sugeridos foram refinados em uma ação conjunta do grupo de Clientes com o Engenheiro de Requisitos e com o Moderador. Dos requisitos sugeridos durante a reunião, alguns foram descartados (posição $=>0$ ), outros foram desejados ( posição =>1) e outros foram priorizados (posição =>2). Os argumentos, perguntas, respostas e posições produzidas foram armazenadas para histórico da discussão. 
A maioria dos participantes concordou que os impactos entre os requisitos eram majoritariamente positivos, requisitos fortalecidos um pelo outro. O maior conflito ocorrido entre os participantes, foi no momento de priorizá-los (decisões sobre os posicionamentos 1 ou 2), porque parte dos participantes argumentou que um ou outro requisito era essencial e a outra parte discordou, reforçando que eram apenas desejáveis. O Moderador interveio em dois requisitos e definiu o posicionamento pela maioria. A primeira rodada da dinâmica colaborativa gerou as quantidades totais apresentadas na Tabela 12.

Tabela 12. Cesta Automática de Medicamentos

\begin{tabular}{|l|c|}
\hline \multicolumn{1}{|c|}{ Itens } & Quantidade \\
\hline RFs & 4 \\
\hline RNFs Construídos & 5 iniciais +35 \\
\hline Correlações & 49 \\
\hline Argumentos & 48 \\
\hline Dúvidas/Sugestões & 10 \\
\hline
\end{tabular}

A lista de requisitos gerados e o registro dos itens do debate, como por exemplo os argumentos, não podem ser divulgados por sigilo do produto que ainda não foi patenteado pela StartUp. Porém, os resultados numéricos totais fornecidos acima, sugerem que o uso do processo pode ser benéfico na construção de requisitos já que os requisitos triplicaram se comparados a lista inicial sugerida pelo Engenheiro de Requisitos. Fato ocorrido em apenas uma primeira rodada de discussão. Além disso, a consulta aos catálogos proporcionou o exercício efetivo de reutilização do conhecimento existente. Houve direcionamento e atenção para o debate sobre os impactos entre os RNFs. Os números sugerem também que o processo incentiva a participação, pois os resultados mostram um volume substancial de itens de debate, como argumentos, dúvidas e sugestões.

Os resultados citados avaliam o processo. Foi possível constatar que o processo é viável e fornece resultados utilizáveis. Com relação aos produtos produzidos, os indícios são igualmente positivos, já que os RNFs construídos no uso do processo, fazem parte atualmente do desenvolvimento do protótipo da Cesta Automática de Medicamentos.

Após a primeira rodada da dinâmica da Cesta de Medicamentos, realizamos um POC (Prova de Conceito) no software RNF Colab. Cadastrou-se os dados e 
resultados do uso do processo no apoio computacional, isso é, lista de requisitos, posicionamentos, argumentos, dúvidas e esclarecimentos. Essa atividade ajudou em a melhoria do software, posto que ao longo dos cadastros foram detectadas novas necessidades de informações a serem apresentadas. Como por exemplo, o campo de "Forma de Decisão" e "Posição Final"; além da detecção de erros e ajustes.

\section{Caso 2 - RNF Colab}

O Engenheiro de Requisitos criou 10 RNFs como sugestão para o debate, portanto, inicialmente o cadastro deste projeto no RNF Colab continha 24 requisitos, entre os quais 14 eram RFs, e 10 eram RNFs. Ao final da dinâmica, foram sugeridos mais 17 requisitos, destes, 13 foram construídos e 6 implementados. O número de RNFs listados inicialmente pelo Engenheiro de Requisitos (pesquisadora), foi quase duplicado ao longo da dinâmica. O fato sugere que o processo colaborativo é benéfico. Questões não pensadas isoladamente, em grupo foram construídas.

Algumas outras ocorrências ao longo da dinâmica valem ser também ressaltadas, uma delas é o fato de que todos os requisitos listados inicialmente foram por consenso construídos. Levando a crer que o processo obteve aceitação pelo grupo de participantes, já que tais requisitos em si, implementam o processo.

O Mural funcionou como esperado, tornou-se um espaço para discussão e origem de ideias, compartilhamento de dúvidas e esclarecimentos, e inclusive relato de erros do software. Do Mural foram coletadas pelo Engenheiro de Requisitos, as sugestões dos novos RNFs. As sugestões implementadas durante a execução da atividade, suprindo as necessidades dos usuários ao longo do uso do software, motivaram a geração de novas sugestões, num ciclo positivo de aumento da qualidade do processo e seu software de apoio.

Outras sugestões de requisitos não foram implementadas, ainda. Por exemplo, a sugestão de configuração de pesos para cada perfil do usuário, isso é, um peso de voto maior do que outro, em função do perfil do usuário. O cliente teria um peso maior que o desenvolvedor, se assim for desejado. O peso de cada perfil 
seria transparente, de conhecimento de todos envolvidos, como uma regra de processo $^{19}$.

A lista de todas as sugestões, assim como todas as dúvidas e respectivos esclarecimentos foram registradas no Mural por classificação selecionada no momento da "postagem": dúvida ou sugestão. É possível recuperar o histórico organizado. Esta classificação das postagens em "dúvidas" e "sugestões", foi mais uma sugestão dos participantes implementada durante a execução da atividade. O Mural portanto funcionou como mecanismo incentivador da interação dos usuários e fomentou a participação. No caso das dúvidas compartilhadas, o efeito positivo foi de agilização da passagem de conhecimento e facilitação do entendimento por parte de todo o grupo das questões levantadas, pois as respostas eram publicadas para todos os envolvidos, no mesmo tempo.

Percebeu-se, durante a atividade e através dos comentários no Mural, dificuldades comuns a todos, como por exemplo, o esforço na detecção de que RNFs já haviam sido posicionados e quais ainda faltavam os usuários se posicionar. O mesmo o corria com a ação de classificar argumentos. A sugestão de trocar a cor do requisito já posicionado e posicionamento já classificado, foi transformada em requisito de usabilidade associado ao catálogo de transparência. Aceito por todos como essencial, também foi implementado durante a execução da atividade.

Uma outra ocorrência que é interessante relatar foi a argumentação dada por um dos participantes, afirmando que a responsabilidade de mapear os impactos entre os requisitos é apenas do Engenheiro de Requisitos. E que o grupo deveria participar prioritariamente das decisões acerca dos RNFs e seus Refinamentos. A discussão gerou o aprofundamento da reflexão sobre o assunto de elicitação de RNFs, papeis e responsabilidades destas atividades. O entendimento final e comum foi, que o grupo deveria colaborar para ambas decisões, RNFs e Correlações. Esse entendimento se deu a partir da argumentação de que um RNF pode invalidar outro RNF caso sejam conflitantes. Nesse caso, a decisão em grupo de qual RNF priorizar, será mais consistente que a decisão isolada do Engenheiro de Requisitos. Cabe aqui chamar atenção para que em alguns casos o mecanismo de decisão dos

\footnotetext{
19 No trabalho proposto por Antunes et al (Antunes et al, 2006) também há a ideia de pesos para participantes. O peso de um participante diminui de acordo com as atitudes "ganha-perde" e "perde-perde" que são tomadas pelo mesmo durante a utilização do software MEG.
} 
RNFs fica sob a responsabilidade do Mediador. Mas são casos onde a discussão em grupo já foi efetuada, e não se chegou a um consenso; ou ainda, por existirem motivos de "força maior" como tempo, custo ou desejo do cliente.

A tabela 13 traz a lista das sugestões postadas durante a dinâmica e seus resultados. Desta lista foram avaliados o que poderia ser ou não implementado em tempo da atividade. A posição final foi dada pelo Moderador. Das 17 sugestões 13 foram aceitas como Essenciais ou Desejáveis. As 4 restantes foram descartadas. A lista não passou portanto pela ação de posicionamentos de cada participante durante a atividade. Aqueles requisitos que não foram implementados por falta de tempo no cronograma da pesquisa ("Feitos?" = "Não") serão insumo para uma segunda construção do mesmo projeto, para buscar uma decisão do grupo. Isto é, dos 13 requisitos construídos, 6 foram implementados antes da terceira atividade da avaliação e os 7 restantes farão parte da lista de trabalhos futuros.

Tabela 13. Sugestões para RNF Colab

\begin{tabular}{|c|c|c|c|c|}
\hline & Sugestão & Argumento & $\begin{array}{l}\text { Posição } \\
\text { Final }^{20}\end{array}$ & Feito? \\
\hline 1 & $\begin{array}{l}\text { Definição de perfis } \\
\text { diferentes, por projeto }\end{array}$ & $\begin{array}{l}\text { Importante para empresas } \\
\text { médias ou grandes }\end{array}$ & Essencial & Não \\
\hline 2 & $\begin{array}{l}\text { Definição de cadastro } \\
\text { detalhado do Participante }\end{array}$ & $\begin{array}{l}\text { Descrição da área, } \\
\text { departamento, cargo, } \\
\text { contato }\end{array}$ & Essencial & Não \\
\hline 3 & $\begin{array}{l}\text { Definição de um peso } \\
\text { diferente de "importância } \\
\text { na votação" (dependendo } \\
\text { do requisito) }\end{array}$ & $\begin{array}{l}\text { Um stakeholder da equipe } \\
\text { de implantação e } \\
\text { manutenção pode achar } \\
\text { essencial a clareza dos } \\
\text { logs e sua opinião deve } \\
\text { ter peso maior neste } \\
\text { requisito quando contra } 5 \\
\text { outras opiniões contrárias } \\
\text { de stakeholders de } \\
\text { marketing. }\end{array}$ & Desejável & Não \\
\hline 4 & $\begin{array}{l}\text { Definições por projeto, } \\
\text { grupos de requisitos e } \\
\text { mapear peso de cada } \\
\text { participante relacionado } \\
\text { aquele grupo de requisitos }\end{array}$ & $\begin{array}{l}\text { Stakeholder de áreas } \\
\text { distintas com pesos } \\
\text { distintos para responder } \\
\text { cada grupo de "classes" } \\
\text { de RNFs. É um } \\
\text { refinamento do requisito } \\
\text { anterior (3). }\end{array}$ & Desejável & Não \\
\hline 5 & $\begin{array}{l}\text { Desenvolver uma forma } \\
\text { mais simples para o } \\
\text { posicionamento sobre as } \\
\text { correlações ("like"/"dislike" }\end{array}$ & $\begin{array}{l}\text { Muitas vezes não se tem o } \\
\text { que "adicionar" em } \\
\text { termos de argumentação } \\
\text { de porque concorda com }\end{array}$ & Descartável & Não \\
\hline
\end{tabular}

\footnotetext{
${ }^{20}$ Posição final dada pelo Moderador.
} 


\begin{tabular}{|c|c|c|c|c|}
\hline & $\begin{array}{l}\text { do Facebook e a adição de } \\
\text { comentários) }\end{array}$ & $\begin{array}{l}\text { uma correlação. Esta } \\
\text { mudança na interface } \\
\text { agilizaria e geraria menos } \\
\text { cliques na tarefa de } \\
\text { posicionamento; além de } \\
\text { tornar esta tarefa mais } \\
\text { "interessante". Também } \\
\text { pode se posicionar apenas } \\
\text { quando descorda da } \\
\text { correlação. }\end{array}$ & & \\
\hline 6 & $\begin{array}{l}\text { O sistema poderia } \\
\text { apresentar uma "marca" } \\
\text { informando que um } \\
\text { argumento foi classificado }\end{array}$ & $\begin{array}{l}\text { Para facilitar o controle } \\
\text { das tarefas no sistema. }\end{array}$ & Essencial & Sim \\
\hline 7 & $\begin{array}{l}\text { Alerta de argumento } \\
\text { classificado }\end{array}$ & $\begin{array}{l}\text { O participante que teve } \\
\text { seu posicionamento } \\
\text { classificado por outro, } \\
\text { receba um alarme e assim } \\
\text { ele possa ler o que foi } \\
\text { comentado em seu } \\
\text { argumento. }\end{array}$ & Desejável & Não \\
\hline 8 & $\begin{array}{l}\text { As mensagens do mural } \\
\text { forem exibidas por ordem } \\
\text { de data-hora }\end{array}$ & $\begin{array}{l}\text { Conseguiremos interagir } \\
\text { melhor e as trocas sobre } \\
\text { as sugestões ou } \\
\text { mensagens colocadas } \\
\text { serão mais ricas. }\end{array}$ & Essencial & Sim \\
\hline 9 & $\begin{array}{l}\text { Visualização dos requisitos } \\
\text { que já tiveram } \\
\text { posicionamento e os que } \\
\text { ainda precisam ser } \\
\text { analisados e comentados }\end{array}$ & $\begin{array}{l}\text { Poderiam criar uma marca } \\
\text { nos que já foram } \\
\text { trabalhados ou um } \\
\text { relatório somente para } \\
\text { visualizar a execução da } \\
\text { atividade }\end{array}$ & Essencial & Sim \\
\hline 10 & $\begin{array}{l}\text { Para o Mural: classificar o } \\
\text { assunto como "sugestão" } \\
\text { ou "dúvida" }\end{array}$ & $\begin{array}{l}\text { Eu quero ver a dúvida dos } \\
\text { outros pra não perguntar a } \\
\text { mesma coisa. }\end{array}$ & Essencial & Sim \\
\hline 11 & $\begin{array}{l}\text { Caso o participante altere } \\
\text { seu posicionamento, pois } \\
\text { mudou de ideia, não criar } \\
\text { mais uma linha na listagem } \\
\text { geral de posicionamentos } \\
\text { do requisito. Alterar o valor } \\
\text { do posicionamento na lista } \\
\text { geral e guardar o histórico } \\
\text { de alterações apenas no } \\
\text { posicionamento do próprio } \\
\text { participante. }\end{array}$ & $\begin{array}{l}\text { Não poluir a tela e } \\
\text { confundir os usuários }\end{array}$ & Desejável & Sim \\
\hline 12 & $\begin{array}{l}\text { Trocar o nome de } \\
\text { "correlações" para } \\
\text { "interdependências" }\end{array}$ & Facilita o entendimento & Descartável & Não \\
\hline 13 & $\begin{array}{l}\text { Alterar a visualização de } \\
\text { informações no momento } \\
\text { de correlacionar requisitos. } \\
\text { O requisito A está } \\
\text { relacionado ao requisitos B. }\end{array}$ & $\begin{array}{l}\text { No momento de refletir } \\
\text { sobre a correlação que } \\
\text { existe entre eles, senti } \\
\text { falta de visualizar meus } \\
\text { posicionamentos no }\end{array}$ & Desejável & Não \\
\hline
\end{tabular}




\begin{tabular}{|c|c|c|c|c|}
\hline & $\begin{array}{l}\text { Me posicionei acerca do } \\
\text { requisito A e também } \\
\text { acerca do requisito B. Mas } \\
\text { estão em telas separadas, o } \\
\text { detalhamento de A e de B }\end{array}$ & $\begin{array}{l}\text { requisito B quando estou } \\
\text { avaliando impactos de A. }\end{array}$ & & \\
\hline 14 & $\begin{array}{l}\text { Estender a proposta do } \\
\text { sistema para englobar } \\
\text { requisitos funcionais } \\
\text { também }\end{array}$ & $\begin{array}{l}\text { Pois serve para debate de } \\
\text { qualquer tipo de requisito }\end{array}$ & Descartável & Não \\
\hline 15 & $\begin{array}{l}\text { O Mural deveria } \\
\text { possibilitar a entrada de } \\
\langle<\text { enter }\rangle\end{array}$ & $\begin{array}{l}\text { Melhorar o uso para } \\
\text { redação dos comentários }\end{array}$ & Essencial & Sim \\
\hline 16 & $\begin{array}{l}\text { O mural deveria ter um } \\
\text { campo para indicar o } \\
\text { requisito que o comentário } \\
\text { se refere }\end{array}$ & Para futuras consultas & $\underset{21}{\text { Descartável }}$ & Não \\
\hline 17 & $\begin{array}{l}\text { A listagem inicial dos } \\
\text { requisitos poderia ter } 2 \\
\text { campos: } \\
\text { 1) mostrando a quantidade } \\
\text { de classificações feitas em } \\
\text { seu argumento sobre um } \\
\text { requisito e/ou sobre } \\
\text { correlações deste requisito; } \\
\text { 2) mostrando quantos, } \\
\text { dentre os argumentos feitos } \\
\text { em posicionamentos, de } \\
\text { outros participantes, } \\
\text { tiveram réplica ("Retorno } \\
\text { da Justificativa"). }\end{array}$ & $\begin{array}{l}\text { Penso que estes campos } \\
\text { auxiliarão ao participante } \\
\text { a interagir com os demais. }\end{array}$ & Desejável & Não \\
\hline
\end{tabular}

A tabela 13 lista sugestões de melhoria tanto para o processo, por exemplo os itens 1, 3 e 4; quanto para o suporte computacional, por exemplo, os itens 5, 6, 7 e 10. O processo funcionou na medida em que obteve sugestões de melhorias para o próprio processo. Se as sugestões de evolução também ocorreram para melhoria do apoio computacional, é mais um ponto positivo, já que sem apoio computacional o processo é menos eficiente. $\mathrm{O}$ suporte computacional não é essencial para o exercício do processo - como fora demonstrado na primeira atividade da avaliação realizada sem apoio computacional, porém o torna mais eficiente e promove facilidade de uso e adoção.

De um modo geral, o processo foi facilmente entendido pelos participantes, e visto como de suma importância para o mundo corporativo. Fato observado pela pesquisadora e posteriormente evidenciado através das respostas ao questionário

${ }^{21}$ Discussão de requisito específico deve ficar no Requisito. Fora isso, no mural existe possibilidade de busca por assunto. 
aplicado. Os relatórios das pontuações dos participantes também reforçam a participação intensa, e, engajamento é um indicio positivo.

A pontuação, conforme descrito na seção 4.6.2.3, mede os seguintes parâmetros: Abstenção, Participação, Pontualidade, Colaboração e Contribuição dos Argumentos. Na RNF Colab a Participação foi dividida em "Posicionamento" e "Argumentação". E a Colaboração foi dividida em "Convergência" e "Block/Firm". Isso foi feito para maior transparência e legibilidade dos dados. Lembrando que para o parâmetro "abstenção" a pontuação alta se dá quando o resultado é baixo. Lembrando que na tela de detalhamento do participante, pode-se consultar o racional dos resultados, assim como as fórmulas de cálculo de cada parâmetro.

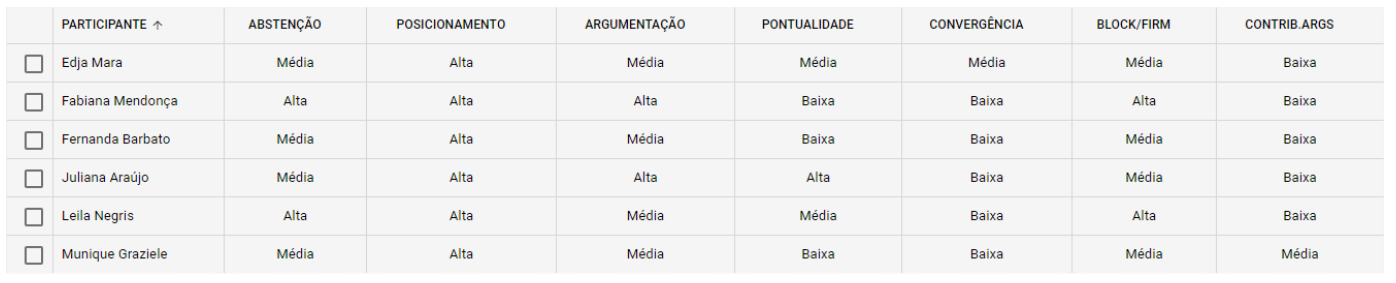

Figura 24. Resultado da Pontuação Participantes RNF Colab

Nota-se que a participação (posicionamento e argumentação) foi intensa, não havendo pontuação baixa para nenhum participante. A abstenção também foi pequena - e portanto a pontuação alta. Isso significa que além de o grupo se posicionar na maioria de requisitos e correlações, preencheram "abster-se" em poucos casos.

Outro resultado relevante, no quesito colaboração, é que pouco se notou a postura de colaboração negativa "firm" ou "block", que impedem o consenso. Não houve ocorrência de baixa pontuação. Em contra partida, foram poucas as alterações de posições para ir de encontro ao consenso. Este parâmetro deve ser analisado cuidadosamente. Pode ocorrer em determinadas situações que o grupo vote em sua maioria na mesma posição, fato este que automaticamente excluiu a mudança de voto para convergir. Existe também participantes que possuem, em algumas situações, o comportamento de "José vai com os outros", quer dizer, seguem a opinião da maioria, alterando seu posicionamento quando percebem que não é o voto da maioria. Tal postura pode significar convergência, porém não colabora para enriquecer o resultado. 
Metade dos participante se "atrasaram" para a atividade, isso é, obtiveram pontuação baixa no parâmetro pontualidade. Significa que iniciaram a atividade depois da metade do período pré-estabelecido de duração da mesma. Em um contexto organizacional esse fato poderia ser relevante, pois aponta para uma possível falta de comprometimento por parte da equipe. Porém, como o contexto é distinto, é de pesquisa acadêmica, e a atividade foi realizada pelos participantes em seus momentos de descanso, o parâmetro não revela tanto peso para uma análise de comportamento dos envolvidos.

No parâmetro de contribuição de argumentos tivemos a maior parte de pontuações como baixa ${ }^{22}$. Apesar do número de argumentos cadastrados ter sido alto, a classificação de argumentos foi pequena, ao todo apenas 37 dos 155 argumentos postados, foram classificados. A amostra foi reduzida talvez pelo fato de que o prazo da construção já finalizava quando as classificações começaram a ser efetuadas.

Contudo deve-se levar em conta, a faixa configurável dos parâmetros. Dependendo da "calibragem" dos intervalos de baixa, média e alta, o resultado é totalmente distinto. A análise de um parâmetro, assim como, até de todas as pontuações do participante, não formam um parecer completo do comportamento dos participantes. Para se estudar o comportamento dos envolvidos é preciso investigar em conjunto todos os dados coletados ao longo da dinâmica.

Vale informar que, como a atividade era de avaliação do processo e software, e não dos participantes em si, e, que a atividade foi realizada para uma pesquisa acadêmica; resolvemos "desligar" os avisos de pontualidade baixa. Para não "pressionar" as pessoas envolvidas na atividade, que afinal, já estavam trabalhando em seu horário de descanso e, sem nenhum outro interesse além do de aquisição de conhecimento e contribuição para a pesquisa acadêmica.

$\mathrm{Na}$ tabela 14 são apresentadas as quantidades totais coletadas no software relativas a atividade. Observa-se pela quantidade de argumentos que a participação foi intensa, também constatado no Relatório de Pontuação do Participante. E se

\footnotetext{
22 Lembrando que argumentos julgados "inconsistentes" não pontuam, isso é, valem zero. Para não intimidar a participação. Lembrando também que no caso do argumento receber mais de uma classificação, a classificação do argumento que prevalece é a da maioria (ou a de maior valor para estimular a argumentação).
} 
levarmos em consideração que o campo de argumento é opcional e nem todos os posicionamentos são acompanhados de argumentos e que os participantes não são obrigados a se posicionarem em todos os requisitos; a intensidade da participação ainda é melhor reconhecida. Os resultados quantitativos apresentados avaliam o processo proposto e sugerem indícios positivos.

Tabela 14. RNF Colab

\begin{tabular}{|l|c|}
\hline \multicolumn{1}{|c|}{ Itens } & Quantidade \\
\hline RFs & 14 iniciais +4 \\
\hline RNFs Construídos & 10 iniciais +9 \\
\hline RNFs Descartados & 4 \\
\hline Correlações & 77 \\
\hline Argumentos & 155 \\
\hline Dúvidas/Sugestões & 31 \\
\hline
\end{tabular}

Constatou-se com o caso 2 que a dinâmica do processo proposto assim como a sua estruturação, fazem sentido, pois fomentam o engajamento dos participantes, que ao enriquecerem as discussões, propiciam uma construção de RNFs mais aprimorada.

Sobre a avaliação do produto, isto é, a lista de RNFs resultante da execução do processo, constam no link: https://github.com/gbribeirol/RNFColab.git, os RNFs e interdependências construídos. Lembrando que as correlações apontadas incluem também correlações entre RF e RNFs. Esses produtos foram debatidos e construídos ao longo do processo, sendo assim pelos participantes também avaliados. Portanto, não apenas o processo foi apreciado. Os produtos por este processo produzidos, também o foram. O resultado desta avaliação é expressada especificamente nas respostas à pergunta 4 da segunda parte do questionário aplicado, detalhada mais adiante na seção 5.4.2.

Os dados relativos a execução do processo estão também disponibilizados no link: https://github.com/gbribeirol/RNFColab.git. Os relatórios de "Histórico das Discussões" e "Pontuação dos Participantes". Esses relatórios possuem todas as informações registradas durante a execução do estudo de caso, num total de 50 páginas. Vale ressaltar que os relatórios são mais comumente consultados pontualmente, a partir de visualizações na tela do dispositivo adotado, para 
pesquisa de informações especificas, sem a obrigatoriedade de impressão de todo o conteúdo.

\section{Caso 3 - TUP Virtual}

O Engenheiro de Requisitos criou 12 RNFs para discussão dos participantes. RNFs relacionados em sua maioria a Segurança da Informação. Para associação aos catálogos foi criado, no "Catálogo", um novo requisito de maior nível de abstração denominado "Segurança". Isso foi feito porque o tema de Segurança é tratado em um catálogo separado dos catálogos de Transparência, Consciência de Software e Confiança, anteriormente integrados e carregados no software RNF Colab para utilização na presente pesquisa. Os 12 RNFs sugeridos foram:

1) O Sistema deve possibilitar aumento de filesystem.

2) O Sistema deve possibilitar conectividade entre parceiro empresa e empresa.

3) O Sistema deve possibilitar a criptografia dos dados sensíveis.

4) O Sistema deve possibilitar mecanismos criptográficos para armazenamento das informações.

5) O Sistema deve possibilitar mecanismos criptográficos para trânsito das informações.

6) O Sistema deve garantir aderência aos critérios vigentes de legislação, regulatório e outros.

7) O Sistema deve possibilitar o expurgo de dados.

8) O Sistema deve possibilitar mecanismos de autenticação e autorização.

9) O Sistema deve ser garantir que as atividades realizadas nos sistemas relacionados ao projeto contarão com registro de auditoria.

10) O Sistema deve possibilitar mecanismos de validação de entrada de forma positiva e sanitização de todas as saídas de dados (de usuários e/ou interfaces com outros sistemas) quanto ao formato dos dados e valores/caracteres esperados. 
11) O Sistema deve garantir segurança no acesso aos dados trafegados.

12) O Sistema deve possibilitar mecanismos criptográficos para garantir o sigilo, integridade e confidencialidade no armazenamento e transmissão de informações.

Durante a dinâmica não foram observadas pela pesquisadora muitas divergências de pontos de vistas, e por consequência, ocorreu uma menor necessidade de negociações das posições. Em sua maioria as posições acerca dos RNFs convergiam com facilidade para a decisão da maioria. Todos os 12 RNFs criados foram construídos. Nenhum novo RNF foi construído. As 29 correlações foram aceitas incluindo neste número as associações com as qualidades do catálogo e correlações entre RF e RNFs. A construção do total de 41 itens (29 correlações + 12 requisitos) foi facilitada pelo fato do projeto ter um número pequeno de sistemas envolvidos e um escopo reduzido, com necessidades claras de serem elencadas. Outro fator de influência pode ter sido o fato de que os participantes são profissionais experientes na área de negócio do projeto. O Engenheiro de Requisitos também conhece o assunto do projeto e colocou para a discussão RNFs consistentes.

Ressaltamos que na execução do projeto dentro da organização, nenhum dos RNFs e suas correlações construídos durante a atividade de avaliação, foram elicitados em tempo de especificação. Mesmo os participantes da atividade não sendo os mesmos envolvidos na elicitação do projeto dentro da empresa, o projeto é exatamente o mesmo. Detalhe importante é que na organização não existe documentação de correlação entre requisitos. Existe documentação para associação entre requisitos e regras de negócio ${ }^{23}$ e a falta de um template padrão voltado para as interdependências, tende a afetar diretamente a atenção para esta questão dos envolvidos no projeto.

Sobre a pontuação dos participantes, observamos que todos os participantes receberam pontuação alta ou média em "posicionamento" e "argumentação" que

\footnotetext{
${ }^{23} \mathrm{Na}$ organização, a ferramenta de apoio para criação dos requisitos é um template em planilha Excel. O documento é postado num workflow para aprovação de todas as áreas envolvidas no projeto.
} 
compõem a parâmetro Participação. Complementando, verifica-se uma pontuação igualmente alta ou média para abstenção, que significa poucas posições preenchidas com "abster-se". Isso é, ocorreu preenchimento de mais de $91 \%$ dos requisitos e correlações, e desses preenchimentos, menos de $10 \%$ foram abstendo-se. Apenas 2 participantes receberam baixa pontuação no parâmetros "pontualidade", com dez dias de prazo, iniciaram a atividade no sexto dia. Esses 2 participantes seriam os únicos a receberem um e-mail de baixa pontuação no parâmetro pontualidade, pois passaram da metade do período destinado à construção. Mas como já mencionamos, os avisos foram "desligados" pelo contexto ser de pesquisa acadêmica.

No parâmetro "Colaboração", apenas um participante teve pontuação baixa em "block/firm"24. Nenhum cenário "block" ocorreu. Ocorreram 6 cenários de posição "firm", todos advindos de um único participante. A divergência se deu na prioridade dos requisitos, todos escolheram essencial e o participante se posicionou como desejável. Sob o aspecto de alterar a posição para convergir com a maioria, dois participantes obtiveram pontuação baixa. Não é surpresa um deles ser o mesmo participante da postura "firm". Nesse caso era importante haver um diálogo entre o Moderador e o participante, para entendimento das razões da postura do participante. Mas o Moderador (a pesquisadora no papel de Moderador) optou por não intervir. Esse é um exemplo de necessidade de uma cartilha ou guia do Moderador, conforme sugerido durante a avaliação. Assim a decisão de intervir ou não, estaria baseada em regras e não somente na escolha do Moderador. Embora, a liberdade deste perfil também seja uma vantagem. Se pensarmos que cada caso é um caso, e que não devemos "engessar" as ações do Moderador, pois perder a flexibilidade, implica em chance de perder decisões mais acertadas em determinados cenários.

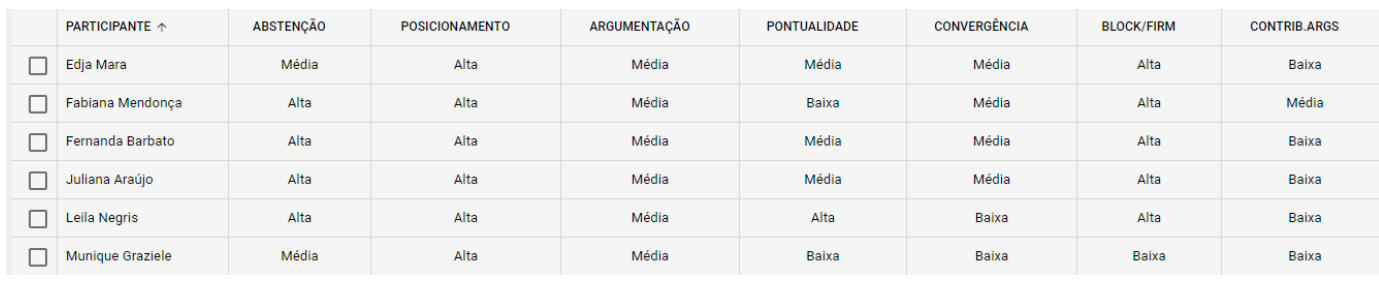

Figura 25. Resultado da Pontuação Participantes TUP Virtual

\footnotetext{
${ }^{24}$ Relembrando, se em algum requisito, todos votam em uma posição e o participante votou em outra posição impedindo o consenso, é atitude "firm". Se, se absteve nesta mesma situação, é atitude "block".
} 
As pontuações foram baixas no parâmetro "contribuição dos argumentos". Observou-se, mais uma vez, que os argumentos postados foram pouco classificados. Neste segundo projeto, 2 participantes não receberam classificação em seus argumentos. Uma calibragem no cálculo deste parâmetro foi detectada como sendo necessária. Casos como esse podem induzir uma análise equivocada de que os argumentos postados não contribuíram suficientemente para enriquecer o debate ao longo da dinâmica de Negociação-Colaboração. Porém o que ocorre é que os argumentos não obtiveram um volume de classificação significativa. $\mathrm{O}$ fato dos participantes terem convergido na maior parte dos requisitos, não ocorrendo portanto uma negociação intensa, possa justificar as poucas classificações. Ou o motivo tenha sido o mesmo do projeto anterior; a construção estava com seu prazo finalizando. Embora, os participantes tenham informado no questionário que o tempo para a atividade foi suficiente.

Voltando ao assunto do tal participante das posições "firm", observamos que ele recebeu pontuação baixa em 4 dos 7 quesitos. Seu comportamento se distingue do comportamento dos demais membros do grupo. Caso o Moderador tivesse atuado, durante a execução da atividade, interagido com o indivíduo, o resultado final poderia ter sido diferente. Se a atuação do moderador fosse de esclarecimento de questões de falha no entendimento por parte do participante, talvez o processo teria sido influenciado em direção ao consenso. Mas se a postura do participante possui viés pessoal? Ou foi um caso de falta de interesse, e não conhecimento, pelo assunto discutido? A função do moderador é, com base nas informações que são atualizadas ao longo da dinâmica, atuar junto aos membros do grupo em questões exemplificada por esse caso, visando uma dinâmica de participações efetivas, que enriqueçam as discussões. Não obstante, existem situações em que uma pessoa possui posições fundamentadas, mesmo estando do lado oposto de todos os outros membros do grupo. O papel do Moderador de mediação é crucial quando não se esclarecem impasses durante ciclo de discussões, ou, na investigação de posturas individuais destoantes do grupo. Além disso, existe a possibilidade de diminuir ou aumentar o número de participantes. $\mathrm{O}$ apoio computacional, através das informações dispostas, visa transparecer essas ocasiões, para a possibilidade de atuação do Moderador. 
O número de dúvidas e sugestões foi relativamente pequeno se comparado aos outros projetos. Mas há que se pensar que o escopo dos projetos e número de requisitos são distintos, sendo assim, a comparação é conceitualmente frágil. Fora isso, a avaliação ter sido feita após um "projeto treinamento" possivelmente influenciou. Na tabela 15 são apresentadas as quantidades totais coletadas no software relativas a atividade. Os dados quantitativos são resultados que avaliam o processo proposto.

Tabela 15. TUP Virtual

\begin{tabular}{|l|c|}
\hline \multicolumn{1}{|c|}{ Itens } & Quantidade \\
\hline RF & 4 \\
\hline RNFs Construídos & 12 iniciais \\
\hline Correlações & 29 \\
\hline Argumentos & 108 \\
\hline Dúvidas/Sugestões & 5 \\
\hline
\end{tabular}

Com este terceiro e último estudo de caso podemos observar fortes indícios que sugerem que o processo é adaptável à indústria, atendendo e suprindo as necessidades do contexto organizacional ao qual foi submetida através do projeto trabalhado. O prazo de quinze dias para construção dos requisitos, foi atendido em até em menos tempo.

\subsubsection{As Respostas ao Questionário}

O objetivo da aplicação do questionário foi coletar a opinião dos participantes sobre o processo proposto, após o uso do mesmo, em um escopo e tempo delimitado. O escopo abrangeu dois projetos - RNF Colab e TUP Virtual, e o tempo de 25 dias corridos. Quarenta requisitos criados pelo Engenheiro de Requisitos foram debatidos (24 do RNF Colab, e 16 do TUP Virtual). Dezessete novos requisitos foram sugeridos (apenas no projeto RNF Colab). O questionário foi aplicado para os participantes para ser respondido com base nesta "degustação" de quase um mês. É importante esclarecer mais uma vez que o foco da avaliação é avaliar o processo, porém observações sobre o produto - RNFs resultantes das construções, reveladas pelos participantes também foram coletadas e analisadas (página 119).

A pesquisadora consolidou as opiniões, explicitadas nas respostas ao questionário, dadas pelos 6 participantes. O questionário foi respondido 
individualmente, sem que um participante tomasse conhecimento das respostas de outro participante. A comunicação em caso de dúvidas, deveria ser através de contato direto e individual com a pesquisadora. Mesmo assim, observou-se que as respostas se assemelham bastante, fato este que aponta para uma comunhão de opiniões, reforçando-as mutuamente.

O questionário de perguntas abertas se divide em duas partes. Uma se destina a avaliação do uso do processo, isto é, do modo como a avaliação do processo foi feito, com o julgamento de ter sido, ou não, adequadas as variáveis; equipe, projeto, material de apoio e tempo. E a outra parte trata da coleta de opiniões sobre o processo e apoio computacional propriamente ditos. Tabulamos as respostas da primeira parte do questionário na Tabela 16 e da segunda parte nas Tabelas 17, 18 e 19.

Com relação a primeira parte do questionário sobre a avaliação do uso do processo (Tabela 16), no julgamento dos participantes foi unânime a adequação das variáveis equipe, projeto, material de apoio e tempo. Mesmo sobre o tempo, que foi limitado, as respostas foram no sentido de que foi suficiente para as tomadas de decisões em relação aos RNFs e suas interdependências.

Tabela 16. Sobre o Uso do Processo

\begin{tabular}{|c|c|c|c|}
\hline Escolha equipe & Escolha projeto & Material de apoio & Tempo disponível \\
\hline $\begin{array}{l}\text { "Tivemos } \\
\text { participantes de } \\
\text { diversas áreas de } \\
\text { atuação o que ajudou } \\
\text { a enriquecer as } \\
\text { discussões com a } \\
\text { experiência e o } \\
\text { conhecimento } \\
\text { distintos." }\end{array}$ & $\begin{array}{l}\text { "O projeto "TUP } \\
\text { Virtual para Novos } \\
\text { Distribuidores" tinha } \\
\text { necessidades } \\
\text { específicas e quase não } \\
\text { gerou divergência na } \\
\text { avaliação dos } \\
\text { Requisitos pelo time. } \\
\text { O projeto "RNF } \\
\text { Colab" tinha requisitos } \\
\text { mais complexos e teve } \\
\text { mais oportunidade de } \\
\text { conflitos." }\end{array}$ & $\begin{array}{l}\text { "Os vídeos foram } \\
\text { bem claros e a } \\
\text { própria troca de } \\
\text { experiências no } \\
\text { mural da aplicação } \\
\text { foi muito útil para } \\
\text { entendimento e } \\
\text { esclarecimento de } \\
\text { dúvidas." }\end{array}$ & $\begin{array}{l}\text { "Considero que o } \\
\text { tempo requerido foi } \\
\text { suficiente e a } \\
\text { possibilidade de } \\
\text { cada participante } \\
\text { definir seu próprio } \\
\text { ritmo e período para } \\
\text { participação foi } \\
\text { essencial e permitiu } \\
\text { unir pessoas } \\
\text { separadas } \\
\text { geograficamente e } \\
\text { com rotinas } \\
\text { diferentes." }\end{array}$ \\
\hline $\begin{array}{l}\text { "Os participantes } \\
\text { escolhidos têm } \\
\text { experiências bem } \\
\text { diversificadas dentro } \\
\text { do universo de TI. } \\
\text { Isso gerou } \\
\text { discussões bem }\end{array}$ & $\begin{array}{l}\text { "O projeto proposto, } \\
\text { "TUP Virtual para } \\
\text { Novos Distribuidores", } \\
\text { foi bem descrito e } \\
\text { adequado ao processo } \\
\text { proposto, permitindo } \\
\text { que todos pudessem se }\end{array}$ & $\begin{array}{l}\text { "O material de apoio } \\
\text { estava bem } \\
\text { detalhado e de fácil } \\
\text { consulta. Isso } \\
\text { permitiu que } \\
\text { qualquer dúvida } \\
\text { fosse facilmente }\end{array}$ & $\begin{array}{l}\text { "Conforme fui me } \\
\text { envolvendo com o } \\
\text { projeto e seus } \\
\text { requisitos a } \\
\text { dinâmica de } \\
\text { posicionamentos } \\
\text { e/ou críticas fluíram }\end{array}$ \\
\hline
\end{tabular}




\begin{tabular}{|c|c|c|c|}
\hline $\begin{array}{l}\text { produtivas e } \\
\text { abrangeu uma gama } \\
\text { de pontos de vista } \\
\text { amplo, permitindo } \\
\text { elaborar e produzir } \\
\text { requisitos mais } \\
\text { adequados às } \\
\text { necessidades do } \\
\text { projeto." }\end{array}$ & $\begin{array}{l}\text { envolver nos requisitos } \\
\text { e propusessem ideias e } \\
\text { discussões } \\
\text { consistentes." }\end{array}$ & sanada." & $\begin{array}{l}\text { naturalmente e o } \\
\text { tempo foi suficiente } \\
\text { para avaliar o que se } \\
\text { pretendia." }\end{array}$ \\
\hline $\begin{array}{l}\text { "Os usuários tinham } \\
\text { conhecimento dos } \\
\text { sistemas e expertise } \\
\text { para realizar as } \\
\text { avaliações dos } \\
\text { requisitos e as } \\
\text { colaborações foram } \\
\text { essenciais para } \\
\text { melhorar a qualidade } \\
\text { do projeto." }\end{array}$ & \begin{tabular}{|l|} 
"O projeto TUP \\
Virtual para Novos \\
Distribuidores foi bem \\
simples, com poucos \\
sistemas envolvidos. \\
Não houve muitas \\
divergências a respeito \\
das negociações."
\end{tabular} & $\begin{array}{l}\text { "O material } \\
\text { disponibilizado foi } \\
\text { fundamental para o } \\
\text { entendimento do } \\
\text { processo de to-do } \\
\text { dos usuários. O } \\
\text { entendimento da } \\
\text { usabilidade da } \\
\text { aplicação foi } \\
\text { simples e eficiente." }\end{array}$ & $\begin{array}{l}\text { "O tempo destinado } \\
\text { para realização das } \\
\text { atividades foi } \\
\text { adequado e } \\
\text { satisfatório." }\end{array}$ \\
\hline $\begin{array}{l}\text { "Os participantes } \\
\text { possuíam diferentes } \\
\text { graus de experiência } \\
\text { no que diz respeito a } \\
\text { atividade de análise } \\
\text { de requisitos, tanto } \\
\text { em termos de tempo } \\
\text { de contato com esse } \\
\text { tipo de atividade, } \\
\text { quanto pelo tipo de } \\
\text { atuação e enfoque } \\
\text { que deram nas } \\
\text { avaliações. Foi } \\
\text { possível perceber } \\
\text { que foi um grupo } \\
\text { multidisciplinar pela } \\
\text { diversidade dos } \\
\text { argumentos } \\
\text { descritos." }\end{array}$ & $\begin{array}{l}\text { "Permitiu que o grupo } \\
\text { se expressasse } \\
\text { sugerindo a inclusão } \\
\text { de requisitos tanto } \\
\text { funcionais, como não } \\
\text { funcionais, além de ter } \\
\text { coberto uma gama } \\
\text { bem variada dentre as } \\
\text { categorias de } \\
\text { requisitos não } \\
\text { funcionais." }\end{array}$ & $\begin{array}{l}\text { "O material, a } \\
\text { descrição inicial na } \\
\text { software quanto aos } \\
\text { conceitos que } \\
\text { norteiam a descrição } \\
\text { de requisitos, a } \\
\text { demonstração do } \\
\text { uso do software e a } \\
\text { interação através do } \\
\text { mural deram a base } \\
\text { pra que pudéssemos } \\
\text { usar o software sem } \\
\text { dificuldades." }\end{array}$ & $\begin{array}{l}\text { "O tempo foi } \\
\text { suficiente e percebi } \\
\text { que, dentro da } \\
\text { realidade de cada } \\
\text { um, alguns puderam } \\
\text { se posicionar sobre } \\
\text { os requisitos de uma } \\
\text { única vez. Eu optei } \\
\text { por separar um } \\
\text { tempo pra refletir } \\
\text { sobre alguns } \\
\text { requisitos e com } \\
\text { isso tive } \\
\text { oportunidade de ler } \\
\text { os argumentos dos } \\
\text { demais, mudar } \\
\text { algum } \\
\text { posicionamento ou } \\
\text { já ter a percepção se } \\
\text { havia consenso com } \\
\text { a minha opinião." }\end{array}$ \\
\hline \begin{tabular}{|l} 
"Foram envolvidos \\
profissionais com \\
muita experiência na \\
área de informática e \\
diferentes \\
backgrounds, \\
incluindo \\
experiência \\
internacional. Os \\
mesmos já \\
desempenharam \\
múltiplos papéis \\
dentro dos projetos
\end{tabular} & $\begin{array}{l}\text { "Foram escolhidos } 2 \\
\text { projetos para trazer ao } \\
\text { debate. Isto foi } \\
\text { extremamente } \\
\text { construtivo pois trouxe } \\
\text { aos participantes uma } \\
\text { visão mais abrangente } \\
\text { do processo proposto. } \\
\text { No primeiro projeto } \\
\text { houve mais } \\
\text { discordância entre os } \\
\text { participantes, o que } \\
\text { gerou maiores debates }\end{array}$ & $\begin{array}{l}\text { "O material de apoio } \\
\text { foi ótimo para que } \\
\text { os participantes } \\
\text { tivessem confiança } \\
\text { sobre como utilizar } \\
\text { o software para } \\
\text { expor suas } \\
\text { avaliações sobre os } \\
\text { requisitos } \\
\text { mapeados." }\end{array}$ & $\begin{array}{l}\text { "O tempo pareceu } \\
\text { bem razoável para o } \\
\text { trabalho de análise } \\
\text { dos requisitos. Estes } \\
\text { passos são } \\
\text { importantes para } \\
\text { uma definição } \\
\text { apropriada do } \\
\text { projeto. Uma vez } \\
\text { que os envolvidos } \\
\text { na análise de cada } \\
\text { projeto percebem o } \\
\text { andamento das }\end{array}$ \\
\hline
\end{tabular}




\begin{tabular}{|c|c|c|c|}
\hline $\begin{array}{l}\text { em que se } \\
\text { envolveram ao longo } \\
\text { das suas carreiras; } \\
\text { com visão de como } \\
\text { empresas dentro e } \\
\text { fora do Brasil tratam } \\
\text { os requisitos não } \\
\text { funcionais em } \\
\text { projetos de pequeno, } \\
\text { médio e grande } \\
\text { porte." }\end{array}$ & \begin{tabular}{|l} 
e maior \\
engrandecimento para \\
o projeto: vários \\
novos requisitos \\
funcionais e não \\
funcionais foram \\
levantados. Já no \\
segundo projeto os \\
votos convergiram \\
mais; mas ainda assim \\
houve o estímulo ao \\
alinhamento entre os \\
participantes, que \\
puderam mudar seu \\
ponto de vista ao \\
analisar o \\
posicionamento dos \\
demais participantes."
\end{tabular} & & $\begin{array}{l}\text { discussões e a } \\
\text { importância dos } \\
\text { seus votos nas } \\
\text { decisões sobre a } \\
\text { implantação dos } \\
\text { requisitos } \\
\text { mapeados, este } \\
\text { trabalho passa a ser } \\
\text { ainda mais } \\
\text { interessante e } \\
\text { cativante." }\end{array}$ \\
\hline $\begin{array}{l}\text { "Todos os } \\
\text { participantes tem o } \\
\text { conhecimento na } \\
\text { área e atuam no } \\
\text { mercado de trabalho } \\
\text { com projetos de TI. } \\
\text { Então a equipe } \\
\text { escolhida tem todo o } \\
\text { conhecimento } \\
\text { necessário para } \\
\text { contribuir no } \\
\text { projeto." }\end{array}$ & $\begin{array}{l}\text { "Os participantes } \\
\text { tinham o } \\
\text { conhecimento na área } \\
\text { de negócio do projeto } \\
\text { escolhido." }\end{array}$ & $\begin{array}{l}\text { "O software é muito } \\
\text { intuitivo e o } \\
\text { treinamento foi bem } \\
\text { mais rápido para o } \\
\text { entendimento geral. } \\
\text { O Material de apoio } \\
\text { como os filmes são } \\
\text { totalmente } \\
\text { dispensáveis pois o } \\
\text { software é de uso } \\
\text { bem fácil." }\end{array}$ & $\begin{array}{l}\text { "Como o software é } \\
\text { muito intuitiva e o } \\
\text { seu uso é de extrema } \\
\text { necessidade e o } \\
\text { assunto faz parte do } \\
\text { cotidiano dos } \\
\text { participantes, o } \\
\text { tempo requerido } \\
\text { para utilização do } \\
\text { processo foi bem } \\
\text { proveitoso e } \\
\text { rápido." }\end{array}$ \\
\hline
\end{tabular}

A percepção sobre as vantagens e desvantagens dos participantes (Tabela 17) se aproximou mais para o acolhimento do processo do que para sua rejeição. Embora dois pontos de atenção tenham sido declarados - o risco de maior gasto de tempo e a expressividade da comunicação escrita em comparação a comunicação falada e presencial, pontos estes que detalharemos mais adiante no texto; a maioria das respostas valorizaram as vantagens advindas do uso do processo. Por exemplo, foram enaltecidas as vantagens de rastreabilidade das discussões e facilidade de recuperação das informações; visão ampla de todas as interdependências entre os requisitos e seus possíveis impactos no projeto; posturas mais profissionais e menos emotivas são estimuladas; e, o compartilhamento dos posicionamentos de todos os participantes possibilita a melhor argumentação de cada ponto de vista e muitas vezes a mudança consciente de opinião.

Tabela 17. Sobre o Processo Proposto 


\begin{tabular}{|c|c|}
\hline $\begin{array}{l}\text { "Os benefícios do processo proposto é o } \\
\text { compartilhamento de ideias, discussões } \\
\text { e uma estrutura para resolução de } \\
\text { conflitos. Contribui também para que } \\
\text { uma parte importante do projeto não } \\
\text { seja esquecida ou despriorizada. As } \\
\text { informações sobre as RNFs estarão } \\
\text { disponíveis de forma estruturada e } \\
\text { confiável. A comunicação e colaboração } \\
\text { entre as partes será otimizada e } \\
\text { incentivada pelo uso do software." }\end{array}$ & $\begin{array}{l}\text { "Risco de alto consumo de tempo, até que haja } \\
\text { convergência entre as opiniões, e os requisitos } \\
\text { serem inviabilizados depois, por fatores como } \\
\text { custo total do projeto." }\end{array}$ \\
\hline $\begin{array}{l}\text { "Ter as opiniões documentadas no } \\
\text { software induz um comportamento } \\
\text { mais assertivo e mais polido mesmo } \\
\text { durante os conflitos." }\end{array}$ & $\begin{array}{l}\text { "Em reuniões presenciais ou por chamadas de } \\
\text { áudio/vídeo, nas quais a voz está presente e a } \\
\text { emoção de quem critica negativamente ou } \\
\text { exalta positivamente um ponto de vista } \\
\text { (inclusive o seu próprio) tem um impacto de } \\
\text { influência mais intenso do que um texto } \\
\text { escrito. " }\end{array}$ \\
\hline $\begin{array}{l}\text { "Colaborar de forma remota sem a } \\
\text { necessidade de fazer reuniões } \\
\text { presenciais." }\end{array}$ & $\begin{array}{l}\text { "Dependência da maturidade profissional das } \\
\text { pessoas para se obter um bom uso do } \\
\text { processo. Os usuários devem lidar com } \\
\text { opiniões diversas e até mesmo contrárias às } \\
\text { suas, sendo o debate através de argumentos } \\
\text { registrados." }\end{array}$ \\
\hline $\begin{array}{l}\text { "Facilidade de se obter uma visão das } \\
\text { correlações entre os requisitos, suas } \\
\text { classificações, no desenrolar da } \\
\text { discussão estabelecendo um consenso } \\
\text { em torno do requisito. A discussão } \\
\text { sobre os impactos dos requisitos entre } \\
\text { si que em geral fica esquecida." }\end{array}$ & $\begin{array}{l}\text { "Muitas vezes é mais fácil de explicar e/ou } \\
\text { entender algo falado do que escrito. " }\end{array}$ \\
\hline $\begin{array}{l}\text { "Poder verificar as colaborações dada } \\
\text { por outros participantes de forma } \\
\text { organizada com argumentos e contra } \\
\text { argumentos. A transparência e } \\
\text { acessibilidade para todos os } \\
\text { participantes ao conjunto de requisitos } \\
\text { previstos, e a possibilidade de ter } \\
\text { contato com o posicionamento dos } \\
\text { demais participantes, o que pode levar } \\
\text { as pessoas a abrirem novas perspectivas } \\
\text { sobre suas próprias opiniões, à medida } \\
\text { que passam a ter contato com a } \\
\text { diversidade de argumentos registrados. } \\
\text { Isso enriquece bastante a discussão } \\
\text { sobre o que deve ser contemplado, ou } \\
\text { não, em um projeto. " }\end{array}$ & \\
\hline $\begin{array}{l}\text { "Ter posicionamentos e argumentos } \\
\text { registrados textualmente. A opinião } \\
\text { escrita é lida com mais neutralidade, } \\
\text { posturas mais profissionais e menos } \\
\text { "emocionais" são estimuladas." }\end{array}$ & \\
\hline $\begin{array}{l}\text { "Ter as discussões organizadas, facilita } \\
\text { o acesso a todas as informações. Melhor } \\
\text { do que a troca por e-mails ou em atas de }\end{array}$ & \\
\hline
\end{tabular}




\begin{tabular}{|c|c|}
\hline $\begin{array}{l}\text { reuniões, onde muitas vezes } \\
\text { informações importantes podem ser } \\
\text { perdidas. " }\end{array}$ & \\
\hline $\begin{array}{l}\text { "O fato de ter que revisar algum } \\
\text { argumento comentado pelo restante do } \\
\text { time também foi interessante para nos } \\
\text { dar a opção de amadurecer nosso } \\
\text { posicionamento e argumentos." }\end{array}$ & \\
\hline
\end{tabular}

A percepção sobre mecanismos de colaboração, negociação e foco nas interdependências entre requisitos (Tabela 18) também foi apurada na segunda parte do questionário. As respostas dos participantes são positivas ao processo em sua maioria, e indicam que os mecanismos propostos foram percebidos pelo grupo e utilizados de maneira adequada durante a dinâmica.

Tabela 18. Opinião dos Participantes acerca dos mecanismos de apoio

\begin{tabular}{|c|c|c|}
\hline Apoio a Negociação & Apoio a Colaboração & $\begin{array}{l}\text { Tratamentos das } \\
\text { Interdependências }\end{array}$ \\
\hline $\begin{array}{l}\text { "Poder questionar ou } \\
\text { responder as classificações } \\
\text { aos meus argumentos me } \\
\text { permitiu defender meu } \\
\text { entendimento e muitas } \\
\text { vezes me fez mudar de } \\
\text { opinião." }\end{array}$ & $\begin{array}{l}\text { "A etapa de classificar os } \\
\text { argumentos dos demais } \\
\text { participantes e ter seus } \\
\text { argumentos classificados } \\
\text { estimulou a discussão e } \\
\text { favoreceu a colaboração } \\
\text { entre os participantes." }\end{array}$ & $\begin{array}{l}\text { "O software permite a } \\
\text { correlação entre os } \\
\text { requisitos de forma fácil e } \\
\text { permite a classificação } \\
\text { sobre esta relação } \\
\text { aumentando a assertividade } \\
\text { e reforçando ou anulando } \\
\text { as interdependências." }\end{array}$ \\
\hline $\begin{array}{l}\text { "Durante os } \\
\text { posicionamentos sobre um } \\
\text { dado requisito foi possível } \\
\text { comentar os } \\
\text { posicionamentos dos outros } \\
\text { participantes. E em } \\
\text { algumas situações o } \\
\text { comentário suscitou } \\
\text { mudanças de } \\
\text { posicionamentos ou } \\
\text { esclareceu o entendimento } \\
\text { de pontos de vista que o } \\
\text { participante não tinha } \\
\text { atentado. E vice-versa. } \\
\text { Esta situação foi } \\
\text { particularmente mais } \\
\text { enriquecedora nos pontos } \\
\text { onde os posicionamentos } \\
\text { estavam em extremos } \\
\text { opostos, por exemplo. E a } \\
\text { discussão permitiu uma } \\
\text { análise mais aprofundada }\end{array}$ & $\begin{array}{l}\text { "Alguns requisitos nos } \\
\text { quais não tinha muito a } \\
\text { acrescentar foi possível ter } \\
\text { uma oportunidade de } \\
\text { aprendizado sobre o } \\
\text { requisito e sobre processos } \\
\text { que ele atendia, mediante a } \\
\text { leitura e visualização dos } \\
\text { tópicos que os demais } \\
\text { participantes abordaram. } \\
\text { Entendo que, não somente } \\
\text { para registrar requisitos } \\
\text { importantes para o projeto, } \\
\text { também há espaço para que } \\
\text { haja disseminação de } \\
\text { conhecimento através do } \\
\text { uso desse processo. O } \\
\text { histórico de projetos e seus } \\
\text { requisitos poderão } \\
\text { apresentar informações } \\
\text { valiosas para uma tomada } \\
\text { de decisão em projetos }\end{array}$ & $\begin{array}{l}\text { "Entendo que a visibilidade } \\
\text { das inter-relações e } \\
\text { interdependências dos } \\
\text { requisitos ajuda bastante no } \\
\text { seu entendimento mais } \\
\text { amplo. Em minhas } \\
\text { experiências anteriores, } \\
\text { percebi que ficava muito } \\
\text { difícil ter uma visão ampla } \\
\text { de todas as } \\
\text { interdependências e seus } \\
\text { possíveis impactos no } \\
\text { projeto. E com isso muitos } \\
\text { RNFs deixavam de ser } \\
\text { relacionados pela falta de } \\
\text { visão dos demais requisitos } \\
\text { com os quais ele se } \\
\text { relacionava também. Outra } \\
\text { experiência que vejo é que } \\
\text { muitos RNFs eram } \\
\text { identificados e relacionados } \\
\text { quando o projeto já estava }\end{array}$ \\
\hline
\end{tabular}




\begin{tabular}{|c|c|c|}
\hline $\begin{array}{l}\text { sobre o tópico tanto para } \\
\text { confirmar um } \\
\text { posicionamento ou } \\
\text { reconhecer e mudar de } \\
\text { posição sobre um aspecto } \\
\text { do requisito." }\end{array}$ & $\begin{array}{l}\text { futuros, bem como para o } \\
\text { bom entendimento do } \\
\text { funcionamento de um } \\
\text { projeto e como seus } \\
\text { requisitos se inter- } \\
\text { relacionam." }\end{array}$ & $\begin{array}{l}\text { em etapas avançadas de } \\
\text { construção ou de testes } \\
\text { integrados, nos quais os } \\
\text { detalhes das } \\
\text { interdependências surgem e } \\
\text { geram muito impacto } \\
\text { quando não estão mapeadas } \\
\text { e previstas no projeto } \\
\text { inicialmente. Portanto, vejo } \\
\text { que o uso do processo } \\
\text { impacta diretamente na } \\
\text { construção dos RNFs, pois } \\
\text { permitirá a todos uma visão } \\
\text { mais ampla e organizada, } \\
\text { permitindo uma análise e } \\
\text { construção mais completa } \\
\text { dos requisitos necessários } \\
\text { ao projeto." }\end{array}$ \\
\hline $\begin{array}{l}\text { "O software possibilita que } \\
\text { o usuário veja o parecer dos } \\
\text { demais colaboradores. } \\
\text { Sendo assim, os conflitos } \\
\text { puderam ser percebidos e } \\
\text { negociados. Foi } \\
\text { interessante ter visibilidade } \\
\text { dos posicionamentos dos } \\
\text { demais e poder mudar de } \\
\text { opinião. " }\end{array}$ & $\begin{array}{l}\text { "O software permite uma } \\
\text { importante interação entre } \\
\text { os usuários. Sendo assim, } \\
\text { os conflitos são facilmente } \\
\text { identificados e a busca da } \\
\text { solução se torna mais } \\
\text { interativa e eficiente." }\end{array}$ & $\begin{array}{l}\text { "As interdependências } \\
\text { possibilitam uma visão } \\
\text { geral do projeto. As partes } \\
\text { envolvidas terão } \\
\text { conhecimento dos impactos } \\
\text { dos requisitos em outras } \\
\text { áreas. Essa contribuição } \\
\text { que o processo traz soma } \\
\text { benefícios para as empresas } \\
\text { e para o sucesso dos } \\
\text { projetos. Minha experiência } \\
\text { em projetos de software } \\
\text { prova o quanto essa } \\
\text { comunicação e } \\
\text { interdependência é } \\
\text { importante. Muitas vezes } \\
\text { apenas em fase de testes } \\
\text { que os problemas surgem } \\
\text { por falta de definições no } \\
\text { início de especificação do } \\
\text { projeto." }\end{array}$ \\
\hline $\begin{array}{l}\text { "A possibilidade de ler os } \\
\text { argumentos usados pelos } \\
\text { outros participantes, em } \\
\text { seus posicionamentos, e } \\
\text { classificá-los, contribuiu } \\
\text { muito para a negociação. } \\
\text { Me levou a tentar } \\
\text { influenciar o ponto de vista } \\
\text { de outro participante, como } \\
\text { também, ao ler os } \\
\text { argumentos, cheguei a } \\
\text { mudar e reavaliar } \\
\text { posicionamentos que eu } \\
\text { tinha feito. " }\end{array}$ & $\begin{array}{l}\text { "Pra mim, a colaboração foi } \\
\text { mais presente através do } \\
\text { mural, em que pudemos } \\
\text { esclarecer o entendimento } \\
\text { de alguns requisitos e } \\
\text { sugerir novos ou a revisão } \\
\text { de alguns. O legal do mural } \\
\text { é que é um local único e } \\
\text { exclusivo para sugestões e } \\
\text { duvidas, então seria muito } \\
\text { interessante que as } \\
\text { empresas que utilizarem } \\
\text { futuramente o processo } \\
\text { mantenham o objetivo do }\end{array}$ & $\begin{array}{l}\text { "A forma como o processo } \\
\text { exibe as interdependências, } \\
\text { permitindo ao participante } \\
\text { visualizar os requisitos } \\
\text { correlatos, simplifica } \\
\text { consideravelmente todo o } \\
\text { emaranhado de correlações } \\
\text { que requisitos podem ter } \\
\text { entre si." }\end{array}$ \\
\hline
\end{tabular}




\begin{tabular}{|l|l|l|}
\hline & $\begin{array}{l}\text { mural focado em assuntos } \\
\text { pertinentes apenas aos } \\
\text { requisitos do projeto sendo } \\
\text { avaliado." }\end{array}$ & \\
\hline $\begin{array}{l}\text { "Foi possível notar o } \\
\text { aspecto da argumentação, } \\
\text { onde todos os participantes } \\
\text { do projeto puderam expor } \\
\text { de forma clara e detalhada } \\
\text { suas opiniões sobre cada } \\
\text { um dos requisitos } \\
\text { levantados." }\end{array}$ & $\begin{array}{l}\text { "Todos os participantes do } \\
\text { projeto puderam avaliar } \\
\text { também as opiniões } \\
\text { fornecidas por outros } \\
\text { participantes com os quais } \\
\text { concordavam ou não; desta } \\
\text { forma, foi possível um } \\
\text { maior alinhamento de } \\
\text { opiniões entre os } \\
\text { participantes." }\end{array}$ & $\begin{array}{l}\text { "O trabalho colaborativo } \\
\text { engrandece o levantamento } \\
\text { e priorização de requisitos. } \\
\text { Oacilitou também a a } \\
\text { correlação entre requisitos } \\
\text { funcionais e não funcionais. } \\
\text { Isto é altamente produtivo } \\
\text { para a equipe envolvida no } \\
\text { projeto." }\end{array}$ \\
\hline $\begin{array}{l}\text { "Achei muito bom e de } \\
\text { grande valia a parte de } \\
\text { negociação do uso deste } \\
\text { processo." }\end{array}$ & $\begin{array}{l}\text { "Achei bom, pois podemos } \\
\text { verificar as colaborações } \\
\text { dada por outros } \\
\text { participantes e discutir } \\
\text { pontos de vista da } \\
\text { colaboração dada." }\end{array}$ & $\begin{array}{l}\text { "Com o processo, o assunto } \\
\text { não fica negligenciado e se } \\
\text { mantém uma base de dados } \\
\text { viva para futuras } \\
\text { discussões." }\end{array}$ \\
\hline
\end{tabular}

A Tabela 19 apresenta as opiniões sobre a recomendação da adoção do processo nas empresas onde os participantes trabalham e o papel do software como suporte ao processo de construção de RNFs. Foi unânime e positiva a resposta para a recomendação da implantação do processo nas empresas onde os participantes trabalham. Cabe mencionar que os profissionais possuem aproximadamente vinte anos de experiência em TI. O entendimento do software também aderiu ao objetivo proposto na pesquisa, que era de permitir a construção de forma colaborativa de requisitos de maneira facilitada, além de remota e assíncrona.

Tabela 19. Sobre a adoção do Processo (com o RNF Colab)

\begin{tabular}{|l|l|}
\hline \multicolumn{1}{|c|}{ Recomendaria o processo proposto? } & \multicolumn{1}{c|}{ E qual o papel do software? } \\
\hline "Sim, achei o processo muito interessante. & "O software que permite a construção de \\
Promoveu a identificação e refinamento de & forma colaborativa de requisitos, mantendo \\
requisitos de forma colaborativa. Acredito & um histórico organizado das discussões e \\
que este processo seria bastante útil para & permitindo a criação de um catálogo de \\
definição e reaproveitamento de & $\begin{array}{l}\text { requisitos que podem ser reutilizados. Com } \\
\text { requisitos." }\end{array}$ \\
base nas discussões os requisitos podem \\
ser construídos ou descartados. O software \\
possui uma estrutura que permite a \\
avaliação da participação dos envolvidos e \\
estimula a colaboração."
\end{tabular}




\begin{tabular}{|c|c|}
\hline $\begin{array}{l}\text { "Sim. Porque avalio que a implantação do } \\
\text { processo poderá contribuir positivamente } \\
\text { para realização de análise de requisitos } \\
\text { mais consistentes e consequentemente } \\
\text { gerar projetos bem definidos e que } \\
\text { agreguem conhecimento para os } \\
\text { participantes e naturalmente para a } \\
\text { organização." }\end{array}$ & $\begin{array}{l}\text { "O software tem um papel importante, pois } \\
\text { proporciona a oportunidade de trazer a } \\
\text { elaboração dos RNFs de forma mais } \\
\text { colaborativa para que todos os envolvidos } \\
\text { no projeto possam visualizá-los no início } \\
\text { do projeto. Além de permitir que as } \\
\text { informações discutidas sejam armazenadas } \\
\text { e sirvam como histórico para projetos no } \\
\text { futuro. Por exemplo, identificar o RNFs } \\
\text { que esteja relacionado a alguma troca de } \\
\text { informações entre sistemas críticos e poder } \\
\text { destrinchá-los e para dá-los a devida } \\
\text { importância às necessidades mais técnicas } \\
\text { de cada lado, trará um ganho de tempo e } \\
\text { de produtividade no desenvolvimento. } \\
\text { Proporcionando construir uma } \\
\text { comunicação que poderá ser elaborada de } \\
\text { forma consistente porque já será pensada } \\
\text { desde o início do projeto com o apoio de } \\
\text { todos os envolvidos. Consequentemente, } \\
\text { os testes integrados tenderão a ocorrer com } \\
\text { menos surpresas tendo resultados mais } \\
\text { satisfatórios." }\end{array}$ \\
\hline $\begin{array}{l}\text { "Sim. Existindo um processo bem definido } \\
\text { para construção de requisitos, o software } \\
\text { contribui para a qualidade dos sistemas e } \\
\text { entrega dos projetos, evitando prejuízos } \\
\text { financeiros que não foram estimados por } \\
\text { falta de levantamento e execução." }\end{array}$ & $\begin{array}{l}\text { "O software visa apoiar as negociações e } \\
\text { colaborações em torno dos requisitos de } \\
\text { um projeto. As informações cadastradas } \\
\text { servirão de apoio para consultas, a } \\
\text { reutilização de informações em outros } \\
\text { projetos, rastreio de negociações } \\
\text { realizadas, negociações e redução de } \\
\text { conflitos, resultando em projetos bem } \\
\text { sucedidos e de qualidade." }\end{array}$ \\
\hline $\begin{array}{l}\text { "Sim, por conta dos ganhos que podem ser } \\
\text { obtidos a partir da colaboração que o } \\
\text { processo promove e também por conta da } \\
\text { forma como a negociação ocorre, pois o } \\
\text { processo permite uma discussão aberta, em } \\
\text { que todos os envolvidos podem se } \\
\text { expressar, e ao mesmo tempo, permite se } \\
\text { ter o registro da negociação, o que vejo } \\
\text { como um ponto muito positivo. }\end{array}$ & $\begin{array}{l}\text { "Vejo o RNF Colab como um software que } \\
\text { pode ser amplamente usada pelas empresas } \\
\text { em seus departamentos de TI, } \\
\text { principalmente porque a colaboração que } \\
\text { vimos no âmbito mais pontual do } \\
\text { experimento pode se estender para todos } \\
\text { os projetos, envolvendo as diversas } \\
\text { equipes de TI. Além de criar a cultura de } \\
\text { colaboração, estimula uma postura mais } \\
\text { participativa e positiva dos participantes }\end{array}$ \\
\hline
\end{tabular}




\begin{tabular}{|c|c|}
\hline $\begin{array}{l}\text { Também recomendaria pela possibilidade } \\
\text { da interação remota, da construção de } \\
\text { benchmark de requisitos, mas } \\
\text { principalmente pelo dinamismo com que o } \\
\text { processo possibilita que a avaliação de } \\
\text { requisitos seja feita, não sendo necessárias } \\
\text { reuniões cansativas e extensas, que afetam } \\
\text { a produtividade, tanto em termos de } \\
\text { tempo, quanto no consumo de energia } \\
\text { emocional das pessoas. A possibilidade da } \\
\text { própria pessoa se organizar e planejar o } \\
\text { momento em que irá se dedicar à avaliação } \\
\text { dos requisitos é um diferencial muito } \\
\text { vantajoso." }\end{array}$ & $\begin{array}{l}\text { durante a análise de requisitos dos } \\
\text { projetos. Num âmbito mais concreto, é um } \\
\text { software que permitirá se ter um } \\
\text { mapeamento vasto de requisitos, com } \\
\text { possibilidades positivas de uso na } \\
\text { preservação e compartilhamento do } \\
\text { conhecimento. Assim como também } \\
\text { permitirá aos seus usuários trabalharem } \\
\text { numa dinâmica de negociação baseada em } \\
\text { posicionamentos, argumentos e } \\
\text { classificações, o que a meu ver traz } \\
\text { simplicidade, praticidade e clareza para o } \\
\text { processo de avaliação de requisitos." }\end{array}$ \\
\hline $\begin{array}{l}\text { "Recomendaria sim. As decisões } \\
\text { atualmente sobre a implementação ou não } \\
\text { de um requisito não ficam devidamente } \\
\text { documentadas e nem sempre todos os } \\
\text { stakeholders necessários são envolvidos. O } \\
\text { processo proposto explicita todos os } \\
\text { argumentos/posicionamentos destes } \\
\text { stakeholders e possibilita a manutenção de } \\
\text { um histórico único sobre estas decisões, } \\
\text { além de permitir uma interação assíncrona } \\
\text { entre os envolvidos no projeto o que } \\
\text { facilita o trabalho principalmente em } \\
\text { projetos de médio ou grande porte. " }\end{array}$ & $\begin{array}{l}\text { "O software é de grande valia no processo } \\
\text { de avaliação dos requisitos, pois ela } \\
\text { provem um espaço neutro para a } \\
\text { colaboração de cada um dos participantes } \\
\text { do projeto. Através do software foi } \\
\text { possível que cada participante pudesse se } \\
\text { posicionar de forma clara e detalhada a } \\
\text { respeito de cada um dos requisitos. } \\
\text { O software permitiu que cada participante } \\
\text { gerenciasse seu tempo de trabalho } \\
\text { possibilitando o posicionamento sobre } \\
\text { cada requisito de forma assíncrona. Isto } \\
\text { possibilita uma dinâmica que respeita } \\
\text { limitações de tempo ou até diferenças de } \\
\text { fuso-horário de trabalho dentre todos os } \\
\text { envolvidos. Cada um dos participantes } \\
\text { teve o tempo que julgou necessário para } \\
\text { entrar com suas considerações, sem } \\
\text { interrupções por parte de outros membros } \\
\text { do projeto. } \\
\text { Através do software também foi possível } \\
\text { propor novos requisitos e acompanhar o } \\
\text { trabalho dos demais participantes, o que } \\
\text { tornou a avaliação de requisitos um } \\
\text { trabalho interativo e interessante." }\end{array}$ \\
\hline $\begin{array}{l}\text { "Claro. Se estivesse este processo na } \\
\text { minha empresa não teríamos tantos RNF } \\
\text { negligenciados nos projetos." }\end{array}$ & $\begin{array}{l}\text { "Como uma base viva de RNF da } \\
\text { companhia e para requisitos Funcionais } \\
\text { com a correlações entre eles." }\end{array}$ \\
\hline
\end{tabular}


As respostas sobre o uso do processo proposto e seu efeito com relação a negligência aos RNFs também foram positivas ao processo proposto. Selecionamos três delas:

- $\quad$ "A questão é que os requisitos não funcionais são tão importantes quanto os requisitos funcionais ou até mesmo as regras de negócio. Infelizmente é muito difícil encontrar alguma empresa que leve isso a sério, e por esse motivo, muitos projetos de software fracassam. Um processo que preza pela importância dos RNFs dentro do processo de construção de software contribuirá positivamente para que as partes envolvidas dêem a devida atenção aos RNFs."

- $\quad$ "Entendo que o processo evita a negligência, pois além de fornecer uma biblioteca padrão de tipos de RNFs, quando uma empresa utilizar o processo, ao longo do tempo, terá um benchmark dos requisitos contemplados em projetos anteriores. Além de ser um repositório crescente é excelente para as empresas terem visibilidade do que possui implementado em seus sistemas e do que pode ser reutilizado em novos projetos."

- $\quad$ O uso do processo proposto fomenta a discussão sobre os RNF. Isto a longo prazo altera o mindset de uma empresa, de forma que os RNF passam a ser levados em consideração em conjunto com os requisitos funcionais."

Como já mencionamos, além das perguntas unicamente focadas no processo utilizado, a impressão sobre o produto produzido, isto é, sobre a qualidade da lista de RNFs produzida, também foi indagada: "De que maneira o uso do processo influenciou no resultado da lista de RNFs construída? Por quê?". Seguem as respostas consolidadas:

- A lista de RNFs construída levou em consideração as opiniões e argumentos inseridos por todos. Trazendo confiança para o processo e também a visão de que os posicionamentos feitos pelos participantes foram considerados em sua integridade, sem manipulações.

- A dinâmica das discussões ajudou a identificar outros RFNs que não tinham sido inicialmente previstos. O envolvimento de indivíduos de diferentes 
frentes da organização é um diferencial importante para que o resultado seja mais rico. E também que proporcione uma visão mais completa e abrangente sobre o requisito criado para atender ao projeto.

- A influência do resultado também ocorreu por conta da dinâmica de negociação. Como os argumentos de todos ficam visíveis a todos, assim como são classificados por todos, os participantes podem ter trocado de posicionamento ao perceber o nível de importância de um requisito, a partir do argumento ou posicionamento colocado por outro participante. A possibilidade, de uma visibilidade transparente, contribui de forma benéfica para o resultado final da lista de RNFs construída.

- Através da colaboração de todos os participantes do projeto, muitos requisitos novos foram incluídos no projeto e outros foram melhor detalhados. Ao mesmo tempo que o projeto foi simplificado uma vez que requisitos inicialmente listados como essenciais foram ao final alterados para apenas desejáveis após observados os argumentos de outros participantes.

Constatou-se que foram percebidos os mecanismos de negociação e colaboração desenhados no processo, assim como o tratamento dos impactos entre os requisitos. O processo e software foram bem aceitos pelos participantes que em sua maioria elencaram pontos positivos em relação as mesmas. No entanto, dois aspectos de preocupação foram apontados: tempo e expressividade.

A estruturação do processo de discussão com a integração de um modelo de argumentação, e mecanismos de incentivo a colaboração, tem por objetivo ao mesmo tempo enriquecer, e, agilizar as discussões, otimizando o tempo de processo e a qualidade do produto. Embora, a respeito do tempo despendido nas discussões, o processo conta também com a atuação do Moderador. É de responsabilidade do mediador controlar o tempo e se for o caso, convocar uma nova construção para os requisitos "em negociação". Não obstante existe um controle automático de tempo, traduzido nos avisos automáticos disparados pelo software, para sinalizar, "início", "prazo se esgotando" (falta x dias para o final da construção) e "fim" da construção. Também foi implementado o aviso de pontuação baixa que é enviado caso não 
tenha sido detectado um mínimo esperado de pontualidade, isso é, caso o participante esteja "demorando" a iniciar sua participação e assim atrasando o processo como um todo. No caso de impasses perdurarem, o Moderador também deve atuar nas causas dos conflitos para mediar e possivelmente sanar os problemas.

Sob o aspecto de expressividade, nosso tratamento é limitado pela comunicação não verbal. Depende da capacidade do membro da equipe em se expressar em linguagem textual. Muito embora a implementação futura de inclusão no "Mural" de anexos de imagem, fotos, documentos e arquivos de voz, promova maior possibilidade de expressividade dentro da comunicação remota. Os símbolos para "curtir" comentários postados no Mural já foram uma busca de maior capacidade de expressividade durante as interações do grupo. A ideia é agregar a eles, um conjunto de "emojis" para uso no mural, que representem emoções dos membros do grupo. Os Emojis já são utilizados com muito sucesso em várias plataformas de ensino a distância, por exemplo, no Chat do Teams do Microsoft Office $365^{25}$.

As respostas ao questionário preenchido pelos participantes são indícios positivos que estimulam o aprofundamento e ampliação do uso da solução proposta na continuidade das avaliações. As questões de pesquisa - a) Como aumentar a atenção nos RNFs? b) Como aumentar a qualidade dos RNFs?, c) Como apoiar a construção colaborativa de RNFs?; tratadas pelo processo proposto, na opinião dos participantes, foram atendidas.

Tabela 20. Questões de Pesquisa x Percepção dos Participantes

\begin{tabular}{|l|ll|}
\hline \multicolumn{2}{|c|}{ Questões de Pesquisa } & \multicolumn{1}{c|}{ Percepção Positiva dos Participantes } \\
\hline $\begin{array}{l}\text { a) Como aumentar a } \\
\text { atenção nos RNFs? }\end{array}$ & $\circ \begin{array}{l}\text { Exemplos das respostas sobre o uso do processo proposto } \\
\text { e seu efeito com relação a negligência aos RNFs - vide } \\
\text { página 118. }\end{array}$ \\
\hline $\begin{array}{l}\text { b) Como aumentar a } \\
\text { qualidade dos RNFs? }\end{array}$ & $\circ \begin{array}{l}\text { Respostas da Tabela 17 e 18. } \\
\text { Consolidação das respostas sobre a influência do processo } \\
\text { proposto na lista de RNFs produzidos - vide página 119. }\end{array}$ \\
\hline c) Como apoiar a & $\circ$ Respostas da Tabela 19. \\
\hline
\end{tabular}

${ }^{25}$ Verificado em https://teams. microsoft.com. (Microsoft 365, 2020). 
construção colaborativa de RNFs?

Para além disso, os três estudos de casos que compunham a avaliação, sugerem que o processo proposto: a) produz resultados utilizáveis em um tempo aceitável; b) possui atividades e organização das mesmas que fazem sentido; c) é adaptável a indústria.

\subsection{Ameaças}

As ameaças à avaliação são descritas com base na categorização proposta por Wohlin et al. (2012). Para cada ameaça foi empregado um esforço em resolvê-la de maneira plena. Na impossibilidade de solução completa, o esforço visou minimizar seus efeitos.

Validade de construção: as ameaças relacionadas à elaboração da avaliação, e o que foi feito para minimizá-las, são listadas neste tópico.

- O questionário como instrumento de pesquisa não coletar todos os dados desejados relativos à percepção dos participantes sobre do processo proposto. Porém, o artefato passou pela validação da Câmara de Ética em Pesquisa - CEP da PUC, o que aumentou a qualidade do artefato como um todo. Além disso, o caso 2 possibilitou um tipo de coleta de dados diferenciada. Através do Mural do software RNF Colab foi possível realizar uma espécie de "Focus Group"(Stewart and Shamdasani, 2014).

- Os participantes do caso 2 e 3 serem pessoas que já trabalharam com a pesquisadora há 5 anos atrás e portanto possuíram um relacionamento profissional com a mesma. Porém, o fato do projeto de pesquisa ter sido submetido e liberado pela Câmara de Ética em Pesquisa e a assinatura do Termo de Consentimento Livre e Esclarecido (Anexo I) corroboram para atenuar essa ameaça. O termo claramente assegura a característica de isenção dos participantes na presente pesquisa.

- O projeto utilizado no estudo de caso 3 já havia sido executado e implantado antes da avaliação. Também tinha seu conteúdo conhecido por 
um dos participantes. Porém, a pesquisadora desconhecia o projeto e no papel de Engenheiro de Requisitos criou individualmente os RNFs iniciais que foram para debate coletivo.

Validade interna: as ameaças relacionadas à execução do estudo de caso, e o que foi feito para minimizá-las, são listadas neste tópico.

- O fato do papel do Moderador e o papel de Engenheiro de Requisitos terem sido desempenhados pela mesma pessoa, a própria pesquisadora, também constitui uma ameaça à avaliação. Porém, o Engenheiro de Requisitos apenas criou a lista inicial de RNFs e não se posicionou nem argumentou sobre o mesmo, e como Moderador não ocorreu necessidade de mediar, pois não houve conflitos negativos em nenhum dos estudos de caso.

- O trabalho de condução dos estudos de casos foi realizado unicamente pela pesquisadora. Porém, a pesquisadora não participou dos debates realizados em grupo e nem interferiu nas respostas individuais dos participantes ao questionário. Foi tomado todo cuidado em garantir que os participantes se sentissem livres pra participar e opinar. Foram seguidos rigorosamente os itens do Termo de Consentimento Livre e Esclarecido (Anexo I).

- No caso 1 os dados foram anotados presencialmente pela pesquisadora e posteriormente cadastrados no software RNF Colab. Não sendo diretamente preenchidos pelos participantes no software. Porém, a pesquisadora não efetuou nenhum tipo alteração nos dados anotados durante a reunião. Também todas as informações após registro foram compartilhadas com os participantes para confirmação e complementação, evitando assim o registro de possíveis informações equivocadas.

- O tempo restrito dos participantes impedindo mais rodadas de dinâmicas de Negociação-Colaboração no estudo de caso 2. Porém, na opinião unânime dos participantes o tempo foi suficiente para a realização das atividades e mais rodadas de uso do processo não alterariam as decisões tomadas. Embora poderiam somar um maior volume de dados para futuras análises e ajustes do processo proposto. 
Validade de Conclusão: as ameaças relacionadas à execução da análise dos resultados, e o que foi feito para minimizá-las, são listadas neste tópico.

- Os resultados foram analisados unicamente pela pesquisadora. Porém, a análise foi realizada com atenção e revisada várias vezes pra reduzir o risco de falhas. Também o tempo foi suficiente para o trabalho, com prazo adequado para a conclusão.

Validade externa: as ameaças relacionadas à generalização dos resultados, e o que foi feito para minimizá-las, são listadas neste tópico.

- O número de participantes ser pequeno invalidando a generalização dos resultados obtidos. Porém, o esforço de recrutar profissionais com em torno de 20 anos de experiência e especialistas em construção de requisitos, torna maior a qualidade da amostra aumentando desta maneira o seu peso de poder de avaliação e julgamento. Outro ponto é que a análise é qualitativa, e o foco da avaliação foi na imersão mais detalhada no uso do processo. 


\section{Conclusão}

Neste Capítulo apresentamos as conclusões do trabalho. A descrição sucinta das contribuições da pesquisa, comparação com trabalhos relacionados e as limitações, direcionando os trabalhos futuros.

\subsection{Contribuições}

O problema tratado por nossa pesquisa se resume na baixa qualidade dos RNFs. Por isso buscar mais qualidade para os requisitos de qualidade foi o nosso desafio. Nosso foco foi estruturar o processo de construção de RNFs, visando promover a qualidade dos RNFs produzidos. Discutir RNFs como questão relevante para a qualidade de software, fomenta o debate do assunto tanto na indústria, quanto na academia.

Ao abordar o tema de construção de RNFs, a pesquisa traz novas ideias para melhorar a qualidade dos mesmos, partindo da estruturação do processo de construção colaborativa. As questões de pesquisa listadas na seção 1.3 foram respondidas pela solução que mostra como direcionar a discussão dos RNFs logo no início da construção do software. Como atentar para as características de RNFs com o uso de catálogos de RNFs e o desenho do mapa de impactos entre os requisitos. Também mostra como promover a qualidade do RNF, estruturando a dinâmica de negociação-colaboração durante sua construção. Pensamos que construir RNFs com apoio de um processo colaborativo irá contribuir para que esses requisitos sejam de maior qualidade e mais bem entendidos ao longo da construção de software.

Por e-mails, grupos de WhatsApp, atas de reuniões, ferramenta de workflow, documentações desatualizadas ou inexistentes, a consulta a conteúdos sobre os sistemas e sobre os projetos que os envolvem, custa tempo e nem sempre é bem sucedida. E quando um novo membro inicia na equipe e não há ninguém disponível para passagem de conhecimento? O processo inclui recurso para rastreabilidade das discussões relacionadas a cada requisito criado ou descartado. 
Isto assim foi feito para minimizar o retrabalho por falta de conhecimento, de rastro das decisões tomadas, dos motivos que levaram a se construir os sistemas de uma forma ou de outra.

As soluções existentes para especificar RNFs são baseadas em uma representação gráfica que requer esforços manuais, e o compartilhamento e reutilização podem ser difíceis de serem realizadas (Shah et al., 2019). Uma linguagem complicada de entender, acaba por desencadear mais discussão sobre a própria linguagem do que sobre o que se deseja modelar. Criamos uma linguagem baseada no V-Graph, para alimentação dos RNFs e suas Correlações e Refinamentos em uma base de conhecimento e reuso, e com possibilidade de geração de Diagramas Orientados a Objetivos. Com a intenção de "democratizar" o seu uso, simplificamos a linguagem o suficiente para que não seja necessário se tornar um especialista na mesma para poder utilizá-la. Apesar de limitar os recursos de expressividade; a legibilidade, simplicidade e facilidade de entendimento, fomentam o seu uso. A linguagem foi simplificada para o contexto do mundo real que já é suficientemente complexo de se entender e representar.

A existência dos Catálogos de RNFs apresenta-se como alternativa de solução para minimizar a negligência dos RNFs, um dos problemas tratados na tese. Independentemente do Modelo de Processo adotado pela organização. Os RNFs precisam estar contidos em algum lugar para que a equipe de desenvolvimento tenha ciência deles e da necessidade de os implementar. A estrutura criada para armazenagem dos Catálogos de RNFs é simples, de fácil acesso, cadastro, consulta e associação - além de o conteúdo estar no nível de abstração mais alto, facilitando o seu uso, e diminuindo por consequência a negligência dos RNFs. Portanto, o aproveitamento é possível mesmo com as diferentes conjunturas de levantamentos e documentações dos requisitos encontradas nas organizações.

Muitas vezes os RNFs surgem da análise da equipe de desenvolvimento sobre o domínio e contexto da aplicação, e não como necessidades de usuários/clientes. Nesta conjuntura, a construção colaborativa envolvendo um grupo interdisciplinar, isso é, não somente composto por usuários e sim por membros técnicos e desenvolvedores, é fundamental para a completude e consistência dos RNFs. O papel dos usuários no modelo apresentado continua no 
entanto de decisão sobre o que está sendo discutido, porém com viés colaborativo, a decisão é enriquecida pelas discussões entre profissionais com diferentes perfis, e com pontos de vista distintos. A inclusão de pesos para os posicionamentos de acordo com os perfis, sugestão recebida durante a avaliação, poderá ser implementada para a aprimoramento deste aspecto do processo nas organizações.

Mas, como aferir uma melhora na qualidade dos RNFs com a adoção do processo proposto? A dificuldade em medir qualidade surge também na avaliação de nossa pesquisa que possui cunho subjetivo, já que aborda o tema de qualidade. Para mantermos coerência às nossa premissas, utilizamos para nossa avaliação qualitativa, um grupo de trabalho, para que fossem apreciados pontos de vistas distintos de profissionais com perfis diferentes, e a análise ser feita a partir de vários "ângulos". O processo proposto foi discutido em grupo, no projeto RNF Colab e nos gerou indícios positivos como fora demonstrado no Capítulo 5.

Os indícios positivos também foram notados nos outros dois projetos, Cesta de Medicamentos e TUP Virtual, tanto no engajamento dos participantes quanto no aumento do número de RNFs aceitos e compreendidos, sugerindo maior completeza e consistência dos RNFs construídos. Os participantes se demonstraram com relação ao resultados das dinâmicas, "satisfeitos a contento". Porém mais estudos precisam ser realizados para maior conhecimento sobre o uso do processo proposto.

A figura 26 consolida a contribuição da presente pesquisa, que vai em direção da solução dos problemas de negligência ou tratamento tardio dos RNFs; falta de métodos robustos para o tratamento de interdependências entre RNFs; dificuldade no processamento e reutilização sistemática do conhecimento atual; e, falta de compartilhamento, pelas diferentes equipes, de responsabilidades relacionadas a requisitos. Propomos no trabalho a criação do procedimento de integração de catálogos e facilidades para consulta e uso; a criação da linguagem de representação (Fortalece/ Enfraquece/ Afeta) para apoiar o debate e tratamento das interdependências entre requisitos; e, a criação de um novo processo de construção de RNFs com reuso da dinâmica de Negociação-Colaboração a partir da adaptação do Modelo IBIS. 


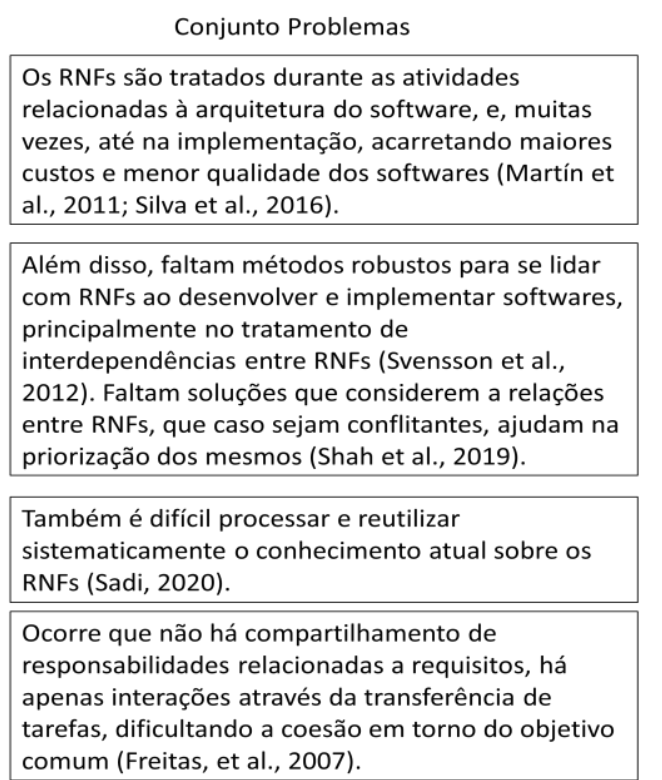

Figura 26. Conjunto de problemas x Conjunto de soluções

\subsection{Comparação com Trabalhos Relacionados}

Durante a investigação de trabalhos relacionados, abordada no Capítulo 3, encontramos na literatura diversos trabalhos sobre construção colaborativa de requisitos. Comparativamente, não detectamos nos achados literários o tratamento para especificidades dos RNFs. A presente pesquisa se difere destes trabalhos, por trazer ao contexto de construção colaborativa de requisitos, a estruturação da discussão dos impactos entre os RNFs, e entre os RFs e RNFs. A busca efetuada pela reflexão dos atributos de qualidade almejados para o software, não leva em conta somente os atributos, mas sim os relacionamentos entre esses atributos. O foco no impacto entre requisitos traz qualidade aos resultados, pois significa maior consistência nas escolhas, já que em impactos negativos um atributo pode anular outro. E em impactos positivos um atributo pode re significar outro.

Assim como encontramos trabalhos sobre construção colaborativa de requisitos, detectamos também trabalhos para apoio à elicitação especificamente de RNFs. Portanto, mesma ênfase da presente pesquisa. Porém diferentemente destes trabalhos, o tratamento dos RNFs na presente pesquisa é unido a uma abordagem que usa mecanismos de Negociação-Colaboração para sua construção, o que não foi detectado nos trabalhos relacionados. Além disso é fornecida uma nova linguagem específica para o tratamento das interdependências entre RNFs. Esta nova linguagem, por ser simples, facilita e fomenta o debate por muitas vezes 
negligenciado, dos impactos entre os requisitos. Debate este fundamental para a qualidade da decisão de inclusão ou não de um RNF em uma especificação.

A ideia de reutilização de conhecimento para criação de RNFs também foi encontrada na literatura pesquisada. Comparativamente o trabalho proposto se difere dos trabalhos relacionados porque não se baseia na reutilização de conhecimento como alicerce para construção de RNFs. O processo proposto parte de um modelo de argumentação para a estruturação de uma dinâmica colaborativa, permeadas por negociações. Embora, similarmente, possua também um recurso para o reuso do conhecimento existente sobre RNFs contido nos Catálogos, que são integrados entre si, de maneira original para consulta durante a construção dos RNFs.

Tabela 21. Comparação com os Trabalhos Relacionados I

\begin{tabular}{|c|c|c|c|}
\hline Temas & $\begin{array}{c}\text { Trabalho } \\
\text { Relacionado }\end{array}$ & Semelhanças & Diferenças \\
\hline $\begin{array}{l}\text { Construção } \\
\text { Colaborativa } \\
\text { de Requisitos }\end{array}$ & $\begin{array}{l}\text { Togneri et al, } 2002 \\
\text { Briggs; Grunbacher, } \\
2002 \\
\text { Antunes et al, } 2006 \\
\text { Freitas et al, } 2007 \\
\text { Laporti et al, } 2009 \\
\text { Jureta et al, } 2009 \\
\text { Pinto et al, } 2020\end{array}$ & $\begin{array}{l}\text { Abordagem colaborativa } \\
\text { para construção de } \\
\text { Requisitos. }\end{array}$ & $\begin{array}{l}\text { Não apresentam } \\
\text { tratamento para } \\
\text { especificidades } \\
\text { associadas aos } \\
\text { RNFs. } \\
\text { Não apresentam } \\
\text { estruturação da } \\
\text { discussão dos } \\
\text { impactos entre os } \\
\text { RNFs, e entre os RFs } \\
\text { e RNFs. }\end{array}$ \\
\hline $\begin{array}{l}\text { Apoio à } \\
\text { Elicitação de } \\
\text { RNFs }\end{array}$ & $\begin{array}{l}\text { Serrano e Leite, } 2011 \\
\text { Ameller et al., } 2012 \\
\text { Kopczyńska e } \\
\text { Nawrocki, } 2014 \\
\text { Carvallo et al., } 2015 \\
\text { Silva et al., } 2016 \\
\text { Mylopoulos, } 2018\end{array}$ & $\begin{array}{l}\text { Tratamento } \\
\text { especificamente de } \\
\text { construção de RNFs. }\end{array}$ & $\begin{array}{l}\text { O tratamento dos } \\
\text { RNFs não é unido a } \\
\text { uma abordagem } \\
\text { Colaborativa. } \\
\text { Não é fornecida uma } \\
\text { linguagem } \\
\text { simplificada } \\
\text { específica para o } \\
\text { tratamento das } \\
\text { interdependências } \\
\text { entre RNFs. }\end{array}$ \\
\hline
\end{tabular}




\begin{tabular}{|l|l|l|l|}
\hline $\begin{array}{l}\text { Reutilização } \\
\text { de } \\
\begin{array}{l}\text { Conhecimento } \\
\text { e RNFs }\end{array}\end{array}$ & $\begin{array}{l}\text { Balushi, 2007 } \\
\text { Araújo et al., 2014 } \\
\text { conhecimento existente } \\
\text { sobre RNFs. }\end{array}$ & $\begin{array}{l}\text { Se baseia na } \\
\text { reutilização de } \\
\text { conhecimento como } \\
\text { alicerce para } \\
\text { construção de RNFs. } \\
\text { Veleda e Cysneiros } \\
2019\end{array}$ & \\
\hline
\end{tabular}

Tabela 22. Comparação com os Trabalhos Relacionados II

\begin{tabular}{|c|c|c|c|c|}
\hline \multirow[b]{2}{*}{$\begin{array}{c}\text { Propriedades / Critérios de } \\
\text { Comparação }\end{array}$} & \multirow[b]{2}{*}{$\begin{array}{l}\text { Processo } \\
\text { Proposto }\end{array}$} & \multicolumn{3}{|c|}{ Trabalhos Relacionados } \\
\hline & & $\begin{array}{c}\text { Construção } \\
\text { Colaborativa } \\
\text { de Requisitos }\end{array}$ & $\begin{array}{l}\text { Apoio à } \\
\text { Elicitação } \\
\text { de RNFs }\end{array}$ & $\begin{array}{c}\text { Reutilização } \\
\text { de } \\
\text { Conhecimento } \\
\text { e RNFs } \\
\end{array}$ \\
\hline $\begin{array}{l}\text { Estruturação da discussão } \\
\text { dos impactos entre os } \\
\text { RNFs, e entre os RFs e } \\
\text { RNFs }\end{array}$ & Sim & Não & Sim & Sim \\
\hline Abordagem colaborativa & Sim & Sim & Não & Não \\
\hline $\begin{array}{l}\text { Linguagem simplificada } \\
\text { específica para o } \\
\text { tratamento das } \\
\text { interdependências entre } \\
\text { RNFs }\end{array}$ & Sim & Não & Não & Não \\
\hline $\begin{array}{l}\text { Reuso de conhecimentos } \\
\text { específicos associados aos } \\
\text { RNFs }\end{array}$ & Sim & Não & Sim & Sim \\
\hline
\end{tabular}

Sucintamente, os dois quadros comparativos referentes às tabelas 21 e 22, apontam as similaridades com a presente pesquisa. Também esclarecem as diferenças, listando as propriedades presentes no processo propostos, e presentes ou não, nos trabalhos relacionados. Tais propriedades também são nossos critérios comparativos, e indicam a "novidade" da tese.

\subsection{Limitações}

Sobre o processo podemos elencar como limitações algumas necessidades: a confecção de um guia para o Moderador definindo ações precisas para sua atuação; 
um maior número de Catálogos de RNFs integrados, por exemplo o catálogo de Segurança da Informação; aprofundamento do estudo sobre mecanismos de colaboração e negociação visando minimizar conflitos negativos e estimular posturas "ganha-ganha"; aprimoramento das alternativas ao consenso, além da votação da maioria e decisão do Moderador; e, a criação de mensagens padrões, com significado dentro de um domínio ao invés de texto livre, para a argumentação objetiva e precisa (Antunes et al., 2006). Atentando para que a comunicação não se torne "engessada" e por consequência, empobrecida.

A execução de novas dinâmicas para discussão dos requisitos sugeridos na avaliação do software RNF Colab que não foram implementados. A saber: a possibilidade de configuração de um peso para posicionamento associado ao perfil do participante; a possibilidade de agrupar os RNFs por área de negócio da organização; a possibilidade de sub divisão do perfil cliente por área de negócio da organização. Também poderia ser possível a associação de sub perfis de clientes a grupos de RNFs por área de negócio.

Sobre o software RNF Colab listamos como principal limitação, a não geração automática dos "Diagramas Orientados a Objetos" a partir do "Relatório de Requisitos e suas Correlações e Refinamentos". Diagrama modelado conforme a linguagem criada, com elementos representados segundo esta nova linguagem RNFs, Operacionalizações, Correlações e Refinamentos; coletados a partir do "Relatório de Requisitos e suas Correlações e Refinamentos", que já os traz mapeados por projeto.

Também sobre o software RNF Colab, somamos as limitações, a não possibilidade de inclusão no Mural de arquivos de imagem, voz e documentos. O intuito é facilitar a comunicação entre os usuários. Falta também o recurso para utilização de emojis para fornecer maior expressividade aos textos postados no software. No aspecto de expressividade da comunicação escrita, recursos que expressem emoções e sentimentos podem ser benéficos se vierem alinhados, por exemplo, a diretrizes de uma Comunicação Não Violenta (CNV), utilizada no intuito de minimizar conflitos negativos (Cruz et al., 2020). O reuso de requisitos de um projeto em outro projeto da mesma área de negócio da organização é também uma limitação atual e item na lista de implementações futuras. 
Por último, se faz necessária, a execução de novas avaliações, com maior número de dinâmicas e participantes. Usar o processo em diferentes tipos de organizações (pequeno, médio e grande porte). Também aplicar o processo em diferentes tipos de projetos, como por exemplo em projetos ágeis, para estudar a sua adaptabilidade principalmente sob o aspecto da variável Tempo.

\subsection{Trabalhos Futuros}

Fora o atendimento às necessidades listadas na seção anterior 6.2 para redução das limitações atuais do trabalho, e a investigação de trabalhos relacionados ao problema tratado na tese, que é uma ação contínua, dois trabalhos futuros são vislumbrados para continuidade do desenvolvimento da presente pesquisa.

A adaptação do processo para construção conjunta dos requisitos em espaço gráfico, de maneira síncrona ou assíncrona e por participantes distribuídos geograficamente, é um enorme desafio que se pretende desenvolver na continuidade desta pesquisa. Quais serão as adaptações necessárias ao processo em termos de comunicação, cooperação, coordenação e percepção? Sobre os mecanismos de influência no comportamento humano, o que poderá ser criado em termos de estímulos a participação e ações colaborativas? E para desencorajar o conflito negativo? Em uma construção gráfica síncrona quais regras deverão ser incluídas no processo? E a organização das atividades e dinâmica de NegociaçãoColaboração continuará a mesma? Que "travas" serão necessárias para que as discussões não demandem mais tempo que o disponível, inviabilizando o uso do processo? Que ajustes no suporte computacional, além da inclusão de recursos gráficos, serão importantes? Lembrando que o objetivo principal é construir RNFs com maior qualidade.

Outro trabalho futuro desafiante é a adequação do processo para diferentes tipos de colaboração, averiguando sua escalabilidade. Como por exemplo, em um contexto de crowdsourcing (colaboração coletiva com volume muito grande de colaboradores). Como adaptar o processo para construção de RNFs de softwares de código aberto, com muitos participantes? Quais novos recursos o processo necessitará para construção conjunta em espaço compartilhado por inúmeras 
organizações? Que RNFs o próprio suporte computacional deste processo deverá possuir? 


\section{Referências Bibliográficas}

Ameller D., Ayala C., Franch X. and Cabot J. How do software architects consider non-functional requirements: An exploratory study. In 2012 20th IEEE International Requirements Engineering Conference (RE). IEEE. p. 41-50. 2012.

Antunes, P. , Ramires, J. , Respício, A. Addressing the conflicting dimension of groupware: a case study in software requirements validation. Computing and Informatics, Bratislava, v. 25, n. 6, p. 523-546. 2006.

Araújo, A.L., Cysneiros, L.M. e Werneck V.M.B. NDR-Tool: Uma Ferramenta de Apoio ao Reuso de Conhecimento em Requisitos Não Funcionais. In WER. 2014.

Balushi T. H. Al,. Sampaio P. R. F, Dabhi D., and Loucopoulos P. ElicitO: A Quality Ontology-Guided NFR Elicitation Tool. In Requirements Engineering: Foundation for Software Quality, Berlin, Heidelberg, 2007, pp. 306-319, Springer Berlin Heidelberg. 2007.

Boehm, B. and Ross, R. Theory-w Software Project Management Principles and Examples. IEEE Transactions on Software Engineering, Vol. 15, No. 7,pp. 902-916. 1989.

Boehm, B. and In, H. Identifying quality-requirement conflicts. In: IEEE Software, vol. 13, 25-35. 1996.

Briggs, R. O., Grunbacher, P. EasyWinWin: managing complexity in requirements negotiation with GSS. In: ANNUAL HAWAII INTERNATIONAL CONFERENCE ON SYSTEM SCIENCES, 35., 2002, Big Island. Proceedings ... Los Alamitos: IEEE. 2002.

Buitron, S.L., Pino F. J., Brenda L. Flores-Rios, Jorge E. Ibarra-Esquer, María Angélica Astorga-Vargas. A Model for Enhancing Tacit Knowledge Flow in Non-functional Requirements Elicitation. in 2017 5th International Conference in Software Engineering Research and Innovation (CONISOFT). 2017. IEEE.p. 25-33.

Camacho, C. Gerenciando Conflitos em Reuniões: Uma Estratégia para a Elicitação de Requisitos de Software. Dissertação de Mestrado, Departamento de Informática PUC-Rio. 2005.

Cappelli, C. An Approach to Transparency in Organizational Processes Using Aspects, Ph.D. Thesis, Dept. de Informática PUC-Rio. 2009.

Carvallo, J.P., Franch X., and Quer C. Improving quality model construction through knowledge reuse. In CIBSE 2015 - XVIII Ibero-American Conference on Software Engineering. 549-562p. 2015. 
Chung, L.,Leite, J.C.S.P. On Non-Functional Requirements in Software Engineering. Book Conceptual Modeling: Foundations and Applications, Pages 363-379, Springer-Verlag Berlin, Heidelberg. 2009.

Chung, L., Nixon, B. A., Yu, E., Mylopoulos, J. NonFunctional Requirements in Software Engineering. Springer, International Series in Software Engineering. 2000.

CMMI Version 1.3 Information Center. Software Engineering Institute. 2011. https://www.sei.cmu.edu/cmmi/tools/cmmiv1-3/ Acessado em 25/10/2020 23:44 pm.

Cruz M. L., Barbosa A., Mergulhão P., Andrade C. Conflito na ER: Proposta de uma Atividade de Narrativa com Auxílio de Realidade Aumentada. In WER 2020.

Cunha, H. Desenvolvimento de Software Consciente com Base em Requisitos. Tese de Doutorado. Dept. de Informática PUC-Rio. 2014.

Cysneiros, L. M. Requisitos Não Funcionais: Da elicitação ao Modelo Conceitual. Tese de Doutorado. Dept. de Informática PUC-Rio. 2001.

Forster, S. Investigating the Collaborative Process of Process Modeling. CAiSE (Doctoral Consortium). 2013 - ceur-ws.org.

Freeman, P. A. Software Perspectives: The System is the Message. AddisonWesley, Reading, Massachusetts. 1986.

Freitas, D., Borges, M., Araujo, R. Colaboração e Negociação na Elicitação de Requisitos. https://www.researchgate.net/publication/221561438. 2007.

Fuks, H., Raposo, A. B.,Gerosa, M.A. Do modelo de colaboração 3C à engenharia de groupware. Dept. de Informática PUC-Rio. 2004.

Grisham, T. The Delphi technique: a method for testing complex and multifaceted topics. International Journal of Managing Projects in Business, 2(1), 112-130. 2009.

Herzwurm, G.Schockert, S. Virtual Product Development. In Proceedings of the Fifth International Symposium on Quality Function Deployment and the First Brazilian Conference on Management of Product Development, Belo Horizonte, Brazil. 1999.

Himanen, P., Torvalds, L., Castells, M. The Hacker Ethic. Random House. 2001.

Horkoff J. and Yu E. Interactive goal model analysis for early requirements engineering. Received: 19 November 2012 / Accepted: 24 July 2014 / Published online: 24 August 2014 Springer-Verlag London. 2014. 
Jarke, M.,Loucopoulos, P., Lyytinen, K., Mylopoulos, J. The Brave New World of Design Requirements. Information Systems, Published by Elsevier. 2011.

Jureta V. J., Faulkner S., Mylopoulos J. Analysis of Multi-Party Agreement in Requirements Validation Conference: RE 2009, 17th IEEE International Requirements Engineering Conference, Atlanta, Georgia, USA, August 31 September 4. 2009.

Kalinowski M., and Travassos, G.H. ISPIS: From Conception towards Industry Readiness. XXVI International Conference of the Chilean Computer Science Society 1522-4902/07. 2007 IEEE.

Kayo, E. K., \& Securato, J. R. Método Delphi: fundamentos, críticas e vieses. Cadernos de Pesquisa em Administração, 1(4), 51-61. 1997.

Knauss, E., Yussuf, A., Blincoe, K., Damian, D., Knauss, A. Continuous clarification and emergent requirements flows in open-commercial software ecosystems Requirements. Eng 23:97-117. https://doi.org/10.1007/s00766-160259-1. 2018.

Kopczyńska, S. and J. Nawrocki. Using non-functional requirements templates for elicitation: A case study. in IEEE 4th International Workshop on Requirements Patterns (RePa 2014). IEEE.p. 47-54. 2014.

Koscianski,A.,Villas-Boas, A., Rêgo, C.M., Asanome, c., Et Al. Guia para Utilização das Normas sobre Avaliação de Qualidade de Produto de Software ISO/IEC 9126 e ISO/IEC 14598. 1999.

Koscianski, A. Qualidade de Software. 2 edição. Novatec Editora. 2007.

Kwang, W.T. Centro de Estudos de Acupuntura e Terapias Alternativas. CEATA. São Paulo. Brasil. https://ceata.com.br. 2009.

Laporti V., Borges M. R. S., Braganholo V. Athena: A collaborative approach to requirements elicitation. Computers in Industry. Volume 60, Issue 6, August 2009, Pages 367-380.

Leal, A.L.C., Souza,H,P, Leite, J.C.S.P. Goal-oriented modeling for establishing mutual contribution relationships between Provenance, Transparency and Trust. In WER 2009.

Leite J.C.S.P. Viewpoint Resolution in Requirements Elicitation. PhD Thesis, University of California, Irvine. 1988.

Leite, J.C.S.P. Gerenciando a qualidade de software com base em requisitos. Qualidade de software: Teoria e Prática, cap. 17. A.R.C. Rocha, J.C. Maldonado, K. Weber (orgs), Prentice-Hall. 2001. 
Leite, J.C.S..P., Cappelli,C. Software Transparency, Bus Inf Syst: 127. https://doi.org/10.1007/s12599-010-0102-z. 2010.

Leite, J.C.S.P. Curso de Engenharia de Requisitos, PUC-RIO. 2017.

Leite, J.C.S.P. Transparency, Trust and Awareness: Basic Qualities in Building Software Requirements. Keynote at WER2019.

Leite, J.C.S.P. Livro Vivo: Engenharia de Requisitos. http://livrodeengenhariaderequisitos.blogspot.com/. Último acesso: 05-10-2018.

Lewicki, R. J., Litteer, J. A. Negotiation. Homewood: Irwin, 1985.

Linhares, G.B.R. Negociação-Colaboração nas Revisões Técnicas Formais de Especificações Funcionais. Dissertação de Mestrado. Universidade Federal do Rio de Janeiro, Instituto de Matemática, Núcleo de Computação Eletrônica. 2009.

Linhares, G.B.R, Borges, M.R.S., Antunes, P. Collaboration and Conflict in Software Review Meetings. International Journal of Information Technology \& Decision Making 2012 (IJITDM: Vol 11 No 6 Nov 2012).

Linhares, G.B.R, e Leite J.C.S.P. Negotiation-Collaboration for Quality of Quality Re-quirements. In Proceedings of XVIII Simpósio Brasileiro de Qualidade de Soft-ware(SBQS'19).Brazil,6pages. SBQS ISBN: 978-1-45037282-4 (2019).

Linhares, G.B.R, e Leite J.C.S.P. Negociação-Colaboração para a Qualidade de Requisitos de Qualidade. In WER 2020.

Marczak, S., Kwan, I., Damian, D. Investigating Collaboration Driven by Requirements in Cross-Functional Teams. In: Proceedings of the Collaboration and Intercultural Issues on Requirements Communication (CIRCUS 09), Atlanta, US. 2009.

Marques, J. B. V., Freitas, D. Método DELPHI: caracterização e potencialidades na pesquisa em Educação. Pro-Posições vol.29 no.2 Campinas May/Aug. 2018.

Martín,A., Cechich,A., Rossi, G. Accessibility at early stages: insights from the designer perspective. In Proceedings of the International Cross-Disciplinary Conference on Web Accessibility. ACM, 9. 2011.

Mathias, A.G. Gerenciamento de Conflitos na Elicitação de Requisitos. Dissertação de Mestrado, Dept. de Informática PUC-Rio. 1994.

Microsoft 365, em https://teams.microsoft.com. Acesso em junho/2020. 
Mylopoulos, J. A Calculus for Requirements Engineering (CaRE) Founded on Argumentation Theory. In WER 2018.

Oliveira, G., Marczak, S., Moralles, C. How to Evaluate BDD Scenarios' Quality? SBES 2019, September 23ś27, Salvador, Brazil. 2019.

Oliveira, R., Silva L., Leite, J.C.S..P., Moreira, A. Eliciting accessibility requirements an approach based on the RNF framework. In: Proceedings of the 31st Annual ACM Symposium on Applied Computing. ACM. p. 1276-1281. 2016.

Pinto R., Silva L. and Valentim R. Managing Sessions of Creative Requirements Elicitation and Assessment. In 35th ACM/SIGAPP Symposium On Applied Computing (SAC) in Brno, Czech Republic. March 30-April 3, 2020.

Prilla, M. Supporting Collaborative Reflection at Work: A Socio-Technical Analysis. AIS Transactions on HumanComputer Interaction, (7) 1, pp. 1-16. 2015.

Ramires, J. J. C. V. Negociação de requisitos no processo de desenvolvimento de software. Dissertação (Mestrado em Informática) - Faculdade de Ciências, Universidade de Lisboa, Lisboa. 2004.

Rittgen P. End-User Involvement and Team Factors in Business Process Modeling. https://www.researchgate.net/publication/25405159. 2012.

Rocha,R.,Costa, C.,Prikladnicki, R., Azevedo, R.R., Junior, I.H.F.,Meira, S. Modelos de Colaboração no Desenvolvimento Distribuído de Software: uma Revisão Sistemática da Literatura. https://www.researchgate.net/publication/266486616. 2010.

Runeson, P., \& Höst, M. Guidelines for conducting and reporting case study research in software engineering. Empirical software engineering. 2009

Serrano, M., Leite, J.C.S.P. Capturing Transparency-Related Requirements Patterns through Argumentation. IEEE 978-1-4577-1022-3/11. 2011.

Shah U. S., Patel, S. J., Jinwala, D. C. An Ontological Approach to Specify Conflicts among Non-Functional Requirements. ICGDA 2019: Proceedings of the 2019 2nd International Conference on Geoinformatics and Data Analysis. Pages 145-149. 2019.

Shull, F., Carver, J., Travassos, G.H., An Empirical Methodology for Introducing Software Processes. In: European Software Engineering Conference, Vienna, Austria, pp. 288-296. 2001.

Silva, L.F. Uma estratégia orientada a aspectos para modelagem de Requisitos. Tese de Doutorado, Dept. de Informática PUC-Rio. 2006. 
Silva, A., Pinheiro, P., Albuquerque, A., and Barroso, J. A process for creating the elicitation guide of non-functional requirements. In Software Engineering Perspectives and Application in Intelligent Systems. Springer. p. 293-302. 2016.

Simon, H.A. Theories of Decision-Making in Economics and Behavioral Science. The American Economic Review, Vol. 49, No. 3, Pags. 253-283. 1959.

Softex. https://softex.br/mpsbr/ Acessado em 25/10/2020 22:44 pm.

Stewart, D. W. and Shamdasani, P. N. Focus Groups: Theory and Practice. Sage. Washington DC. 2014.

Suh, N.P. Designing and engineering through collaboration and negotiation. Collaborative Engineering. https://www.researchgate.net/publication/245529017. 2009.

Svensson, R.B., Gorschek, T., Regnell,B., Torkar, R., Shahrokni, A., Feldt, R. Quality Requirements in Industrial Practice - an extended interview study at eleven companies. In IEEE Transactions on Software Engineering, vol. 38, no. 4, pp. 923-935, July-Aug. 2012.

Togneri D. F., Falbo R. A., Menezes C. S. Supporting Cooperative Requirements Engineering with an Automated Tool. In WER 2002.

Touchstone. The Ibis manual: short course in touchstone tools and resources. Washington. 2000.

Tsukumo, A. N., Rêgo C. M., Salviano, C.F., Azevedo, G.F., Meneghetti, L.K. Costa, M.C.C., Carvalho, M.B., Colombo, R.M.T. Qualidade de Software:Visões de Produto e Processo de Software - II ERI da SBC Piracicaba, SP - Junho de 1997, págs: 173 - 189.

Veleda, R., Cysneiros L. M. Towards an Ontology-Based Approach for Eliciting Possible Solutions to Non-Functional Requirements. International Conference on Advanced Information Systems Engineering CAiSE 2019: Advanced Information Systems Engineering pp 145-161. 2019.

Vinuto, J. A Amostragem em Bola de Neve na Pesquisa Qualitativa: um Debate em Aberto. Temáticas, Campinas, 22, (44): 203-220, ago/dez. 2014.

Wikipedia. https://en.wikipedia.org/wiki/Issue-based_information_system. Acessado em 03/05/2020 21:25 pm.

Wohlin, C., Runeson, P., Höst, M., Ohlsson, M. C., Regnell, B., \& Wesslén, A. Experimentation in software engineering. Springer Science \& Business Media. 2012.

Yu Y., Leite, J. C. S. P., Mylopoulos, J. From goals to aspects: discovering aspects from requirements goal models. Proceedings. 12th IEEE International Requirements Engineering Conference, Kyoto, Japan, 2004, pp. 38-47. 2004. 


\section{Anexo I - Termo de Consentimento Livre e Esclarecido}

O projeto "Negociação-Colaboração para Qualidade de Requisitos de Qualidade" é uma pesquisa científica na área de Engenharia de Requisitos de Software. Esse termo refere-se a participação voluntária através de uma atividade intelectual, no contexto da referida pesquisa. A pesquisa será relatada em uma Tese de Doutorado do Departamento de Informática da PUC-Rio. A pesquisa abordará a problemática dos Requisitos Nãofuncionais (RNFs). Esses requisitos de origem qualitativa, de uma maneira geral, são insuficientemente tratados na construção de software. A pesquisa proporá um método para que esses requisitos sejam devidamente tratados. A tese demonstrará teoricamente o ganho do método proposto. No entanto, como trata-se de um método colaborativo, é razoável ter uma retroalimentação de profissionais da área sobre seu uso.

A retroalimentação será no sentido de solidificar os resultados teóricos com uma avaliação parcial do uso do método. Portanto, buscar-se-á, através de uma abordagem qualitativa, opiniões de profissionais sobre a utilização do método em parte de um projeto de software.

A atividade intelectual a ser exercida pelos participantes será a própria utilização do método com um apoio computacional próprio. Após a utilização do método, os participantes deverão preencher um questionário qualitativo relativo ao uso do método.

Através do presente termo, o convidamos a participar, como profissional da área de software, da atividade acima descrita, bem como a fornecer seus comentários em resposta a um questionário sobre o método.

É importante ressaltar que:

1. Os dados coletados por meio do questionário se destinarão estritamente a avaliação qualitativa do método.

2. Será garantida a preservação material dos documentos, a fidelidade dos dados coletados e a garantia de sigilo e confidencialidade.

3. Caso o participante sinta cansaço ou desconforto durante a participação da atividade de uso do método serão concedidas todas as oportunidades necessárias para interromper ou descansar. O participante tem pleno direito de interromper ou terminar a atividade quando e como quiser.

4. Não haverá benefício financeiro decorrente da participação na atividade.

5. O participante atestará que sua participação voluntária preserva suas opiniões como profissional, segundo o código de ética da profissão.

6. Os resultados produzidos durante a participação na atividade estarão disponíveis na própria Tese de Doutorado.

7. A utilização dos resultados do questionário se pautará no respeito à privacidade, portanto o anonimato dos participantes será preservado em quaisquer documentos elaborados. 
8. O participante terá a oportunidade de esclarecer suas dúvidas, bem como dispor do tempo que the for adequado para a tomada de uma decisão autônoma.

9. O consentimento para participação é uma escolha livre, feita mediante a prestação de todos os esclarecimentos necessários sobre as atividades envolvidas na atividade. A participação poderá ser interrompida a qualquer momento e o participante não sofrerá qualquer penalização ou constrangimento por sua decisão. Não há qualquer impedimento para isto nem qualquer necessidade de apresentar uma justificativa ou explicação.

10. É garantido que o material será arquivado pelo período mínimo de cinco anos e o guardião do material será a pesquisadora, Giovana Brandão Ribeiro Linhares.

11. O conflito por divergência de opiniões dos participantes, é um conflito positivo e que só enriquece o debate, por fazer com que uma questão seja analisada por seus diferentes ângulos. Uma votação é aberta no caso de não se atingir o consenso e o voto da maioria decide o requisito. Há também a figura do Moderador que apóia a dinâmica todo o tempo e se for o caso, atua mediando o debate.

12. O tempo médio para a dinâmica do grupo e o desenvolvimento de todos os Requisitos Não-Funcionais é de 4 horas, podendo ser combinada uma segunda dinâmica de mesmo tempo médio para complemento dos requisitos, caso necessário.

13. A pesquisadora Giovana Brandão Ribeiro Linhares encontra-se disponível para contato pelo e-mail gbribeirol@gmail.com e celular 21 98801-4429.

14. O orientador da pesquisa Professor Julio Cesar Sampaio do Prado Leite, encontra-se disponível para contato pelo e-mail julio@inf.puc-rio.br. Telefone: $213114-1530$.

15. O presente termo encontra-se em duas vias, que quando assinadas uma fica com o participante e a outra com a pesquisadora e guardião.

16. O projeto está registrado na Comissão de Ética em Pesquisa da PUC-Rio com o número 55-2020. A Câmara de Ética em Pesquisa, que é a instância da Universidade para avaliação ética dos projetos de pesquisa, fica localizada no endereço: Rua Marquês de São Vicente, 225 - Edifício Kennedy, $2^{\circ}$ andar. Gávea, Rio de Janeiro, RJ. CEP: 22453-900. Fone: (21) 3527-1618.

De posse das informações apresentadas, gostaríamos que você se pronunciasse acerca da sua participação. 
( )Estou de acordo com minha participação na atividade, dando meu consentimento para a utilização de minhas respostas ao questionário.

( ) Estou de acordo com minha participação na atividade, mas não autorizo a utilização de minhas respostas ao questionário.

Identificador do Participante (utilizado para anonimização):

Nome completo:

Assinatura: Correio Eletrônico:

Pesquisadora: Giovana Brandão Ribeiro Linhares

Assinatura: Correio Eletrônico:

Rio de Janeiro, __ de ___ de 2020 


\section{Anexo II - Questionário Qualitativo}

\section{Sobre o uso do processo proposto:}

1) Qual o objetivo de usar o processo proposta?

2) A escolha da equipe (participantes) para a utilização do processo foi apropriada? Justifique.

3) A escolha do projeto para a utilização do processo foi a apropriada? Justifique.

4)Como o material de apoio (treinamento, tutorial, exemplos) foi útil para os participantes?

5) De que maneira os participantes avaliaram o tempo requerido para a utilização do processo? Justifique.

6) Comente sobre o uso do processo proposto, tanto positivamente quanto negativamente. Justifique.

\section{Sobre o processo proposto:}

1) Comparando com suas experiências anteriores em construção de RNFs, relate os pontos fortes e fracos do processo.

2) Quais aspectos de negociação você percebeu durante o uso do processo? Por quê?

3) Quais aspectos de colaboração você percebeu durante o uso do processo? Por quê?

4) De que maneira o uso do processo influenciou no resultado da lista de RNFs construída? Por quê?

5) Como entende que o uso do processo afeta a negligência aos RNFs? Justifique.

6) Comparando com suas experiências anteriores em construção de RNFs, comente como o uso do processo impacta o entendimento das interdependências entre requisitos? Justifique.

7) Você recomendaria a implantação do processo proposto na sua empresa? Por quê?

8)Como você entende o papel do software RNF Colab? Dê exemplos.

Sugestões: 